\title{
The telescopic locking nail : clinical experiences with a dynamic locking nail system for femur and tibia
}

Citation for published version (APA):

Goessens, M. L. (2003). The telescopic locking nail : clinical experiences with a dynamic locking nail system for femur and tibia. [Doctoral Thesis, Maastricht University]. Universiteit Maastricht. https://doi.org/10.26481/dis.20030116mg

Document status and date:

Published: 01/01/2003

DOI:

10.26481/dis.20030116mg

Document Version:

Publisher's PDF, also known as Version of record

\section{Please check the document version of this publication:}

- A submitted manuscript is the version of the article upon submission and before peer-review. There can be important differences between the submitted version and the official published version of record.

People interested in the research are advised to contact the author for the final version of the publication, or visit the DOI to the publisher's website.

- The final author version and the galley proof are versions of the publication after peer review.

- The final published version features the final layout of the paper including the volume, issue and page numbers.

Link to publication

\footnotetext{
General rights rights.

- You may freely distribute the URL identifying the publication in the public portal. please follow below link for the End User Agreement:

www.umlib.nl/taverne-license

Take down policy

If you believe that this document breaches copyright please contact us at:

repository@maastrichtuniversity.nl

providing details and we will investigate your claim.
}

Copyright and moral rights for the publications made accessible in the public portal are retained by the authors and/or other copyright owners and it is a condition of accessing publications that users recognise and abide by the legal requirements associated with these

- Users may download and print one copy of any publication from the public portal for the purpose of private study or research.

- You may not further distribute the material or use it for any profit-making activity or commercial gain

If the publication is distributed under the terms of Article $25 \mathrm{fa}$ of the Dutch Copyright Act, indicated by the "Taverne" license above, 
Stryker Howmedica Osteonics Eindhoven Nederlandse Vereniging voor Traumatologie Smith \& Nephew B.V. Hoofddorp

Orthomed B.V. Zwijndrecht

B. Braun Medical B.V. Oss

Johnson \& Johnson Medical B.V. Amersfoort Sanofi-Synthelabo B.V. Maassluis

\section{COLOFON}

- Marco Goessens Zutphen All rights are reserved Lay-out: Vivian van Oorschot | Gorssel Omslag: Menno Mous |'s-Hertogenbosch Drukwerk: Comparion | Velp

Edition limited to 1000 copies 


\section{The Telescopic Locking Nail}

clinical experiences with a dynamic

locking nail system for femur and tibia

Marco L.M.J. Goessens 


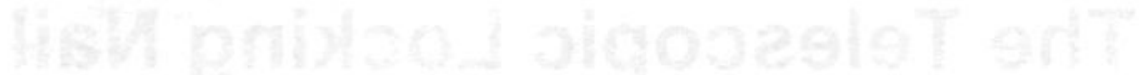




\section{The Telescopic Locking Nail}

\section{ACADEMISCH PROEFSCHRIFT}

ter verkrijging van de graad van doctor aan

de Universiteit te Maastricht

op gezag van de Rector Magnificus

Prof. dr. A.C. Nieuwenhuijzen Kruseman

volgens het besluit van het College van Decanen,

in het openbaar te verdedigen op 16 januari 2003 om 16.00 uur

door

Marcus Leonardus Martha Johannes Goessens 
Promotor:

Prof.dr. J.W.J.L. Stapert

Beoordelingscommissie:

Prof. dr. R.G.T. Geesink (voorzitter)

Prof. dr. J.M.A. van Engelshoven

Prof .dr. H.J.Th.M. Haarman (Vrije Universiteit Amsterdam)

Dr. H. van Mameren

Dr. J.P.A.M. Vroemen (Amphia Ziekenhuis, Breda) 
Voor Monique Voor Max en Luuk 


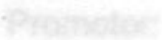

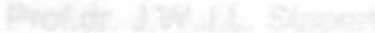

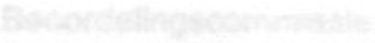

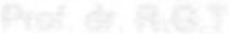

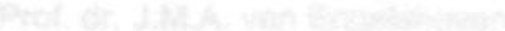

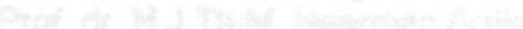


History of intramedullary nailing

CHAPTER III

The development of the Telescopic Locking Nail

CHAPTER IV

The TLN: implant and operation technique

CHAPTER V

The treatment of fractures of femur and tibia with the Telescopic Locking Nail - the design of a new implant and first clinical results

CHAPTER VI

The treatment of acute femoral shaft fractures with the Telescopic Locking Nail - a multicenter experience

CHAPTER VII

The treatment of acute tibial shaft fractures with the Telescopic Locking Nail - a prospective multicenter study

CHAPTER VIII

Application of a proximal entry point for intramedullary nailing of the tibia

Osteolysis of the tibia at the junction of the Telescopic Locking Nail

CHAPTER X

Clinical cases

CHAPTER XI

Summary and Conclusions

Samenvatting en Conclusies

CHAPTER XII

Appendix: follow up form

Dankwoord 


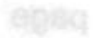




\section{Chapter I}

INTRODUCTION 
Fractures of the long bones are common injuries. They can result from high or low energy trauma, in multiple injured patients or as isolated injury. In the Netherlands, yearly 1000 patients are treated operatively for femoral shaft fractures and 8000 patients for tibial shaft fractures respectively (data from National Medical Registry, 1998-2000). During the last decades intramedullary osteosynthesis has become the preferred treatment modality for femoral shaft fractures and most tibial shaft fractures. Also when primary fracture treatment results in delayed union, non-union or mal-union, the intramedullary nail is often used to achieve adequate fracture healing.

Modern interlocking nailing systems can provide stable fracture fixation, allowing early functional rehabilitation of the injured limb, while the process of fracture healing proceeds.

The Telescopic Locking Nail is a further development of the interlocking nail. Its design was based on the premise that the implant should permit:

- minimal invasive operation technique

- cyclic dynamic loading at the fracture site

- $\quad$ the application of compression between the fracture fragments

- early weight bearing

- the use of one universal locking nail system for femur, tibia and humerus

Since 1991 the Telescopic Locking Nail has been used clinically in the Netherlands. Approximately 1500 Telescopic Locking Nails have been implanted in femur or tibia in 27 hospitals in the Netherlands, from its introduction until 2001.

The aim of this thesis is to explain why and how the Telescopic Locking Nail was developed, and to describe the clinical experiences with this implant.

Chapter 2 provides an historical review of intramedullary nailing until the early 1990's.

Chapter 3 reports on the actual development of the Telescopic Locking Nail, from drawing table to first clinical application of the finalized design.

In chapter 4 the instrumentation and operation technique are described, which are different from standard interlocking nailing systems.

Chapter 5 reports on the first clinical experiences with the TLN, in a single center setting (Medisch Spectrum Twente, Enschede (JWJL Stapert)) on patients with wide ranging indications.

Chapters 6 and 7 include reports of multi center studies focused on the treatment of acute femoral and tibial fractures. The participating hospitals in these studies were: Groene Hart Ziekenhuis, Gouda (DJ Swank); Leyenburg Ziekenhuis, the Hague (PVM Pahlplatz); Slotervaart Ziekenhuis, Amsterdam (BJ Dwars); Amphia Ziekenhuizen, locatie Molengracht (JPAM Vroemen); Sint Franciscus Gasthuis, Rotterdam (AJH Kerver); Medisch Centrum, Leeuwarden (R Leemans) and Academisch Ziekenhuis Maastricht (JWJL Stapert).

The chapters 8 and 9 focus on two items specific for the Telescopic Locking Nail: the use of a proximal entry-point for tibial nailing and the occurrence of osteolysis at the junction of the two parts of the TLN. 
As mentioned earlier, the goal for modern interlocking nailing systems is to provide stable fracture fixation, allowing early functional rehabilitation of the injured limb, while the process of fracture healing proceeds. This study was performed to evaluate the clinical results of fracture treatment with the Telescopic Locking Nail and to answer whether this goal was achieved. It will be discussed that this locking nail takes in a special place amongst conventional interlocking nail systems. Its unique design parameters provide the Telescopic Locking Nail with specific advantages and disadvantages compared to other locking nail systems. 


\section{Chapter II}

HISTORY OF INTRAMEDULLARY NAILING 
Intramedullary nailing has been widely accepted as standard treatment of fractures of femoral, tibial and humeral shaft fractures for several decades. From the first application of intramedullary devices to routine implantation is believed to span some 4 centuries. The first recorded reports of intramedullary fixation methods have been attributed to the conquistadors, who, in the $16^{\text {th }}$ century, described a practice of the Aztecs and the Incas in which resinous wooden pegs were placed in the medullary canal of long bones to treat non-unions ${ }^{\text {after } 1,2}$.

In Europe, the first reports on intramedullary fixation techniques go back as far as the first half of the nineteenth century. Dieffenbach (1848) is reported to have used ivory pegs for intramedullary fixation of non-unions ${ }^{\text {atter }} 3$. Bernhard von Langenbeck (1850) is reported to have inserted ivory pins through the intramedullary space to stabilize an osteotomized mandible. Both surgeons have fixated femoral neck fractures with metallic screws ${ }^{\text {after } 2}$. Throughout the late $19^{\text {th }}$ century, Heine $(1870)$, von Volkmann (1870), Bardenheurer (1875), Socin (1879) and Bruhns (1879) used ivory pins for the treatment of pseudarthrosis after 2, 4-6.

At the 1886 annual meeting of the German Surgical Society, Bircher reported the use of ivory pegs for the treatment of fresh fractures ${ }^{7}$. Lejahr (1902) was the first to
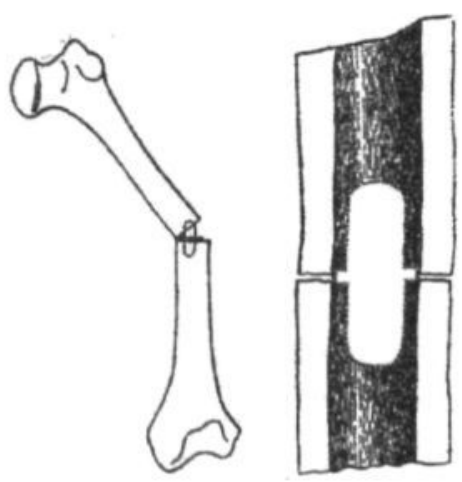
refer to these ivory pegs as 'nails', because he used long well fitting rods $^{\text {after }} 6$. Lejahrs contemporaries, Delbet, Rissler and König also em-

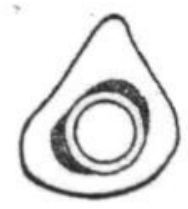
ployed ivory pins for the fixation of fresh fractures in 1906, 1911 and 1913, respectively ${ }^{8}$, after' 9 . The first application of fresh autologeous bone graft implants for the intramedullary fixation of fresh fractures is attributed to Rissler (1911) and Hoglund $(1917)^{10, \text { after } 5,9}$.

Figure 2.1

Example of fracture fixation with intramedullary ivory peg. (Bircher 1887)

In summary, before the beginning of the $20^{\text {th }}$ century, intramedullary fixation was far from routine practice. This method was mainly reserved for cases where conservative fracture treatment was not successful. The devices used were made of biodegradable materials like iyory, autologeous and beef bone. The problem with these materials was that they were resorbed too soon to allow stable fracture healing. Furthermore the implants were mostly too short to provide stable fracture fixation. The technique of intramedullary fixation was always through the fracture; today this would be referred to as the open technique. 


\section{From 1900 to 1940}

At the end of the nineteenth century the principles of creating aseptic conditions during surgery, as propagated by Semmelweis (1846) and Lister (1873) were introduced and commonly practiced. Furthermore better techniques for anesthesia and analgesia were introduced with the use of ether and chloroform. These developments lead to more widespread use of surgical treatment for fractures and to a more rapid evolution of surgical techniques. Nicolaysen (1897), Delbet (1906) and Lambotte (1907) practiced intramedullary stabilization of long bones ${ }^{\text {after }}{ }^{11}$. Because of the limited success of biodegradable implants that were used in the second half of the nineteenth century, metal implants were increasingly being used after 1900 . Delbet practiced internal fixation of fractures of the femoral neck by screws introduced under X-ray control. Albin Lambotte was the first to use intramedullary metal splints as stabilization devices for long bone fractures.

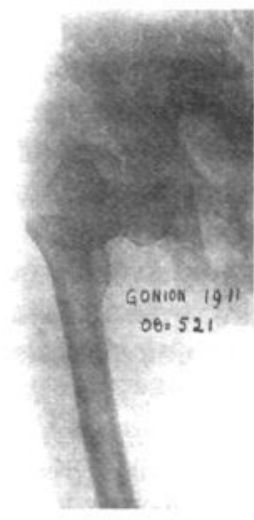

Fig. 2.2

Intramedullary fixation of a subtrochanteric fracture by A. Lambotte (1911)

He reported the use of long screws "inserted at the tip of the greater trochanter into the medullary canal of the proximal third of the femur for inter and subtrochanteric fractures"12. Schöne used silver pegs for forearm fractures ${ }^{\text {after } 4,5,9}$. During World War I, Hey Groves started using large intramedullary nails for femoral shaft fractures. He preferred the use of solid nails, which were inserted in the medullary canal retrograde through the fracture site. This method of fixation, he found, was stable enough to prevent fracture dislocation without any other means of immobilization ${ }^{13,14}$. His practice of intramedullary nailing with large steel implants was however not widely accepted due to the tissue reactions accompanying the corrosion of the implants.

Figure 2.3

Technique of intramedullary rod fixation as practiced by Hey Groves(1916). The fracture was exposed, the intramedullary rod was inserted through the fracture in retrograde direction; after reduction the rod was then hammered back in anterograde direction to fixate the fracture.

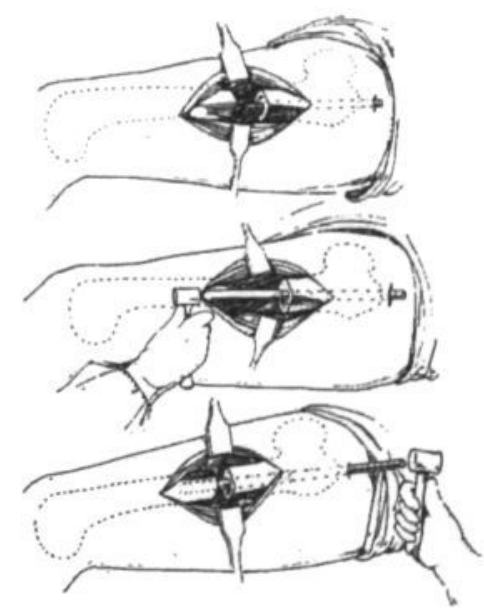


Venable et al. proved in 1937 that bone resorption did not occur when the metal of the implant was electrolytically inert ${ }^{15}$.

Even before that time, in 1925, Smith-Petersen et al. successfully used stainless steel nails, star shaped in cross section, for the internal fixation of femoral neck fractures $^{16}$.

Smith-Petersen used an open anterior surgical approach which allowed both reduction and internal fixation to be carried out through one incision. Johannsen and Jerusalem improved Smith-Petersen's technique using a closed internal fixation method by using an aiming device to insert the nail distant to the fracture site without opening the joint ${ }^{17,18}$. This was made possible by the development of better fracture tables, which permitted a lateral X-ray of the hip during surgery, as well by the introduction of cannulated nails which assured accurate placement of the device without exposure of the fracture. By 1938 the closed reduction and nailing of femoral neck fractures became a well established procedure ${ }^{19}$.

Before World War II, intramedullary fixation of long bones was advocated by Labrudini in England and Joly and Danis in Belgium, who used Kirschner wires ${ }^{\text {after }}{ }^{11}$. In Germany, Müller-Meernach was the first to use laminated rods mad of non-corrosive stee $^{20}$. In the United States, the Rush brothers developed an intramedullary nailing system which depended on the use of flexible pins with sled rudder points. The stability of fixation depended on the recoil of the pre-bent pins, rather than on their tight fit within the medullary canal ${ }^{21}$. As Watson-Jones stated, these methods were never mechanically sufficient and it was not until wide nails - fully engaging the medulla of the bone - were reintroduced, that the technique of intramedullary osteosynthesis of fractures of the long bones commanded respect ${ }^{11}$.

\section{From 1940 to 1970: "The Küntscher Era"}

Also Gerhard Küntscher was successfully treating femoral neck fractures with closed nailing during the late 1930 's. Actually, it was this development in intramedullary fracture treatment that provided the intellectual seed for Küntscher's later developments in Germany. In his book, published in 1950, he wrote: "The author arrived at the concept of intramedullary nailing based on theoretical studies on fracture healing and the practice of nailing of the femoral neck"22. Having gained much clinical experience on femoral neck nailings and after numerous experimental femoral nailings in dogs in the University Clinic in Kiel, Germany, Küntscher dared to make the final im-

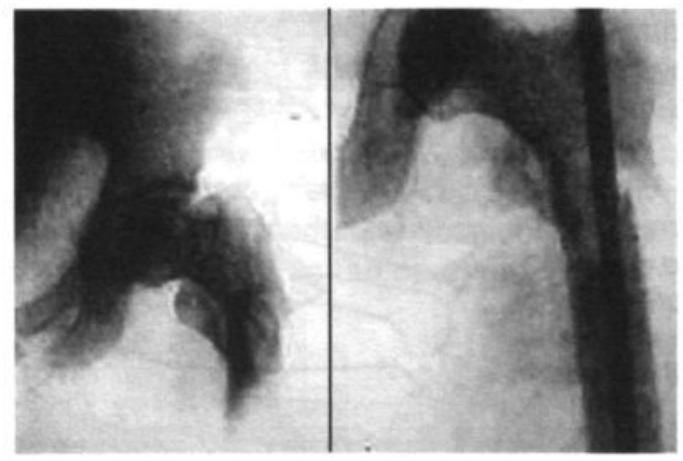
portant step. In November 1939 he did his first intramedullary nailing of a subtrochanteric femoral fracture in a 35 year old male patient ${ }^{\text {after } 9}$.

Figure 2.4

First published radiographs of a subtrochanteric fracture treated by closed intramedullary nailing by Gerhard Küntscher in 1939. 
In March 1940 Küntscher reported to the German Surgical Society in Berlin on his first 12 femoral fractures treated with the intramedullary technique ${ }^{23}$.

The reception of his presentation was extremely critical, as most opponents were astonished by the large size of the "foreign object" occupying the medullary canal". Despite the initial criticism Küntschers method rapidly gained in popularity in Germany. In 1942 already, the distinguished Lorenz Böhler stated: "Intramedullary nailing is the most important contribution to the treatment of fractures of long bones", and "Küntscher's intramedullary nailing is the method of the future" after 5 . Because of the stability of fracture fixation after Küntscher nailing, the post-operative rehabilitation of patient was much easier and not as long lasting compared to the conservative fracture treatment. This was an important aspect of the method during wartime. With the widespread use of the Küntscher method also complications of the technique were increasingly reported. Indications for intramedullary nailings were wrongly chosen and the operative technique was not easily mastered by inexperienced surgeons. Adequate anesthesiological techniques and muscle relaxants were not available. Equipment like fracture tables, reduction apparatus and X-ray were scarce and often not adequately functioning. In 1950 Watson-Jones et al. warned for the many, sometimes disastrous, complications that can arise after intramedullary nailing ${ }^{11}$. Despite his initial enthusiasm for the Küntscher method, Böhler expressed his concern about the many complications that arose in 1944: "A great tragedy has befallen mankind, intramedullary nailing."

After the war, Küntscher was able to further refine his method of intramedullary osteosynthesis. The first nail he inserted had the same star shaped cross section as the Smith-Petersen nail for femoral neck fractures. Later he used V-shaped nails and nails with a cloverleaf shaped cross section. The design of the nail was based on the principle of elastic impingement of the nail in the medullary canal. "The fragments are held together by elastic forces just as a carpenter's nail connects two wooden boards".

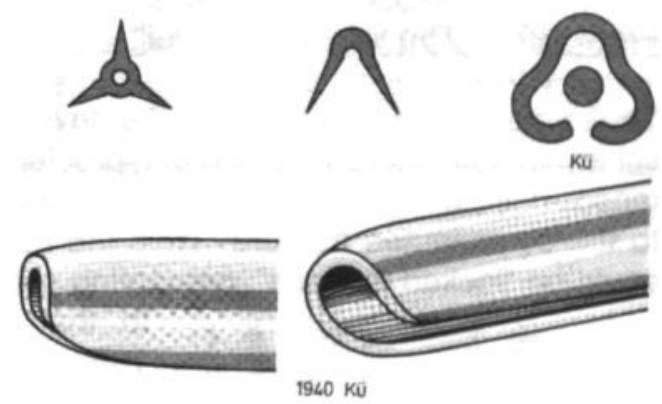

Fig. 2.5

Evolution of the Küntscher nail. From star shape and $V$-shape to cloverleaf shape cross-section (with guide wire)

Another important principle of Küntscher's method was "closed bone surgery". In contrast to earlier medullary nailing techniques, according to Küntscher, the fracture site should not be exposed, to prevent infections and to not interfere with the fracture hematoma, which acts as a precursor of callus formation. Therefore the medullary canal was not reamed in fresh fractures.

The diameter of the used nail depended on the size of the smallest portion of the medullary canal, the isthmus. Actually, the impingement of the nail, which was desired for stable fracture fixation only occurred at the isthmus ${ }^{22,24-26}$. Fractures distal or proximal to the isthmus were therefore not suitable for Küntscher nailing. 
From 1942 Maatz and Pohl developed flexible medullary reamers to widen the isthmal portion of the medullary canal, without the need for exposing the fracture. Now larger nails could be introduced. By reaming the area of nail impingement was enlarged, making medullary nailing possible for supra- and infra isthmal fractures.

For tibial nailing, Herzog improved the design of the nail, by adding a proximal recurvation bend for easier nail insertion from the eccentric entry-point. Maatz developed the so-called split nail for distal tibial fractures.

An important development for closed intramedullary nailing was the introduction of the image intensifier in the operation rooms from 1955. This reduced the radiation exposure of patient and theatre staff and facilitated closed reduction and accurate implant insertion ${ }^{27}$.

By 1965, Küntscher used his method of intramedullary nailing for fresh fractures, non-unions and correctional osteotomies in femur, tibia, humerus, radius and ulna. The main drawbacks of his method remained however. The weak torsional strength of the fixation lead to rotational instability. Metafysal fractures and fractures with a comminution zone were not suitable for this method of fracture treatment, because, with the Küntscher concept, (length)stability was insufficient in these cases.

Kaessmann, in Germany, modified Küntscher's nail by adding a possibility for intrafragmentary compression ${ }^{28}$. With this compression rod a better rotational stability could be achieved than with the original Küntscher nail, due to interfragmentary compression. Also simple metaphysal fractures could be stabilized with this nail. The operative technique was however difficult, $\mathrm{X}$-ray exposure of theatre staff was great and the method never gained much acceptance.

\section{From 1970: "The Interlocking Nail"}

These drawbacks have lead to the development of the interlocking nail. It was Küntscher himself who addressed this problem by the development of the so called "Detensor-nail", a clover leaf shaped implant with transfixation bolts proximal and distal to the comminuted fracture. Thus the major proximal and distal fracture fragments could be "locked in place", preventing shortening. In 1968 he presented this implant
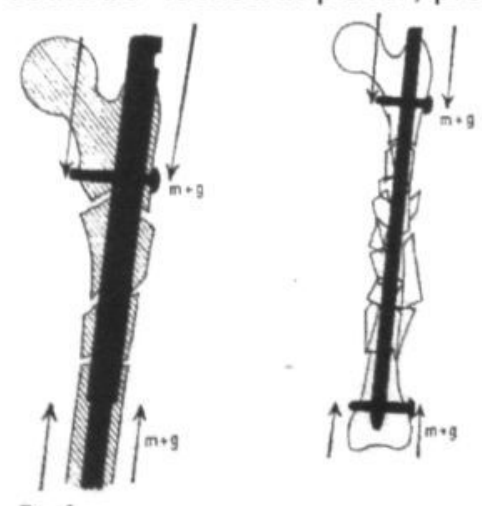

to the German Surgical Society ${ }^{29}$. However, in 1953 already Modney and Bambarra developed an interlocking nail in the United States. This was a cross shaped nail, which permitted screw insertion from varying directions. This non-cannulated nail required an open insertion techique ${ }^{30}$. Hucksstep and Halloran added a proximal mounted aiming system to Modney's original design to simplify screw insertion ${ }^{31,32}$. Küntscher's "Detensor nail" was further developed by Klemm and Schellmann $(1972)^{33}$.

Figure 2.6

Küntscher's Detensor nail, the precursor of the modern interlocking nail (1969) 
Their curved cloverleaf nail exhibited a tapered tip with two distal and one proximal interlocking bolt. They described successful treatment of (infected) femoral nonunions and comminuted fractures with their interlocking nail ${ }^{34,35}$. Grosse and Kempf (1976) further refined the design of interlocking nail for femur and tibia, by developing a target device mounted on the image intensifier to facilitate distal locking ${ }^{36,37}$. Fractures of femoral and tibial shaft could be locked dynamically, by only using the distal or proximal locking holes, in case of length stable fractures, or statically, by using both proximal and distal locking holes, in case of length unstable fractures. Derweduwen, in Belgium, developed an interlocking nail capable of interfragmentary compression, especially for the use in non-unions ${ }^{38^{\circ}}$.

From this period on the use of locking nails expanded over Europe. The Swiss Arbeidsgemeinschaft für Osteosynthesefragen (AO/ASIF) incorporated the interlocking nail in their treatment modalities for long bone fractures and further developed implants and instruments ${ }^{39}$. Operation techniques were instructed at the AO/ASIF instructional courses. These methods were exported from Europe to America and the American clinics were able to reproduce the excellent results reported by their European colleagues

Since three decades intramedullary osteosynthesis with the interlocking nail has become an established technique worldwide for the treatment of long bone fractures. Many different nailing systems have been developed in this period: reamed and unreamed nails, cannulated and solid nails, slotted and non-slotted nails, nails for anterograde and retrograde femoral nailing, stainless steel and titanium nails, and nails with compression modalities or dynamic locking modes. Regardless of the implants employed, the interlocking nail today constitutes a minimal invasive treatment modality for long bone fractures, which provides the maintenance of alignment of fracture fragments and allows for solid bone healing, while functional rehabilitation of the injured limb is restored. Thus, at the beginning of the twenty-first century the interlocking nail plays a key role in the treatment of the trauma patient. 


\section{REFERENCES}

1. Farill, J. Orthopedics in Mexico. J Bone Joint Surg[Am], 1952; 34-A(3): p. 506-12.

2. Knothe, U., Knothe Tate, ML and Perren, SM. 300 Years of Intramedullary Fixation - from Aztec Practice to Standard Treatment Modality. Eur J Trauma, 2000; 26(5): p. 217-25.

3. König, F. Ueber die Implantation von Elfenbein zum Ersatz von Knochenund Gelenkenden. Beitr Klin Chir, 1913; 85: p. 91-114.

4. Contzen, H. [Development of intramedullary nailing and the interlocking nail]. Aktuelle Traumatol, 1987; 17(6): p. 250-2.

5. Maatz, R., History of Intramedullary Osteosynthesis, in Intramedullary Nailing nd other Intramedullary Osteosyntheses, R. Maatz, et al., Editors. 1986, Saunders/Schattauer: Philadelphia. p. 274-62.

6. Nonnemann, HC. [Choice of procedure in Kuntscher nailing. A look backward--current status--perspectives]. Chirurg, 1990; 61(6): p. 422-5.

7. Bircher, H. Eine Neue Methode unmittelbarer Retention bei Fracturen der Röhrenknochen. Langenbecks Arch Chir, 1878; 34: p. 410-22.

8. König, $F$ and Lister, J. Ueber die Berechtigung frühzeitiger blutiger Eingriffe bei subcutanen Knochenbrüchen. Langenbecks Arch Chir, 1905; 76: p. 72577.

9. Lentz, W. [The history of intramedullary nailing. A brief look backwards]. Chirurg, 1990; 61(6): p. 474-80.

10. Hoglund, EJ. New method of applying autogenous intramedullary bone transplants and of making autogenous bone screws. Surg Gynecol Obstet, 1917; 24: p. 243-46.

11. Watson-Jones, R, Bonnin, JG, King, T, Palmer, I, Smith, H, VaughanJackson, OJ, Crawford Adams, J, Jackson Burrows,H, Nicoll, EA, Vom Saal, F, Trevor, D and Le Vay, AD Medullary Nailing of Fractures after Fifty Years. J Bone Joint Surg[Br], 1950; 32B(4): p. 694-729.

12. Lambotte, A. Chirurgie Opératoire des Fractures. 1913, Paris: Masson \& Cie.

13. Hey Groves, EW. On Modern Methods of Treating Fractures. 1916, Bristol: Wright \& Sons.

14. Hey Groves, EW. Experimental Principles of the Operative Treatment of Fractures and their Clinical Application. Lancet, 1914; (4720): p. 435-41.

15. Venable, CS, Stuck, W and Beach,A. Effect on Bone of the Presence of Metals: Based upon Electrolysis. Ann Surg, 1937; 105: p. 917.

16. Smith-Petersen, MN, Cave, EF and Vangorder, GW. Intracapsular Fractures of the Neck of the Femur. Arch Surg, 1931; 23: p. 715-59.

17. Johannson, S. Operative Behandlung von Schenkelhalsbrüchen. 1934, Leipzig: Thieme.

18. Jerusalem, M. Zur operativen Behandelung der Schenkelhalsbrüche. Chirurg, 1932; 4 : p. 773.

19. Schatzker, J. Osteosynthesis in trauma. Int Orthop, 1996; 20(4): p. 244-52.

20. Müller-Meernach. Die Bolzung der Brüche der langen Röhrenknochen. Zentralbl Chir, 1933; 60: p. 1718-23.

21. Rush, LV and Rush, HL. Evolution of medullary fixationof fractures by the longitudinal pin. Am J Surg, 1949; 78: p. 324-33. 
22. Kuntscher, G., Die Marknagelung. 1950, Berlin: Saenger.

23. Kuntscher, G. Die Marknagelung von Knochenbrüchen. Langenbecks Arch Chir (Kongressbericht), 1940; 200: p. 443-55.

24. Kuntscher, G. Intramedullary Surgical Technique and its place in Orthopedic Surgery. J Bone Joint Surg[Am], 1965; 47-A(4): p. 809-18.

25. Küntscher, G and Maatz, R. Technik der Marknagelung. 1945, Leipzig,: Thieme. 102.

26. Küntscher, G. Praxis der Marknagelung. 1962, Stuttgart: Schattauer.

27. Böhler, J. Percutaneous Internal Fixation utilizing the X-ray Image Amplifier. J Trauma, 1965; 5(2): p. 150-61.

28. Kaessmann, $\mathrm{HH}$ and Weber, HG. [Principles, indications and results of fracture compression nailing]. Bull Soc Int Chir, 1971; 30(1): p. 37-43.

29. Kuntscher, G. [Intramedullary nailing of comminuted fractures]. Langenbecks Arch Chir, 1968; 322: p. 1063-9.

30. Modny, MT and Bambarra, J. The perforated cruciate intramedullary nail: preliminary report of its use in geriatric patients. J Am Geriatr Soc, 1953; 1: p. $579-88$.

31. Huckstep, RL. Rigid intramedullary fixation of femoral shaft fractures with compression. J Bone Joint Surg[Br], 1972; 54: p. 204.

32. Halloran, WX. The slotted femoral rod increases vascularity, thus promoting early fracture healing and faster rehabilitation. Orthop Rev, 1980; 10: p. 57.

33. Klemm, K., Schellmann, WD and Vittali, HP. [Intramedullary nail bolted to the femur and tibia]. Bull Soc Int Chir, 1975; 34(2): p. 93-6.

34. Klemm, KW and Borner, M. Interlocking nailing of complex fractures of the femur and tibia. Clin Orthop, 1986; (212): p. 89-100.

35. Klemm, KW. Treatment of infected pseudarthrosis of the femur and tibia with an interlocking nail. Clin Orthop, 1986; (212): p. 174-81.

36. Kempf, I, Grosse, A and Beck, G. Closed locked intramedullary nailing. Its application to comminuted fractures of the femur. J Bone Joint Surg Am, 1985; 67(5): p. 709-20.

37. Kempf, I, Grosse, A and Abalo, C. Locked intramedullary nailing. Its application to femoral and tibial axial, rotational, lengthening, and shortening osteotomies. Clin Orthop, 1986; (212): p. 165-73.

38. Derweduwen, J. A new intramedullary compression device for fractures and pseudarthroses of the long bones. A preliminary report. Acta Orthop Belg, 1979; 45(6): p. 659-65.

39. Müller, ME., Manual of internal fixation : techniques recommended by the AO Group. 2d , expanded and rev. ed. 1979, Berlin ; New York: SpringerVerlag. xii, 409. 


\section{Chapter III}

THE DEVELOPMENT OF THE TELESCOPIC LOCKING NAIL 
The aim of this chapter is to explain why the Telescopic Locking Nail was developed as an alternative for other locking nail systems. The concept of the TLN is based on certain ideas about the process of fracture healing and different methods of fracture treatment, which will be described. The chronology of the events in the evolution of the TLN is given, starting from the drawing table in 1985 until the widespread clinical application of the Telescopic Locking Nail from 1994.

\section{A. Fracture healing and the stability of fracture fixation}

Since its foundation in 1958, the AO/ASIF has enormously influenced the practice of fracture treatment throughout the world. Based on the four principles: restoration anatomical relationship, stable fixation, preservation of blood supply and early mobilization, the AO/ASIF has developed techniques that have become the standard of surgical fracture treatment ${ }^{1}$. The $A O$ advocated an anatomical reduction of the fracture and absolute rigid internal fixation. Interfragmentary compression was the basis of osteosynthesis, and the $\mathrm{AO}$ developed implants and instruments for achieving this goal. Fractures immobilized by means of interfragmentary compression, with lag screws or compression plates, healed by the so-called primary bone union, without any radiologically visible callus. The appearance of callus was recognized as a sign of impending failure and evidence that absolute stability had not been achieved. It was also recognized that multifragmentary fractures and fractures were there was a defect in the cortex opposite to the plate, healed very slowly and that failure of fixation was common. To overcome this complication the $\mathrm{AO}$ advised bone grafting in these cases. After plate and screw removal it was observated that the bone underlying the plate had become porous due to a marked increase in the number of Haversian canals. This porosis deep to the plates was recognized as a cause of refracture'.

In the same period other methods for treatment of diaphysal fractures of the lower extremity evolved. Simple fractures of the femur and the tibia were treated with intramedullary nails, which were an adaptation of the Küntscher design. In conservative fracture treatment, Sarmiento advocated functional bracing and early weight bearing for stable diaphysal fractures of femur and tibia, a method that gained much acceptance $^{2}$. De Bastiani developed external fixators with a telescopic facility, which allowed for cyclic dynamic loading at the fracture site while weight bearing ${ }^{3}$. With above mentioned types of treatment good clinical results could be achieved, even though they were not based on absolute rigid fracture fixation. On the contrary, because of the unstable fixation, fractures treated by those methods healed secondarily, which means with the formation of fracture callus.

Also experimental animal studies indicate that cyclic dynamic loading is beneficial for fracture healing ${ }^{4}$, that weight bearing improves the quality of bone healing ${ }^{5}$ and that dynamization of interlocked nails improves fracture stiffness ${ }^{6}$.

During the last decades, opinions about the necessity for an anatomical reduction and absolute rigid fixation, as advocated earlier by the $\mathrm{AO}$, have changed. From the AO stronghold Ganz introduced the concept of "biological osteosynthesis" ${ }^{7}$. Fracture fixation should be carried out with minimal interference with the vascularization of the traumatized bone to enhance natural fracture healing. For diaphysal fractures of femur, tibia and humerus anatomical reduction is not necessary. As long as length, 
rotation and alignment are restored, there will be no interference with function. Also rigid fixation after fracture reduction is not needed ${ }^{8.9}$. Micromovements at the fracture side and cyclic dynamic loading while weight bearing lead to good quality of bone healing with the formation of callus.

\section{B. Developments in intramedullary nailing}

The desire to preserve blood supply of bone and soft tissue has resulted in the intramedullary nail becoming the implant of choice for the fixation of diaphysal fractures of femur and tibia ${ }^{10-12}$.

Before the interlocking techniques were available, the Küntscher method of closed intramedullary nailing could be used only in suitable fracture patterns. To achieve stability the intramedullary nail, with its cloverleaf shaped cross section, had to impinge in the medullary canal. Therefore, only transverse or short oblique fractures in the region of the isthmus could be treated with Küntscher nails. Enlarging the isthmus by reaming widened the field of indications slightly. Length unstable fractures and proximal and distal fractures were not suitable for Küntscher nailing.

The development of interlocking techniques has greatly increased the scope of intramedullary nailing. With further refinements in nail design, fractures from the subtrochanteric region to the supracondylar region could be treated with interlocking nails. Comminuted fractures, distant from the isthmus, could be stabilized. The first generation intramedullary nails were relying on impingement in the medullary canal for stable fixation. The second generation, interlocking nails have smaller diameters and closed cross-sections, and do need not impinge in the medullary canal for stability. Actually, modern interlocking nails can act as an internal fixator, analogue to the external fixator.

\section{To ream or not to ream?}

The desire to minimize the damage to the endosteal blood supply in open tibial fractures has lead to the development of unreamed tibial nails. Unreamed nail insertion was thought to spare the delicate endosteal blood supply of the cortex. Reaming would in contrast be associated with cortical necrosis and infections ${ }^{13,14}$. The unreamed tibial nails gained in popularity, also because the easier operation technique and reduced operation time. Furthermore, post-operative infection rates were claimed to be reduced, because the solid unreamed nails have no unvascularised cavity, which can act as an ideal environment for microorganisms.

The field of indications for unreamed tibial nailing widened gradually, also closed tibial fractures were increasingly being treated with these devices ${ }^{15,16}$. The use of these smaller diameter nails with smaller diameter locking screws has however lead to an increasing incidence of nail or screw breakage and higher malunion- and reintervention rates ${ }^{17-19}$. Furthermore, some publications recently indicated that reamed nailing of open tibial fractures does not have to be associated with higher infection rates than unreamed nailing ${ }^{20}{ }^{21}$. At this point, the standard treatment for closed unstable fractures should be reamed interlocking nailing. In high-grade open fractures, excessive reaming is to be avoided and unreamed nails are probably pre- 
ferred $^{22}$. On the other hand, fractures with severe soft tissue injury are due to high kinetic trauma. Therefore, these fractures are usually severely comminuted ${ }^{23}$.

In these cases it is mostly possible to pass the nail between the comminuted fragments without prior reaming.

In practice, minimal reaming is often done to pass a slighter larger nail, decreasing the risk for hardware failure. Until now, there is no clinical evidence to support this practice. Experimental studies in dogs indicate that limited reaming may be advantageous, compared to full reaming, in tibial fractures, where tibial blood supply is already compromised due to the injury ${ }^{24}$.

In contrast to the tibia, the femur is covered with a thick, well vascularized, soft tissue envelope. This provides an optimal environment for fracture healing, even in the presence of contamination in open fractures or bone necrosis due to reaming. Indeed, numerous authors describe high union rates and low infection rates after reamed intramedullary nailing of open femoral fractures ${ }^{25-28}$. The unreamed femoral nail was developed out of concern about the systemic effects of reaming the femoral canal $^{29}$. Reaming and nailing may be associated with undesirable cardiopulmonary events, which are thought to be the result of a rise in intramedullary pressure causing embolization of bone marrow contents to the heart and the lung on one hand, and the enhancement of a generalized inflammatory response through the release of toxic mediators on the other hand. This may cause a further diminution of pulmonary function, in the face of pre-existing pulmonary injury in the multiple trauma patient $^{30}$. The undesired increase in intramedullary pressure during reaming is however also increased during insertion of an undreamed device. The evidence on this issue is conflicting. Recent studies indicate that early fixation of femoral fractures protects the patient against pulmonary complications and that the method of fixation has little influence on the outcome of treatment ${ }^{31-34}$. At this point, reamed interlocking nailing remains the standard treatment for femoral shaft fractures, also in the multiply injured patient ${ }^{12}$.

\section{Implant failure}

Statically interlocked nails are load bearing devices, often for extended periods of time, especially in length unstable fractures. This has consequences for the biomechanical performance of the implant. The use of smaller diameter nails for unreamed tibial nailing, generated the need for smaller diameter locking screws to avoid potential weakening of the nail from large screw holes. This development has lead to the increased incidence of screw breakage after unreamed tibial nailing ${ }^{17,18,35}$. In many instances, screw breakage may lead to malunion, non-union or secondary procedures to promote union ${ }^{18,35}$. In case of open tibial fractures with severe soft tissue injury prolonged union times have to be anticipated for. Especially in these cases, a strong intramedullary implant is desirable. When small diameter locking nail are used for these cases, exchange for a larger diameter nail is advised by some authors to overcome the problem of implant failure ${ }^{22}$.

Early weight bearing after interlocked nailing is possible and safe when implants are used with a relative high fatigue strength ${ }^{18,36,3}$. With use of smaller and therefore weaker implants, clinicians had to adjust the post-operative rehabilitation program, by postponing early weight bearing, to avoid early implant failure. This practice has 
raised the (rhetorical) question: should the weight bearing protocol be adapted to the implant, or should the implant be adapted to an early weight bearing protocol?

\section{E. A universal nailing system?}

As the indications for interlocking nailing expanded, the number of interlocking nailings being done skyrocketed. Many different nailing systems became available, with subtle differences. Also for the humerus, interlocking nailing started as an alternative for open reduction and plate fixation. With all these different nailing systems, stock and expenses for the treatment of long bone fractures escalated, while surgeons and theatre staff were overwhelmed by different instrumentation systems and techniques.

On the base of the concepts and developments as preciously described, a set of preconditions for the development of a new interlocking nail was formulated.

a. The device should be capable of allowing cyclic dynamic loading at the fracture site, while maintaining rotational and angular stability. Also static fracture fixation should be possible. For certain cases the ability for compression at the fracture side could be desirable.

b. The interlocking nail should behave as an internal fixator and should not rely on impingement in the medullary canal for stability.

c. The diameter of the nail should allow for an unreamed or minimally reamed use of the nail.

d. The fatigue strength of nail and locking bolts should allow for early weight bearing without the risk of implant failure.

e. The number of different nails in stock should be reduced by using only one nail diameter. Furthermore, it should be possible to use the same instrumentation set for femoral, tibial and humeral nailing. 
In 1985 the first drawings for the new locking nail were made by J. Stapert, at that time working as a trauma surgeon in Enschede, the Netherlands. These designs were based on the preconditions as described above. A telescope mechanism was developed, by mounting a tube on an inner nail. The locking bolts would go through both the outer tube and the inner nail. With the locking bolts applied, the inner nail

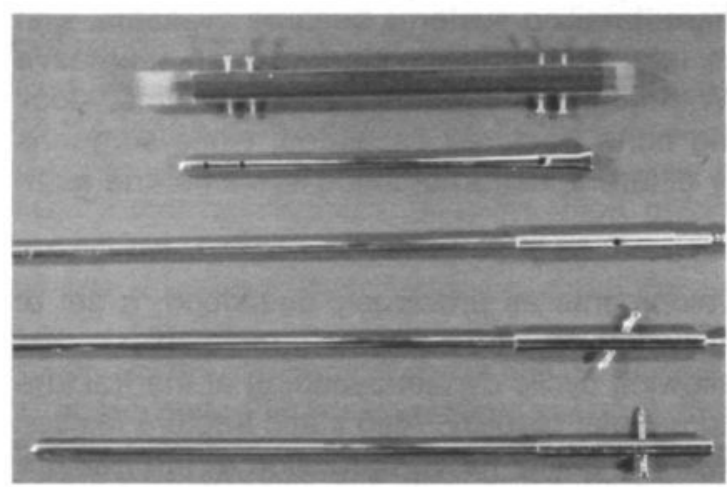

Figure 3.1

Several prototypes of the Telescopic Locking Nail could move in axial direction, in and out the outer tube. After a plastic model, a stainless steel prototype nail was manufactured in 1987 (figure 3.1). This nail had a circular cross section with a diameter of 9 millimeter and a wall thickness of 1 millimeter. A slotted, clover leaf shaped cross section was not necessary, because the nail was supposed to act as an internal fixator, without the need for impingement in the medullary canal.

The circular, closed cross section design was supposed to provide for better torsional rigidity and axial strength than the slotted, cloverleaf shaped nails. Because of the telescope mechanism, the nail was necessarily straight. So no anteversion bend for the femur or proximal Herzog bend for the tibia were incorporated in the design. More than that, it was the intention to use the same nail for femur, tibia and humerus. Differences in design parameters for each long bone were not wanted.

The first prototypes of the Telescopic Locking Nail were tested in the laboratories of the Mechanical Engineering Faculty of the University of Twente, the Netherlands (head prof. dr. Grootenboer). It was concluded from torsion tests that the connection between the outer tube and inner nail could not rely on the proximal locking bolts alone. The proximal locking slot of the inner nail was to weak to withstand torsional forces. These results enabled the finalization of the design of the Telescopic Locking Nail. The inner surface of outer tube and outer surface of inner nail were adapted to obtain optimal torsion strength. The diameter of the proximal part of the inner nail was enlarged from 9 to 10 millimeter.

During the same period, a pilot study was conducted to see whether fractures of femur, tibia and humerus could be treated with a straight nail. In this study a total of 43 nailings were performed in respectively 14 femora, 19 tibia's and 10 humerus with a straight nail with a circular and closed cross section, a diameter of 9 millimeter and without telescope mechanism. The results of treatment with this type of nail were comparable to those of other interlocking nailing systems (unpublished data). At the end of this study, it was concluded that, due to the flexibility of this nail design, it was possible to treat femoral, tibial and humeral fractures with the same design 9 millimeter straight interlocking nail. This was an important requirement for the further development of the Telescopic Locking Nail. 
Special consideration was given to the design of a new locking bolt that could withstand full weight bearing, even after statically locked nailing. The diameter of the nail stipulates the diameter of the locking bolts. For the inner nail of the TLN, with its circular cross section and diameter of 9 millimeter, the maximal diameter of the locking hole is 4.6 millimeter. The most important parameter for fatigue strength of the locking screw is the core diameter. In the locking bolts of most locking nail systems, the core diameter is significantly reduced by the thread of the bolt. For the TLN locking bolt the screw thread was therefore not removed from the core, but added to the core of the locking screw. In consequence, the thread, for securing the bolt into the bone, was located directly under the head of the bolt. In this way, a very stable locking bolt was developed with a core diameter of 4.5 millimeter. In a comparative biomechanical study, the TLN locking bolt was indeed significantly more stable than the fully threaded locking bolts of other tibial nailing systems ${ }^{38}$.

The design of the Telescopic Locking Nail for the humerus has been revised stepwise. In the humerus the telescope tube is not used, because the principle of cyclic dynamic loading is not applicable in this non weight bearing bone. The ability for fracture compression however maintained. The shape of the nail and its flexibility has been refined for better adaptation to the medullar canal of the humerus and for allowing antegrade and retrograde humeral nailing ${ }^{39}$. However, for humeral nailing with the TLN the same instrumentation set can be used as for femoral and tibial nailing.

\section{Biomechanical testing}

The final concept of the Telescopic Locking Nail was extensively tested in the Design Support Laboratories of Howmedica in Kiel, Germany ${ }^{40}$.

Four different test situations were created:

a. the use of the distraction screw and compression screw under axial loading

b. a four-point bending test to evaluate bending stability

c. torsion test to evaluate torsional rigidity

d. cyclic dynamic loading test to evaluate fatigue strength

\section{Distraction and compression}

To assess a safe functioning of the distraction and compression screws, a Telescopic Locking Nail was axially loaded with weights.

During this loading the distraction and compression screw were applied to the nail. The compression screw was easily inserted under a distraction force of 1000 Newton. Under a distraction force of 2000 Newton the twisting of the screw was heavier and accompanied with mechanical noises.

For the distraction screw, it was heavier to produce distraction under a compression force of 1000 Newton. Against a compression force of 2000 Newton, distraction could barely be accomplished, because the screw thread became damaged. 
A four-point bending test was performed according to ASTM F 383 standards.

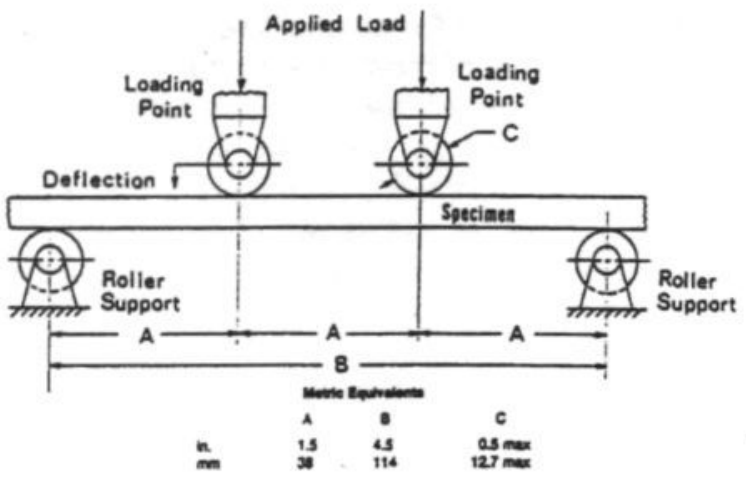

Figure 3.2

Test situation for four point bending test

The test configuration is shown in figure 3.2. The middle part of the 9 millimeter inner nail was used in this test.

At a bending moment of 50 Newton meter plastic deformation of the nail started. A bending moment of $70 \mathrm{New}$ ton meter resulted in a permanent bend of 1 millimeter.

The bending rigidity of the Telescopic Locking Nail was calculated as $B_{s}=25$ Newton meter/ millimeter

\section{Torsion test}

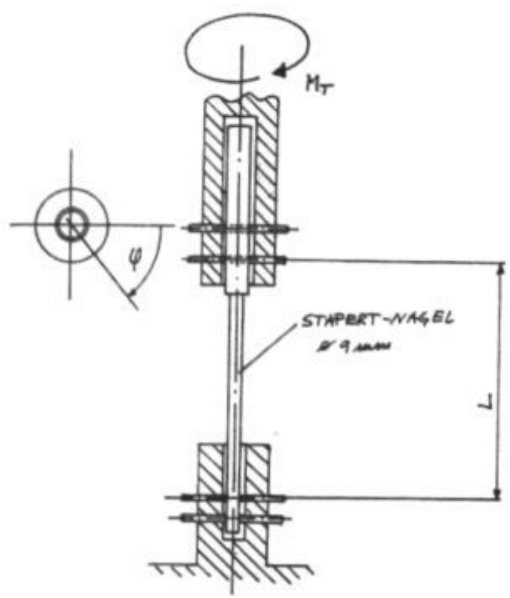

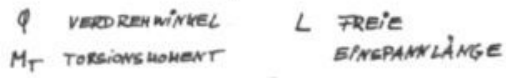

To evaluate torsion rigidity of the TLN, torsion tests were performed according to ASTM F 383 standards. The test configuration is shown in figure 3.3.

For testing, a 360 millimeter long Telescopic Locking Nail was mounted in the test bench with maximal distraction. In this test situation the torsion rigidity of the TLN was calculated as $\mathrm{T}_{\mathrm{s}} \approx 1.5$ Newton meter $/{ }^{\circ}$. For reasons of better comparability the torsion rigidity can also defined after ASTM 383-73. Here the torsion rigidity of a standard torque length of $\mathbf{2 5 4}$ millimeter is calculated. For the Telescopic Locking Nail the torsion rigidity was calculated as $\mathrm{T}_{\mathrm{s}(\mathrm{ASTM})}=$ 1.85 Newton meter $/^{\circ}$.

Figure 3.3

Test situation for torsion test

\section{Dynamic Loading Tests}

To evaluate the fatigue strength of the TLN cyclic dynamic loading tests were performed. The test configuration is shown in figure 3.4. 
The goal of this construction was to simulate a situation were a nail is inserted in a comminuted femoral shaft fracture. The forces applied in this test result in a combination of shifting forces and bending and torsion moments on the tested nail. The applied force $\mathrm{F}$ changed in a sinusoid pattern between a minimal level of $100 \mathrm{New}$ ton and a maximal level which was increased from 300 Newton, in steps of 100 Newton, after each 100.000 cycles. This resembles the clinical situation, where weight bearing is gradually expanded post-operatively. After 500.000 cycles, a fracture is supposed to be united, so the nail should at least withstand this number of cycles.

The Telescopic Locking withstood 900.000 cycles without any sign of plastic deformation. The maximal load applied in the last stages of the test was 1600 Newton.

From these test it was concluded that the Telescopic Locking Nail was more elastic on bending than other locking nails. The bending rigidity was calculated as being half of that of a slotted version of the Grosse-Kempf nail with a diameter of 12 millimeter.

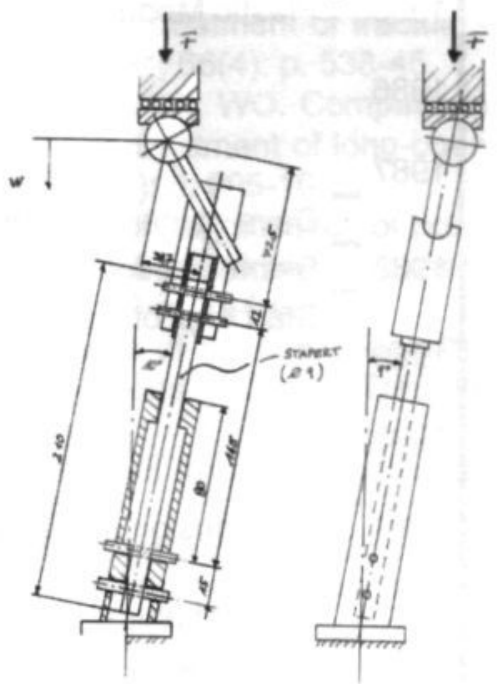

Figure 3.4

Test situation for dynamic loading test

Due to its closed cross section design, the TLN has a torsion stability 13 times higher than that of the 12 millimeter slotted G-K nail.

After 900.000 cycles under loads up to 1600 Newton no plastic deformation of the Nail occurred, suggesting an excellent fatigue strength.

\section{From test bench to clinic}

With the results of the biomechanical tests, the Telescopic Locking Nail could be released for clinical use in 1992. The first nailings with the Telescopic Locking Nail were performed from 1992 in hospital "Medisch Spectrum Twente" in Enschede, the Netherlands. The results of the first 71 consecutive femoral and tibial nailings in a single center setting are described in Chapter 5. From 1993 the Telescopic Locking Nail became available in other hospitals. Six Dutch hospitals were designated as "first user" - clinics. The data on treatment of acute femoral and tibial fractures with the Telescopic Locking Nail derived from these clinics. These hospitals were: Groene Hart Ziekenhuis, Gouda (DJ Swank); Leyenburg Ziekenhuis, the Hague (PVM Pahlplatz); Slotervaart Ziekenhuis, Amsterdam (BJ Dwars); Amphia Ziekenhuizen, locatie Molengracht (JPAM Vroemen); Sint Franciscus Gasthuis, Rotterdam (AJH Kerver); Medisch Centrum, Leeuwarden (R Leemans) and Academisch Ziekenhuis Maastricht (JWJL Stapert) The results of these multicenter studies are described in Chapters 6 and 7 . 


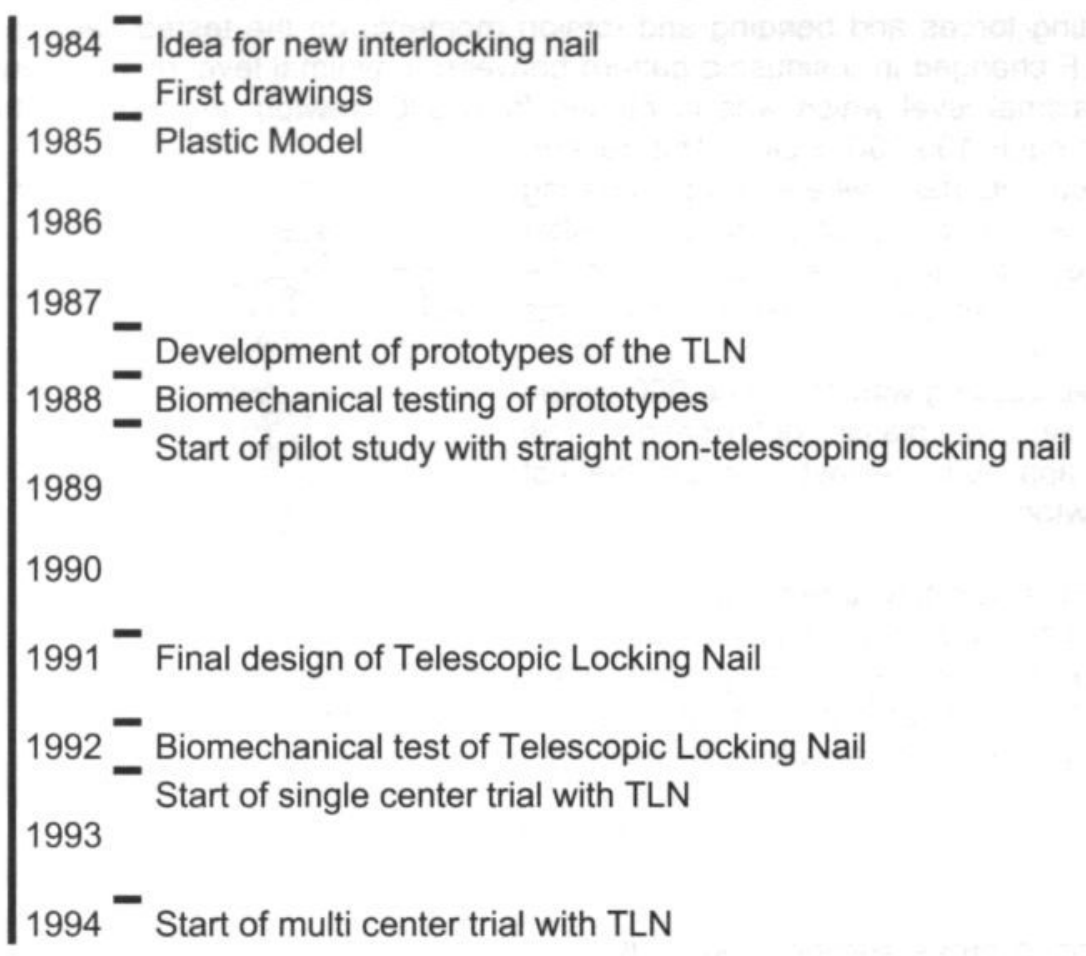




\section{REFERENCES}

1. Schatzker, J. Osteosynthesis in trauma. Int Orthop, 1996; 20(4): p. 244-52.

2. Sarmiento, A. Functional bracing of tibial and femoral shaft fractures. Clin Orthop, 1972; 82: p. 2-13.

3. De Bastiani, G, Aldegheri, R and Renzi Brivio,L. The treatment of fractures with a dynamic axial fixator. J Bone Joint Surg Br, 1984; 66(4): p. 538-45.

4. Wolf Jr, JW, White 3rd, AA, Panjabi, MM and Southwick, WO. Comparison of cyclic loading versus constant compression in the treatment of long-bone fractures in rabbits. J Bone Joint Surg Am, 1981; 63(5): p. 805-10.

5. Heitemeyer, U, Claes, L, Hierholzer, G, and Korber, M. Significance of postoperative stability for bony reparation of comminuted fractures. An experimental study. Arch Orthop Trauma Surg, 1990; 109(3): p. 144-9.

6. Georgiadis, GM, Minster, GJ and Moed, BR. Effects of dynamization after interlocking tibial nailing: an experimental study in dogs. J Orthop Trauma, 1990; 4(3): p. 323-30.

7. Gerber, C, Mast, JW and Ganz, R. Biological internal fixation of fractures. Arch Orthop Trauma Surg, 1990; 109(6): p. 295-303.

8. Schatzker, J and Tile, M. The rationale of operative fracture care. 2nd completely rev. and enlarged ed. 1996, Berlin; New York: Springer. xxiii, 633.

9. Rüedi, TP and Murphy, WO.AO principles of fracture management. 2000, Thieme ; AO Pub.: Stuttgart ; New York, Davos Platz, [Switzerland].

10. Bucholz, RW and Jones, A. Fractures of the shaft of the femur. J Bone Joint Surg Am, 1991; 73(10): p. 1561-6.

11. Watson, JT. Treatment of unstable fractures of the shaft of the tibia. J Bone Joint Surg Am, 1994; 76(10): p. 1575-84.

12. Brumback, RJ. The rationales of interlocking nailing of the femur, tibia, and humerus. Clin Orthop, 1996; (324): p. 292-320.

13. Klein, MP, Rahn, BA, Frigg, R, Kessler, S and Perren, SM. Reaming versus non-reaming in medullary nailing: interference with cortical circulation of the canine tibia. Arch Orthop Trauma Surg, 1990; 109(6): p. 314-6.

14. Bone, LB and Johnson, KD. Treatment of tibial fractures by reaming and intramedullary nailing. J Bone Joint Surg [Am], 1986; 68(6): p. 877-87.

15. Krettek, $\mathrm{C}$, Schandelmaier, $\mathrm{P}$ and Tscherne, H. Nonreamed interlocking nailing of closed tibial fractures with severe soft tissue injury. Clin Orthop, 1995; (315): p. 34-47.

16. Gregory, P and Sanders, R. The treatment of closed, unstable tibial shaft fractures with unreamed interlocking nails. Clin Orthop, 1995; (315): p. 4855.

17. Hutson, JJ, Zych, GA, Cole, JD, Johnson, KD, Ostermann, P, Milne EL and Latta, L. Mechanical failures of intramedullary tibial nails applied without reaming. Clin Orthop, 1995; (315): p. 129-37.

18. Court-Brown, CM, Will, E, Christie, J and McQueen, MM. Reamed or unreamed nailing for closed tibial fractures. A prospective study in Tscherne C1 fractures [see comments]. J Bone Joint Surg Br, 1996; 78(4): p. 580-3.

19. Anglen, JO and Blue, JM. A comparison of reamed and unreamed nailing of the tibia. J Trauma, 1995; 39(2): p. 351-5. 
20. Keating, JF, O'Brien, PJ, Blachut, PA, Meek, RN and Broekhuyse, HM. Locking intramedullary nailing with and without reaming for open fractures of the tibial shaft. A prospective, randomized study. J Bone Joint Surg Am, 1997; 79(3): p. 334-41.

21. Keating, JF, Blachut, PA, O'Brien, PJ and Court-Brown, CM. Reamed nailing of Gustilo grade-IIIB tibial fractures. J Bone Joint Surg Br, 2000; 82(8): p. 1113-6.

22. Templeman, DC, Gulli, B, Tsukayama, DT and Gustilo, RB. Update on the management of open fractures of the tibial shaft. Clin Orthop, 1998; (350): p. 18-25.

23. Court-Brown, $\mathrm{CM}$ and McBirnie, J. The epidemiology of tibial fractures. $\mathrm{J}$ Bone Joint Surg Br, 1995; 77(3): p. 417-21.

24. Hupel, TM, Aksenov, SA and Schemitsch, EH. Effect of limited and standard reaming on cortical bone blood flow and early strength of union following segmental fracture. J Orthop Trauma, 1998; 12(6): p. 400-6.

25. Wolinsky, PR, McCarty, E, Shyr, Y and Johnson, K. Reamed intramedullary nailing of the femur: 551 cases. J Trauma, 1999; 46(3): p. 392-9.

26. Winquist, RA, Hansen Jr, ST and Clawson, DK. Closed intramedullary nailing of femoral fractures. A report of five hundred and twenty cases. $J$ Bone Joint Surg Am, 1984; 66(4): p. 529-39.

27. Rutter, JE, De Vries, LS and Van der Werken, C. Intramedullary nailing of open femoral shaft fractures. Injury, 1994; 25(7): p. 419-22.

28. Brumback, RJ, Ellison Jr, PS, Poka, A, Lakatos, R, Bathon, G.H and Burgess, AR. Intramedullary nailing of open fractures of the femoral shaft. J Bone Joint Surg Am, 1989; 71(9): p. 1324-31.

29. Krettek, C, Rudolf, J, Schandelmaier, P, Guy, P, Konemann, B and Tscherne, H. Unreamed intramedullary nailing of femoral shaft fractures: operative technique and early clinical experience with the standard locking option. Injury, 1996; 27(4): p. 233-54.

30. Pape, HC, Auf'm'Kolk, H, Paffrath, T, Regel, G, Sturm, JA and Tscherne, H. Primary intramedullary femur fixation in multiple trauma patients with associated lung contusion--a cause of posttraumatic ARDS? J Trauma, 1993; 34(4): p. 540-7; discussion 47-8.

31. Bone, LB, Anders, MJ and Rohrbacher, BJ. Treatment of femoral fractures in the multiply injured patient with thoracic injury. Clin Orthop, 1998; (347): p. 57-61.

32. Bone, LB, Johnson, KD, Weigelt, J and Scheinberg, R. Early versus delayed stabilization of femoral fractures. A prospective randomized study. J Bone Joint Surg Am, 1989; 71(3): p. 336-40.

33. Boulanger, BR, Stephen, D and Brenneman, FD. Thoracic trauma and early intramedullary nailing of femur fractures: are we doing harm? J Trauma, 1997; 43(1): p. 24-8.

34. Schemitsch, EH, Jain, R, Turchin, DC, Mullen, JB, Byrick, RJ, Anderson, GI and Richards, RR Pulmonary effects of fixation of a fracture with a plate compared with intramedullary nailing. A canine model of fat embolism and fracture fixation. J Bone Joint Surg Am, 1997; 79(7): p. 984-96.

35. Whittle, AP, Wester, W and Russell, TA. Fatigue failure in small diameter tibial nails. Clin Orthop, 1995; (315): p. 119-28. 
36. Brumback, RJ, Toal Jr, TR, Murphy-Zane, MS, Novak, VP and Belkoff., SM. Immediate weight-bearing after treatment of a comminuted fracture of the femoral shaft with a statically locked intramedullary nail. J Bone Joint Surg Am, 1999; 81(11): p. 1538-44.

37. Arazi, M, Ogun, TC, Oktar, MN, Memik, R and, Kutlu, A. Early weightbearing after statically locked reamed intramedullary nailing of comminuted femoral fractures: is it a safe procedure? J Trauma, 2001; 50(4): p. 711-6.

38. Gabler, C, Tschegg, EK, Greitbauer, M, Stanzl-Tschegg, S, Wozasek, GE, Laube, W and Vecsei, V. [Fatigue stability of locking screws for unreamed tibial intramedullary nailing]. Unfallchirurg, 1999; 102(1): p. 29-34.

39. Goessens, MLMJ, V.d. Wildenberg, FJAM, Eggink, GJ and Stapert, JWJL. The Telescopic Locking Nail for Humerus, implant design, preliminary clinical results. Osteosynthese Int, 1996; 4: p. 270-74.

40. Howmedica, Stapert Telescopic Locking Nail Tests. Prüfbericht Nr. 91-030, 1992;: p. 1-15. 



\section{Chapter IV}

THE TLN: IMPLANT AND OPERATION TECHNIQUE 
The aim of this chapter is to familiarize the reader with the Telescopic Locking Nail. In the previous chapter, the development of the TLN was described. In this chapter a technical description of the implant and the instrumentation set will be given.

Finally, the operation technique will be described.

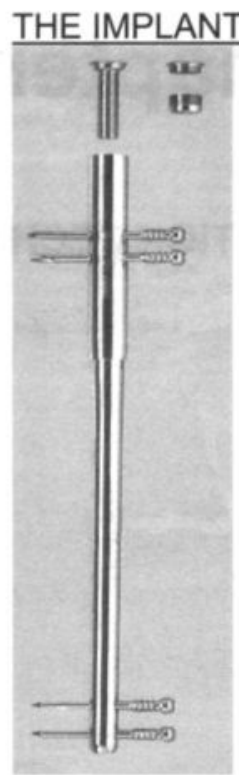

All parts of the Telescopic Locking Nail are made of $316 \mathrm{~L}$ stainless steel. The Telescopic Locking Nail is a modular implant to be assembled intra-operatively. It consists of a telescope tube, an inner nail, locking bolts and optionally a top lock screw, distraction screw or compression screw.

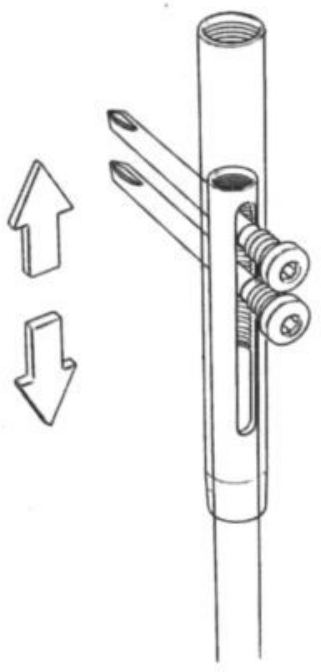

The telescope tube

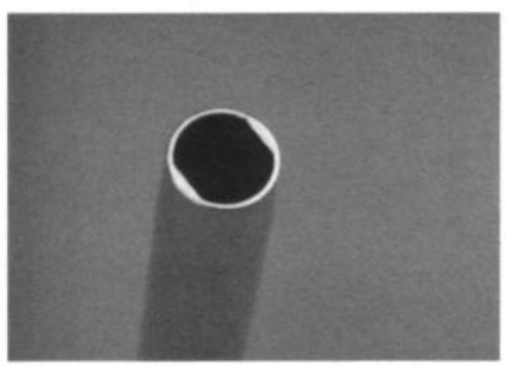

The telescope tube, which is mounted on the inner nail, is 110 millimeters long and has a diameter of 12 millimeter. Proximally, inside the tube, a screw thread is made to accommodate for the top lock screw or the distraction screw. The telescope tube is provided with two locking holes for the proximal locking bolts. The distal part of the tube has two flattened surfaces, which correspond with the flattened surfaces on the proximal part of the inner nail to prevent rotation of the inner nail in the telescope tube.

The inner nail

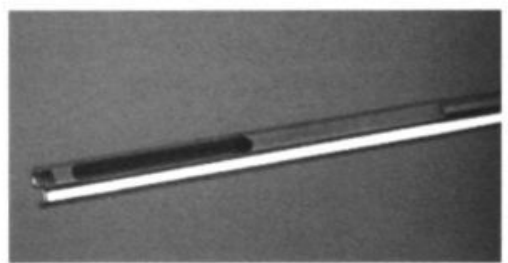

The inner nail has a circular cross section and a diameter of 9 millimeter. The wall thickness is 1 millimeter. The proximal part of the inner nail that moves in and out the telescope tube has a diameter of 10 millimeter. The whole range of nails available for femur and tibia consists of eight different nail lengths, from 310 millimeter to $\mathbf{4 8 5}$ millimeter, in steps of 25 millimeter. The proximal part of the nail has a screw thread in 
the inside of the nail to accommodate for the nail-assembly-screw or for the compression screw. The outside of the proximal part of the inner nail has two flattened surfaces, which correspond with the flat surfaces inside the distal part of the telescope tube to prevent rotation of the nail in the telescope tube. The two distal locking holes are parallel and their centers are located at 10 and 25 millimeter from the distal tip of the nail.

\section{The locking bolts}

The locking bolts were designed in combination with the Telescopic Locking Nail. They have a core diameter of 4.5 millimeter. The windings of the screw thread are actually added to the core of the bolt and are located under the screw head. This design gives the TLN locking bolt more fatigue strength than a fully threaded 4.5 millimeter screw. Locking bolts are available in lengths from 30 to 100

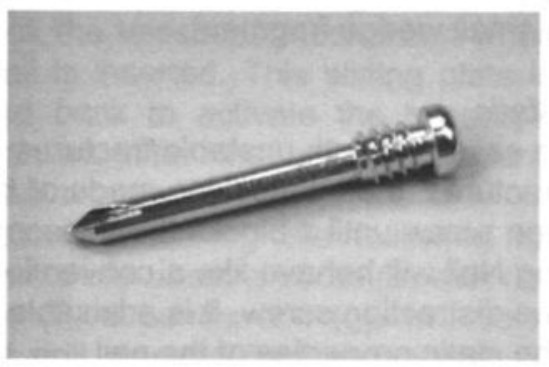
millimeter.

\section{The top lock screw}

At the end of an operation, the opening in the top of the TLN can be sealed of with the top lock screw, to prevent in growth of tissue in the nail.

\section{The distraction screw}

The screw thread of the distraction screw fits in the screw thread on the inside of the telescope tube, but not in the screw thread of the inner nail. When the distraction screw is turned, it will push the inner nail out of the telescope tube, thus lengthening the nail. The distraction screw can be used for bone lengthening in one stage up to 25 millimeter. In most cases however the distraction screw is used for length unstable fractures. When the distraction screw is inserted, it blocks the telescope mechanism of the TLN so shortening of the leg after weight bearing is prevented.

\section{The compression screw}
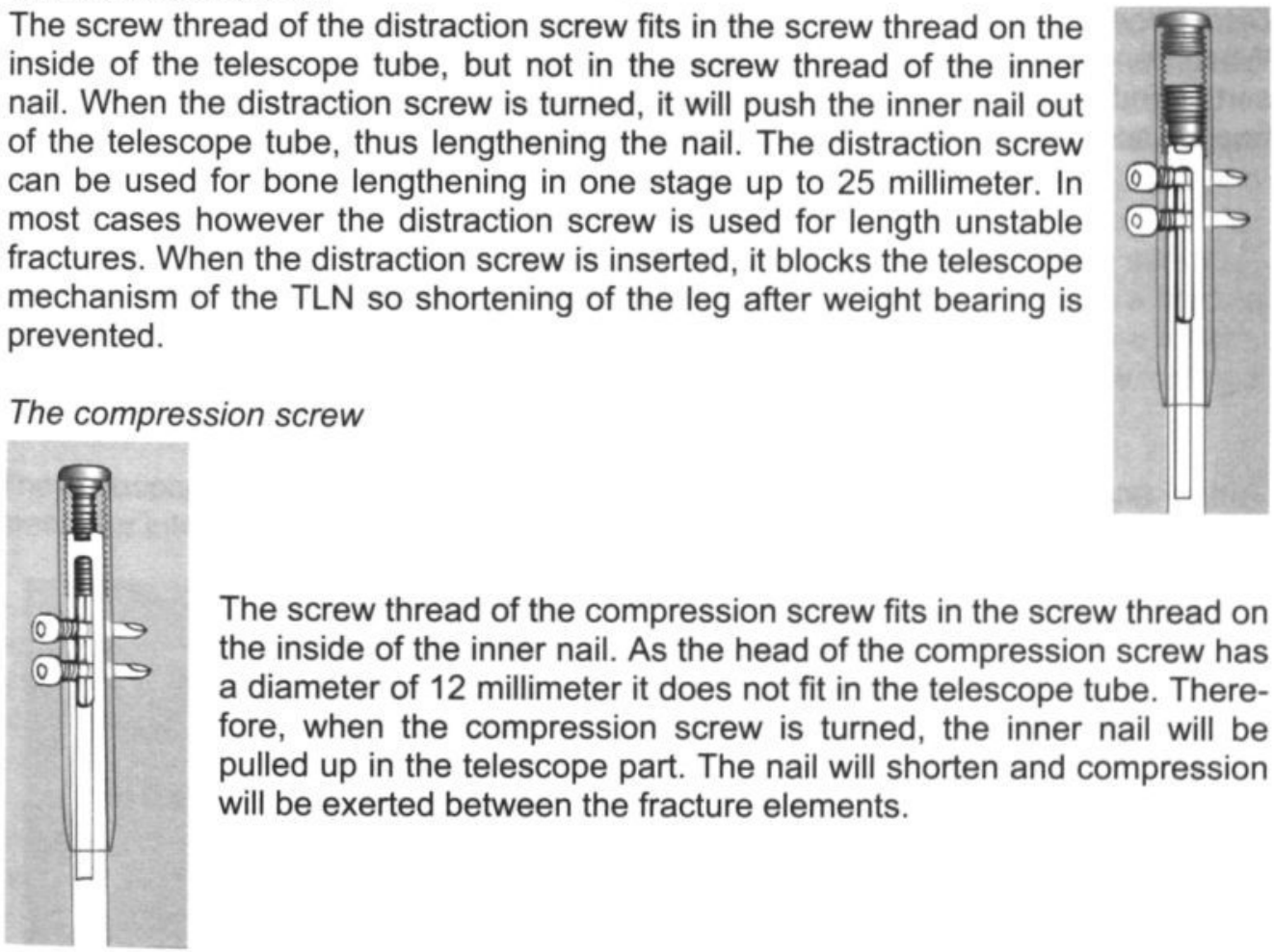

The screw thread of the compression screw fits in the screw thread on the inside of the inner nail. As the head of the compression screw has a diameter of 12 millimeter it does not fit in the telescope tube. Therefore, when the compression screw is turned, the inner nail will be pulled up in the telescope part. The nail will shorten and compression will be exerted between the fracture elements. 


\section{LOCKING NAIL}

\section{Dynamic}

When there is enough cortical contact between the main fragments of the fracture the Telescopic Locking Nail can be used in the dynamic mode. No additional screws have to be inserted in through the top of the nail; the top lock screw is optional. This is possible in transverse, short oblique or spiral fractures, and wedge fractures with a small wedge fragment.

\section{Static}

In case of length unstable fractures: fractures with a comminution zone or long spiral fractures, the interlocking mode of the TLN has to be static, by inserting the distraction screw until it blocks the telescope mechanism. In this way the Telescopic Locking Nail will behave like a conventional statically locked nail. To prevent migration of the distraction screw, it is advisable to insert a second distraction screw for securing the static properties of the nail.

\section{Compression}

The compression screw is inserted when compression between the fracture elements is desired, e.g. in case of delayed or non-unions. The compression screw can also be used to dissolve the diastasis of the fracture, which frequently occurs when the nail is inserted.

\section{Distraction}

When bone lengthening is the primary goal of the operation, the TLN has to be inserted and proximally and distally locked in its shortest way. When after this the distraction screw is inserted, distraction up to 25 millimeter can be achieved. 
THE INSTRUMENTATION SET

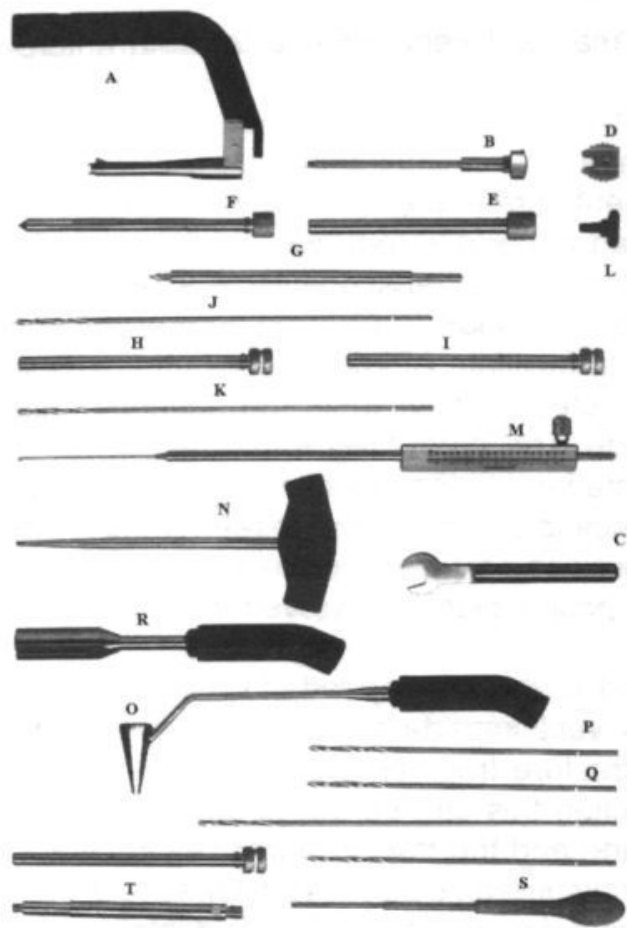

The handle of the targeting device (a) is made of carbon fiber. With the long nail fixation bolt (b) the assembled TLN is fixated tightly to the targeting device with a wrench (c). A special steel sliding plate (d) comes between the head of this bolt and the steel part of the targeting device to block the telescope mechanism when the nail is inserted. This sliding plate is pushed back to activate the telescope mechanism after the proximal locking bolts have been inserted.

For proximal locking the following instruments are used: a trocar (e) with obturator (f), a center drill (g), two color coded drill sleeves (red and green) ( $h$ and i), two color coded long drills (red and green for 6 millimeter and 4.5 millimeter respectively) ( $j$ and $k$ ), a small carbon fiber fixation screw (I), a screw length measure device $(\mathrm{m})$ and a T handle screwdriver $(\mathrm{n})$ with 3.5 millimeter imbus head.

For distal locking there are a funnelshaped targeting device (o) and two color-coded short drills (red for 6 millimeter and green for 4.5 millimeter) ( $p$ and $q$ ) The sleeve hammer ( $r$ ) can be used for nail insertion and for hammering the inner nail out of the telescope tube once proximal locking bolts have been inserted and the sliding plate is pushed back in the targeting device. The 'Allen Key' screwdriver (s) is used for twisting the top lock screw, distraction screw or compression screw. Other instruments that are used besides the TLN specific instruments are: a flexible intramedullary reamer set, drilling equipment, two guide-wires of the same length, one with and one without a bulbed head, a synthetic tube for guide-wire exchange and an awl for opening the medullary canal

The Telescopic Locking Nail is a universal nailing system. All implants and instruments for intramedullary nailing are available in two cassettes.
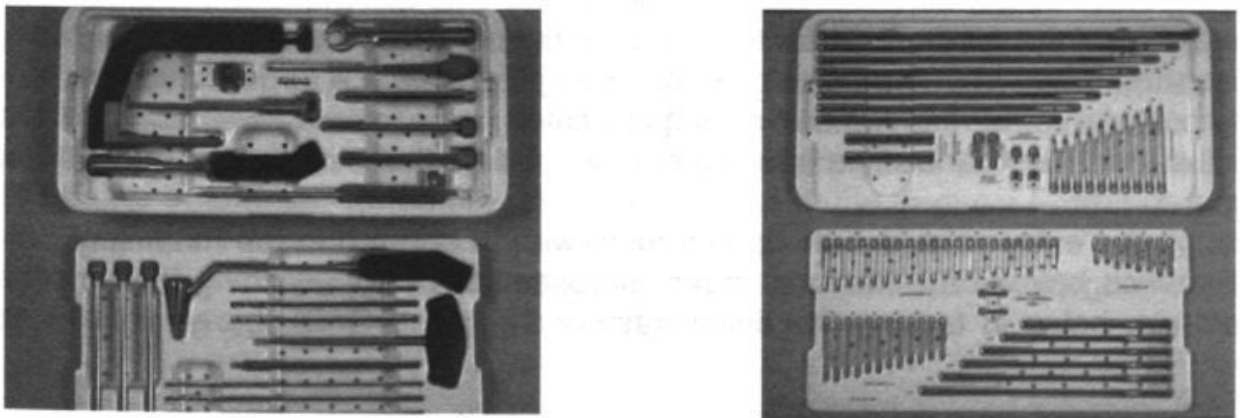
The design of the Telescopic Locking Nail makes it very suitable for both anterograde and retrograde femoral nailing.

\section{Positioning of the patient and fracture reduction}

For the anterograde nailing of the femur patients are in supine position on an extension table. Both feet of the patient are fixated in padded foot holders. In case of a distal femoral fracture, traction can be exerted over a transcondylar K-wire. A padded perineal post serves for counter traction. The short transverse bars of the foot holders are pointed towards the injured side to facilitate AP-view. For better access to the insertion point, the injured leg is adducted slightly, while the patient's trunk and arm are moved away from the injured side. The injured leg is elevated while the unaffected leg is lowered, bringing the feet in a heel to toe position. This is for allowing lateral view of the distal femur. The positioning of the patient for retrograde femoral nailing is much less laborious. The patient can be positioned in supine position, without the use of foot holders. The perineal post is placed to serve for counter traction.

The image intensifier and monitor are placed at the non-injured side; the C-arm is positioned perpendicular to the femur. It is very important to do a trial reduction guaranteeing easy alignment of the major fracture fragments before draping. With careful manipulation of the fracture and traction this can be accomplished in most cases. When these preparations are not made and the fracture turns out to be irreducible intra-operatively, open reduction is the surgeon's last resort. Open reduction implicates a higher risk for delayed union, non-union, implant failure and infection.

\section{Incision}

For anterograde femoral nailing, an incision of 5 centimeters is made from the place were the tip of the greater trochanter is palpated, in cranial direction. The fascia lata is opened and over a length of 3 centimeter the abductor musculature is split above the tip of the greater trochanter. A self-retaining retractor is placed.

For retrograde femoral nailing a 2 centimeter longitudinal incision is made in the middle between the apex patellae and the tibial plateau. After spitting of the patellar tendon, the intercondylar region of the distal femur can be approached without further dissection.

\section{Opening of the medullary canal and reaming}

The entry point for anterograde femoral nailing with the TLN is just medial to the tip of the greater trochanter. This starting point is more in line with the endosteal canal than the tip of the greater trochanter. Care should be taken that the entry point is not chosen too anteriorly. The entry can be accomplished with a large curved awl. The entry point for retrograde femoral nailing is located in the intercondylary notch, in line with the medullary canal. The opening here is made with a straight awl under fluoroscopic control.

Through the entry point, a bulb tipped guide-wire is inserted in the medullary canal and passed beyond the fracture under fluoroscopic control. Bending the tip of the guide-wire helps in tacking the distal fracture fragment. Once the guide-wire has 
passed the fracture, its tip has to be located centrally in the distal metaphysis in both AP and lateral view (in case of anterograde nailing).

Over this guide-wire the medullary canal is reamed with flexible reamers, starting at 9 millimeters and increasing the diameter with steps of 0.5 millimeter. The reamers are advanced beyond the isthmus, until the isthmus is reamed up to 11 millimeter. When passing a comminution zone the drive of the reamer is turned of. The distal femur does not have to be reamed. The proximal 15 centimeter of the medullary canal are reamed up to 13 millimeter to accommodate for the telescope part. The bulb tipped guide-wire is exchanged for a straight guide-wire with the use of a plastic tube. The position of this guide-wire is checked with fluoroscopy in antero-posterior and lateral view.

\section{Choosing the correct nail length}

By subtracting the length of the protruding part of the guide-wire of the length of an equally long entire guide-wire, the desired nail length is found. The TLN should be chosen one size shorter than the desired nail length. The lengths of the available TLN's vary with steps of 25 millimeter. After nail insertion and proximal locking the length of the TLN can be adapted to the desired length, by advancing the inner nail out of the telescope tube over a maximal distance of 25 millimeter. In the Telescopic Locking Nail system every desired nail length is available between 310 and 510 millimeter.

\section{Assembly of the nail and targeting device}

The telescope tube is mounted on the inner nail in a way that the flattened sides of tube and nail are fitting and that the screw thread of the telescope tube is proximal. The metal slide is fit in the targeting device. The nail fixation bolt is inserted through the targeting device and in the nail. The screw thread on the tip of this bolt fits in the screw thread on the inside of the inner nail. Before tightening the nail fixation bolt the metal slide is pulled until it rests against the nail fixation bolt. In this way the TLN has it shortest size.

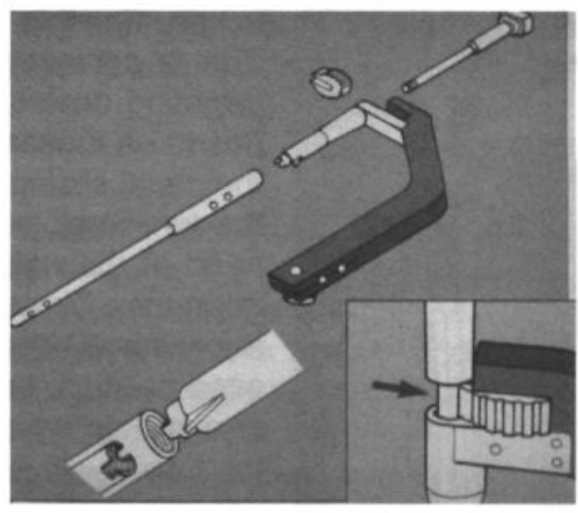

\section{Nail insertion and proximal locking}

Over the guide-wire the nail can be inserted by hand. Only for the last few centimeters a hammer may be used. The position of the nail is checked with the image intensifier. For anterograde nailing, the carbon fiber handle of the targeting device is held in the coronal plane of the femur when the nail is inserted, for retrograde nailing the handle is oriented in the sagittal plane. The top of the nail should be in level with the greater trochanter, for anterograde nailing, and at the deepest level of the intercondylary notch, for retrograde nailing.

The tightness of fixation of the targeting device to the nail is checked again after nail insertion. Before proximal locking, the guide-wire is removed. 
In contrast to conventional nailing systems, the sequence of locking with the TLN is strict and should not be changed: always proximal and distal locking should be performed and proximal locking always comes first.

In anterograde nailing the direction of the proximal and distal locking screws will be from lateral to medial; in retrograde nailing they will be directed from ventral to dorsal.

The trocar with obturator is placed in the proximal hole of the targeting device and pushed against the skin marking the place for incision. After skin incision and splitting of soft tissue, the trocar can be placed against the femoral cortex. It is fixated in this position by twisting the carbon fiber screw in the targeting device. The obturator is removed. The hole in the first cortex is started with a center drill to prevent the 6.0 millimeter drill from slipping of the femur. The red drill sleeve and 6-millimeter drill are used to make the hole in the first cortex. This drill does not fit through the locking holes in the nail. The green drill sleeve and 4.5-millimeter drill are used to make the hole in the second cortex. The desired screw length is measured and the screw with the right length is inserted through the trocar. This procedure is repeated for the second proximal locking bolt.

\section{Length adjustment}

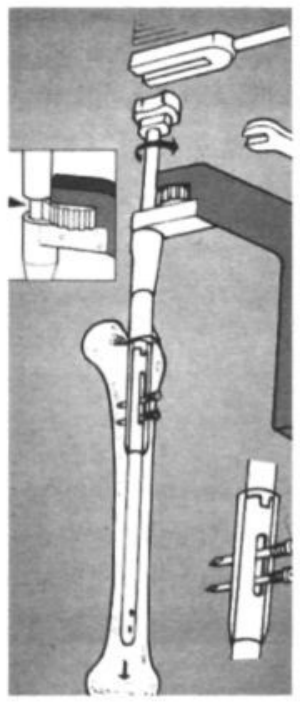

The inserted nail is shorter than the desired nail length. In this stage the length of the nail can be adjusted to the desired nail length. For this the telescope mechanism has to be activated. This is achieved by pulling back the metal sliding plate in the targeting device. To make this possible the nail fixation screw has to be loosened a little and tightened again afterwards. With the metal sliding plate pulled back, it is now possible to advance the inner nail out of the telescope tube by hammering on the head of the nail fixation screw over a maximal distance of 25 millimeter. Through fluoroscopy the position of the tip of the nail is constantly checked while it is advancing, until it is in the desired position. In this way, always exactly the desired nail length is available which can be advantageous in case of very distal fractures.

\section{Distal locking}

The $\mathrm{C}$-arm has to be positioned in such a way that there is enough space on the lateral side of the distal femur for instrumentation. The view on the monitor can be magnified. Round locking holes on the monitor are of utmost importance for successful distal locking. When the locking hole appears on the monitor as a horizontal ellipse the position of the $\mathrm{C}$-arm has to be adjusted in vertical plane and vise versa.

Several techniques can be used for distal locking, with our without the help of a targeting device or radiolucent drill. The problem of distal locking can be divided in two sub-problems: firstly the hole must be made at the right spot; secondly the hole must 
be made in the right direction. With most methods of distal locking, these two sub-problems have to be encountered simultaneously which in some cases can cause difficulties. With the design of the TLN locking bolt and the use of a funnel shaped targeting device it is possible to split these two problems and solve them separately, which makes distal locking easier.

After the installation of the $\mathrm{C}$-arm in such a way that the locking hole appears perfectly round on the monitor, a skin incision is made at the level of the locking hole.

Soft tissue is split onto the femoral cortex. The funnel shape targeting device is placed over the locking hole. The entire locking hole should be visible through it. By careful tapping on the edges of the funnel device, the position of the funnel on the femur is secured. When the direction of the funnel is changed the locking hole will remain visible. This is no problem, because the direction of the hole is not important in this stage. With the center drill through the targeting device a first

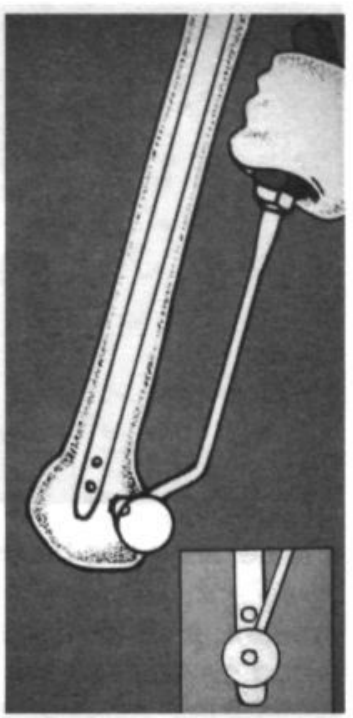
small hole is made in the first cortex to prevent slipping of the larger drill. Then with the short 6 millimeter drill (red) a hole is drilled in the first cortex. This is a large hole at the correct spot. By hand, the 4.5 millimeter drill bit is then advanced through this hole and manipulated through the locking hole in the nail until it reaches the second cortex. Its central position through the locking hole in the nail is checked by fluoroscopy. Then the drill bit is connected to the drill and the hole in the second cortex is made. After measuring, a screw of the correct length is inserted. In all cases two distal locking bolts must be inserted.

\section{Choosing the locking mode}

After these consecutive steps, the TLN has a dynamic configuration. This means that movements in axial direction are possible through the activated telescope mechanism. In case of length stable fractures the nail should be left in the dynamic mode. Optionally the top of the nail can be sealed with a top lock screw. When there is a length unstable fracture pattern, the TLN has to be made static by inserting a distraction screw in the top of the nail. On top of this, the top lock screw can be placed. When compression between the fracture fragments is desired, or when diastasis of the fracture has occurred during the nailing procedure, the compression screw is inserted.

\section{OPERATION TECHNIQUE FOR THE TIBIA}

\section{Positioning of the patient and fracture reduction}

For tibial nailing either an extension table or a standard radiolucent operation table can be used, according to the surgeon's preference. For proper nail insertion, there should always be the possibility for maximal flexion of the knee, regardless of which reduction technique is used. To maintain reduction of the fracture peroperatively a carbon fiber distractor can be used. 


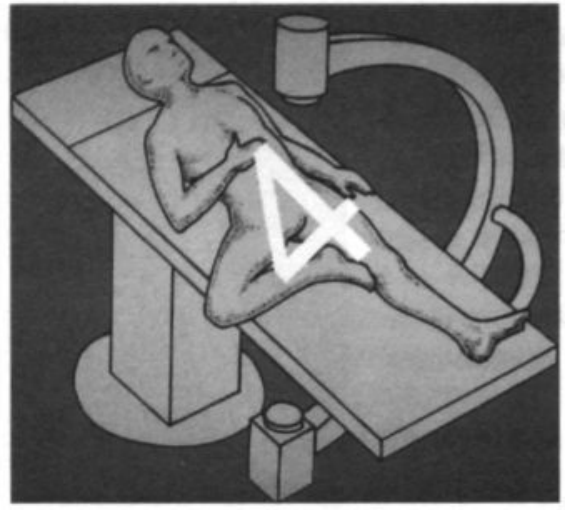

This has the advantage that the injured leg can be moved freely from straight to "position of four" position. This allows for optimal access for the surgeon and for easy AP and lateral view with the image intensifier.

After draping the carbon fiber distractor is placed first. The proximal pin for this distractor is positioned from the anteromedial to the posterolateral aspect of the tibial head so there is no interference with the nail. The distal pin is inserted through the calcaneus. These two pins are interconnected with a 700 millimeter long carbon tube. Together with this distractor a towel sling can be used to correct varus or valgus deformity.
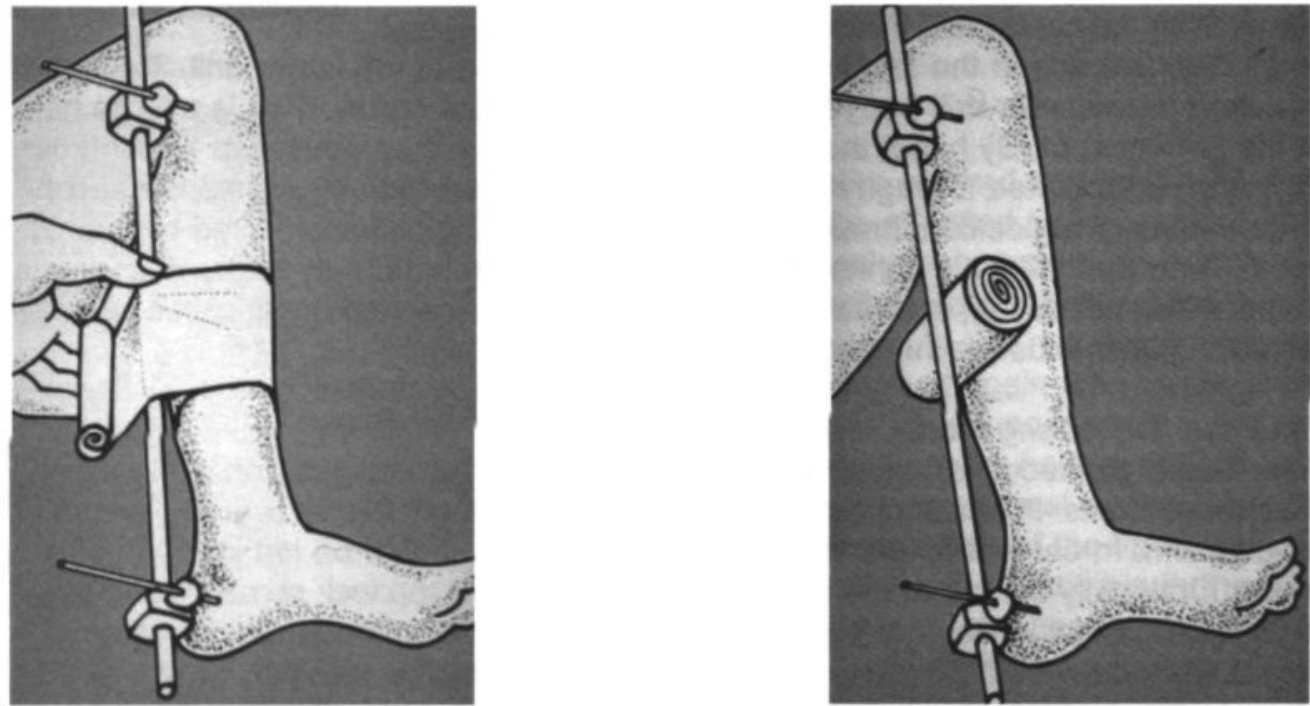

Incision and opening of the medullary canal

A transverse incision is made between the apex of the patella and the tibial tuberosity. The patella tendon can either be split or retracted laterally. The medullary canal is opened on the ventral edge of the tibial plateau in line with the anterior crista of the tibia. A self-retaining retractor can be placed. Chapter 8 describes a study on the use of this more proximal entry point for tibial nailing.

The remainder of the procedure is the same as described before for femoral nailing. On nail insertion, care should be taken that the top of the nail is in level with the tibial plateau, because a protruding nail can cause knee complaints. 


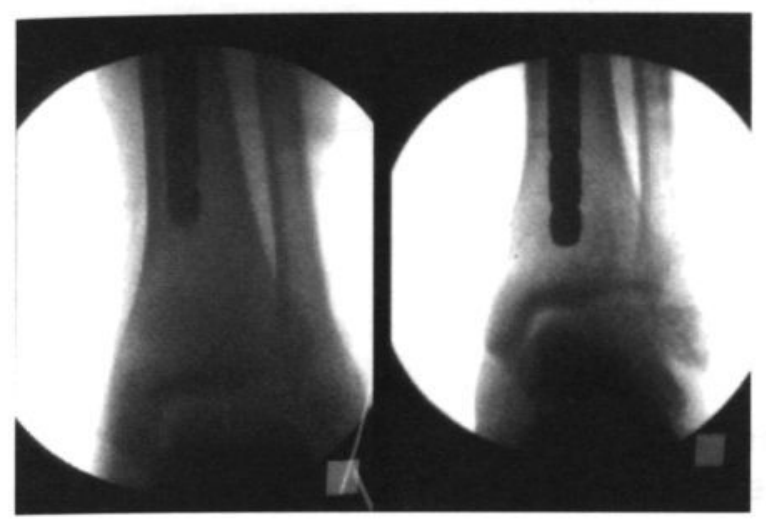

The fact that the length of the TLN can be adjusted to every length of tibia, makes this implant very suitable for distal tibial fractures, as the tip of the nail can be positioned exactly in the subchrondal bone above the tibio-talar joint and the distal locking holes are positioned near the distal tip. 


\section{Chapter V}

The treatment of fractures of femur and tibia with the Telescopic Locking Nail (TLN)

The design of a new implant and the first clinical results

Journal of Trauma, 1999; 46(5):p 853-862 
Intramedullary nailing has long been a satisfactory method of treating fractures of the lower extremity ${ }^{1}$. Küntscher was the first to elaborate a practical method of intramedullary nailing ${ }^{2}$. The first design of his nail was an unreamed model, which was later changed to a reamed one to enlarge the field of indications ${ }^{3,4}$. During the last twenty years, with the development of the interlocking nail, intramedullary osteosynthesis has increasingly been applied for internal fixation of femoral and tibial fractures ${ }^{1,5,6,7,8}$. While the interlocking nail was still in an early stage of development, other methods of fracture treatment were promoted by which fractures were treated in a dynamic fashion, which was thought to promote fracture healing. Publications of Sarmiento ${ }^{9}$ and De Bastiani ${ }^{10}$ showed that good results could be achieved with functional bracing and a dynamic external fixator respectively. Also experimental studies seem to confirm that micro-movements at the fracture-site and cyclic loading are important factors in the proces of fracture healing ${ }^{11}$. Considering these findings a new nail was designed based on this premise. The purpose of this paper was to review early clinical experience with this nail.

\section{Design of the Telescopic Locking Nail}

The Telescopic Locking Nail (TLN) consists of a $9 \mathrm{~mm}$ inner nail with a circular cross-section on which a $12 \mathrm{~mm}$ outer tube (telescope part) is mounted. The proximal locking bolts go through both the locking slot of the inner nail and the locking holes of the telescope part. The inner nail can then move over a maximal distance of $2.5 \mathrm{~cm}$ in the telescope part. The distal locking holes are situated near the tip of the nail. Together with the TLN special strong locking bolts with a core diameter of 4.5 $\mathrm{mm}$ have been developed. After proximal and distal locking, the nail maintains the axis of the limb and provides rotational stability, but permits cyclic dynamic compression. Static interlocking can be obtained when the distraction screw is inserted in the top of the telescope part, this blocks the telescope mechanism. The distraction screw can also be used for distraction over a maximal distance of $2.5 \mathrm{~cm}$ as for instance in correction osteotomies. Compression can be exerted over the fracture elements by using the compression screw, which pulls the inner nail in the outer tube.

The Telescopic Locking Nail can be applied in both femur and tibia and there are no differences for right or left side. All nails have the same diameter, the nail length varies from $28 \mathrm{~cm}$ to $48 \mathrm{~cm}$ in steps of $2.5 \mathrm{~cm}$. Within the $2.5 \mathrm{~cm}$ length difference the telescope mechanism of the TLN allows for exact adjustment of nail length.

As the device has the function of an internal fixator the nail does not have a cloverleave section and longitudinal slot as other intramedullary implants. Because of its telescopic form the nail is necessarily straight and does not have the Herzog bend as in other tibial nails nor an anteversion bend as in other femoral nails ${ }^{12}$. 


\section{Patients and methods}

From November 1991 till July 199424 patients with femoral and 47 patients with tibial fractures were treated with a Telescopic Locking Nail.

\section{Femur}

Osteosyntheses were performed on 16 acute femur fractures. There were 2 open and 14 closed fractures. Patient demographics, mechanisms of injury, and fractures and soft tissue classifications are given in Table 1. Fracture stabilization was carried out as soon as possible. Thirteen patients were operated on within one day of their trauma. In three cases, surgery was delayed for 2,8 and 18 days respectively.

For surgery, patients were positioned supine on a fracture table. The fracture was reduced under image intensification prior to draping. Via a small incision the medullary canal was opened on the medial aspect of the tip of the greater trochanter. After insertion of a guide-wire the medullary canal of the femur was reamed until beyond the isthmus of the medullary canal up to a diameter of $11 \mathrm{~mm}$. The distal metaphysis of the femur was never reamed. The proximal 12 centimeter of the femur were further reamed up to $13 \mathrm{~mm}$ to accommodate the wider telescope part of the nail. After measuring the length of the medullary canal, a nail was chosen which was up to 25 millimeter shorter than the measured length. The TLN was than inserted in its shortest fashion, with its telescope mechanism blocked. Proximal locks were inserted first. After deblocking the telescope mechanism, the inner nail was driven forward, using a small hammer, under fluoroscopic control, until its tip was at the desired position in the distal fragment. Thus the implant always had the exact length of the medullary canal, which made this nail very suitable for distal fractures. After this, the distal locking bolts were inserted, using the free hand technique. Finally, a top lock, a distraction screw or a compression screw was inserted on top of the telescope part, respectively to produce a dynamic or a static osteosynthesis or to exert compression at the fracture site. If there was enough cortical contact between the two main fracture elements to allow weightbearing, the TLN was inserted in the dynamic mode. In case of fractures with a comminution zone between the two main fracture elements, the distraction screw was used for static interlocking. In two cases dynamic interlocking was applied in a comminuted fracture, in these cases the comminution zone was shorter than two centimeters. Four of the acute femur fractures were statically locked; the 12 others were treated dynamically. The compression screw was not used in acute fractures.

Five cases of non-union, one case of infected non-union and 2 cases of mal-union were treated with the Telescopic Locking Nail. Patient demographics, time lapse between trauma and osteosynthesis with TLN and previous treatments are given in Table 2.

After removal of plate or nail from the previous treatment, osteosyntheses on patients with non-unions were performed in the same manner as described for acute femur fractures. No cancelous bone grafts were applied. In three of these cases the compression screw was used to exert compression between the fragments at the non-union site.

In the two cases of mal-union a correcting osteotomy was performed prior to nailing. 
In both these cases the limb length was corrected by applying the distraction screw after proximal and distal locking.

Table 1. Data on patients with acute femoral fractures treated with the Telescopic Locking Nail

\begin{tabular}{|c|c|c|c|c|c|c|c|c|c|}
\hline case & $\begin{array}{l}\text { sex } \\
\text { age } \\
\text { years }\end{array}$ & $\begin{array}{l}\text { mechanism } \\
\text { of injury }\end{array}$ & $\begin{array}{l}\text { fracture } \\
\text { classifi } \\
\text { cation }\end{array}$ & $\begin{array}{l}\text { soft tissue in- } \\
\text { jury } \\
\text { classification }\end{array}$ & $\begin{array}{c}\text { mode } \\
\text { of } \\
\text { interlocking } \\
\text { nailing }\end{array}$ & $\begin{array}{l}\text { time till } \\
\text { full } \\
\text { weight- } \\
\text { bearing } \\
\text { weeks }\end{array}$ & $\begin{array}{l}\text { netime till } \\
\text { radiologi- } \\
\text { cal union } \\
\text { weeks }\end{array}$ & $\begin{array}{l}\text { amount } \\
\text { of } \\
\text { shorten- } \\
\text { ing } \\
\mathrm{cm}\end{array}$ & $\begin{array}{l}\text { Compli- } \\
\text { cations }\end{array}$ \\
\hline$\overline{1}$ & M, 29 & $\begin{array}{c}\text { Shotgun } \\
\text { injury }\end{array}$ & c3 & open grade III & dynamic & 13 & 28 & 0 & \\
\hline 2 & F, 14 & sport & a3 & closed grade 0 & dynamic & 1 & 22 & 0 & \\
\hline 3 & F, 78 & fall at home & a1 & closed grade 0 & dynamic & $?$ & $?$ & $?$ & \\
\hline 4 & F, 38 & moped & b1 & closed grade I & dynamic & 1 & 56 & 0 & \\
\hline 5 & M, 16 & moped & a3 & open grade III & dynamic & 3 & 30 & 0 & \\
\hline 6 & $\mathrm{M}, 30$ & car & c3 & closed grade III & static & 18 & 44 & 1 & $\begin{array}{l}15 \text { degr. } \\
\text { varus }\end{array}$ \\
\hline 7 & M, 18 & bicycle & a1 & closed grade II & dynamic & 7 & 42 & 0 & \\
\hline 8 & F, 36 & car & c3 & closed grade I & dynamic & 5 & 28 & 0 & \\
\hline 9 & F, 24 & bicycle & b3 & closed grade I & static & 8 & 43 & 0 & \\
\hline 10 & M, 73 & $\begin{array}{c}\text { occu- } \\
\text { pational }\end{array}$ & a2 & closed grade 0 & dynamic & 6 & 22 & 0 & \\
\hline 11 & M, 28 & car & b3 & open grade I & dynamic & 12 & 48 & 0 & \\
\hline 12 & M, 22 & car & c3 & closed grade II & static & $?$ & $?$ & ? & \\
\hline 13 & F, 15 & moped & b1 & closed grade I & dynamic & 7 & 12 & 0 & \\
\hline 14 & F, 31 & car & c1 & closed grade I & static & 6 & 20 & 0 & \\
\hline 15 & M, 21 & car & a2 & closed grade I & dynamic & 16 & 26 & 1,5 & $\begin{array}{l}\text { superfi- } \\
\text { cial } \\
\text { infection }\end{array}$ \\
\hline 16 & F, 17 & car & a3 & open grade I & dynamic & 5 & 17 & 0 & \\
\hline
\end{tabular}

\section{Table 1}

Fracture classification according to the AO classification of fractures ${ }^{14}$, soft tissue injury classification according to Oestern and Tscherne ${ }^{15}$ in case of closed fractures and according to Gustillo and Anderson ${ }^{16}$ in case of open fractures. 
Table 2. Data on patients with femoral non-or malunions treated with the Telescopic Locking Nail

\begin{tabular}{|c|c|c|c|c|c|c|}
\hline case & $\begin{array}{l}\text { Sex } \\
\text { age } \\
\text { years }\end{array}$ & $\begin{array}{l}\text { time from } \\
\text { trauma to } \\
\text { operation } \\
\text { months }\end{array}$ & $\begin{array}{l}\text { Indication previ- } \\
\text { ous treatment }\end{array}$ & $\begin{array}{l}\text { mode of } \\
\text { interlocking } \\
\text { nailing }\end{array}$ & $\begin{array}{l}\text { time till full } \\
\text { weight- } \\
\text { bearing } \\
\text { weeks }\end{array}$ & $\begin{array}{l}\text { time till ra- complications } \\
\text { diological } \\
\text { union } \\
\text { weeks }\end{array}$ \\
\hline
\end{tabular}

\begin{tabular}{|c|c|c|c|c|c|c|c|}
\hline \multicolumn{8}{|c|}{ non-union } \\
\hline 17 & F, 79 & 10 & $\begin{array}{l}\text { non-union distal } \\
\text { femur, broken } \\
\text { plate }\end{array}$ & dynamic & - & 28 & $\begin{array}{l}\text { proximal frac- } \\
\text { ture } \\
\text { nail exchange }\end{array}$ \\
\hline \multirow[t]{2}{*}{18} & $\mathrm{~F}, 28$ & 7 & non-union after & compression & 1 & 72 & \\
\hline & & & $\begin{array}{l}\text { Grosse-Kempf } \\
\text { nail }\end{array}$ & & & & \\
\hline 19 & M, 41 & 4 & $\begin{array}{l}\text { infected non- } \\
\text { union } \\
\text { after } 9 \mathrm{~mm} \text { nail }\end{array}$ & dynamic & 1 & 60 & \\
\hline 20 & $M, 48$ & 13 years & & dynamic & 4 & 41 & $\begin{array}{l}\text { Superficial in- } \\
\text { fection }\end{array}$ \\
\hline & & & broken plate & & & & $\begin{array}{l}\text { implant failure, } \\
\text { nail exchange }\end{array}$ \\
\hline 21 & M, 24 & 6 & $\begin{array}{l}\text { non-union } \\
\text { after } \\
\text { GK-nail }\end{array}$ & compression & 5 & 50 & $\begin{array}{l}\text { superficial in- } \\
\text { fection }\end{array}$ \\
\hline \multirow[t]{3}{*}{22} & M, 24 & 6 & non-union after & compression & 5 & 25 & \\
\hline & & & plate fixation & & & & \\
\hline & & & mal-union & & & & \\
\hline$\overline{23}$ & $\mathrm{~F}, 18$ & 10 & $\begin{array}{l}2.5 \mathrm{~cm} \\
\text { shortening } \\
\text { after } \mathrm{c} 1 \text { fracture }\end{array}$ & static & 13 & 40 & \\
\hline 24 & M, 21 & 26 & $\begin{array}{l}4 \mathrm{~cm} \\
\text { shortening } \\
15 \text { degrees val- } \\
\text { gus } \\
\text { after c3 fracture }\end{array}$ & static & 4 & 25 & $\begin{array}{l}3 \mathrm{~cm} \text { length dif- } \\
\text { ference remain- } \\
\text { ing. } \\
\text { valgus cor- } \\
\text { rected }\end{array}$ \\
\hline
\end{tabular}


Twenty-nine osteosyntheses were performed on 28 patients with acute tibial fractures (one patient had bilateral tibial fractures). There were 5 open and 24 closed fractures. Patients demographics, mechanisms of injury, and fracture and soft tissue classification are given in Table 3 .

Of the 29 acute tibial fractures, 17 were operated on within one day of their trauma. Other acute tibial fractures were operated on with a delay ranging from 4 to 31 days after failed non-operative treatment.

For tibial ostheosynthesis, patients were positioned supine on a standard radiolucent operation table.

Tibial fractures were reduced and then temporarily fixed with a radiolucent distractortype external fixator. The proximal Steinmann pin used for this external fixator was positioned from the antero-medial to the postero-lateral aspect of the proximal tibia, the other one through the calcaneus. The advantage of this method is that the extension table is not needed and that the knee can be flexed maximally without loss of reduction.

Because the TLN is a straight implant and does not have the proximal Herzog-bend like other tibial implants, the insertion point is not at the tibial tuberosity but higher, at the ventral edge of the tibial plateau ventrally to the tibial tubercle. This point is closer to the axis of the medullary canal than the conventional insertion point, which makes insertion of a straight nail easier. The knee has to be bent maximally for an optimal access to this insertion point. This point was reached via a transverse incision through the skin between the tuberositas and the patellar apex and cleaving the patella tendon longitudinally. The remainder of the procedure was the same as described for femoral fractures. In tibial osteosyntheses the distraction screw was used two times for fractures with a large communition zone, the other tibial osteosyntheses for acute fractures were dynamically locked.

Seventeen cases of non-union and four cases of infected non-union were treated with the Telescopic Locking Nail. Patient demographics, time lapse between trauma and operation and previous treatment are given in Table 4.

The operation technique for tibial non-union was the same as for acute tibial fractures. The medullary canal was always reamed before nail insertion. In four cases of septic non-union the infection site was debrided and gentamycine beads were left behind. In the 21 osteosynthesis that were performed for non-union two times a cancelous bone graft was applied. The compression screw was used ten times. In one case of non-union (nr.31) the TLN was used for arthrodesis of the tibio-talar joint.

$\underline{\text { Table } 3}$

Fracture classification according to the AO classification of fractures ${ }^{14}$, soft tissue injury classification according to Oestern and Tscherne ${ }^{15}$ in case of closed fractures and according to Gustillo and Anderson ${ }^{16}$ in case of open fractures. 


\section{Table 3. Data on patients with acute tibial fractures treated with the Telescopic Locking Nail}

\begin{tabular}{|c|c|c|c|c|c|c|c|c|c|}
\hline case & $\begin{array}{l}\text { sex } \\
\text { age } \\
\text { years } \\
\end{array}$ & $\begin{array}{l}\text { mecha- } \\
\text { nism of in- } \\
\text { jury }\end{array}$ & $\begin{array}{l}\text { fracture } \\
\text { classifi- } \\
\text { cation }\end{array}$ & $\begin{array}{l}\text { soft tissue in- } \\
\text { - jury classifica- } \\
\text { tion }\end{array}$ & $\begin{array}{c}\text { mode of } \\
\text { interlocking } \\
\text { nailing }\end{array}$ & $\begin{array}{l}\text { time till } \\
\text { weight- } \\
\text { bearing } \\
\text { weeks }\end{array}$ & $\begin{array}{c}\text { amount } \\
\text { of short- } \\
\text { ening } \\
\mathrm{cm}\end{array}$ & $\begin{array}{c}\text { time till } \\
\text { radiologi- } \\
\text { cal union } \\
\text { weeks }\end{array}$ & $\begin{array}{c}\text { complica- } \\
\text { tions }\end{array}$ \\
\hline 1 & $M, 35$ & bicycle & a1 & closed grade 0 & dynamic & 1 & 0 & 36 & \\
\hline 2 & F, 69 & fall & c1 & closed grade II & dynamic & 4 & 1,5 & 18 & \\
\hline 3 & $\mathrm{M}, 17$ & moped & a3 & closed grade I & dynamic & 9 & 0 & 15 & \\
\hline 4 & $F, 89$ & fall & b2 & closed grade I & dynamic & 1 & 0 & 16 & $\begin{array}{l}\text { proximal } \\
\text { fracture } \\
\text { during in- } \\
\text { sertion }\end{array}$ \\
\hline 5 & F, 59 & pedestrian & b1 & open grade II & dynamic & 10 & 0 & 14 & \\
\hline 6 & M, 39 & fall & a1 & closed grade I & dynamic & 6 & 0 & 24 & \\
\hline 7 & $M, 40$ & sport & a2 & closed grade II & dynamic & 9 & 0 & 24 & \\
\hline 8 & $\mathrm{M}, 16$ & moped & b2 & closed grade II & dynamic & 3 & 0 & 20 & $\begin{array}{l}15 \text { degr. } \\
\text { endo- } \\
\text { rotation }\end{array}$ \\
\hline 9 & F, 18 & fall & a1 & closed grade 0 & dynamic & 3 & 0 & 16 & \\
\hline 10 & $\mathrm{M}, 31$ & sport & b3 & closed grade 0 & dynamic & 15 & 0 & 23 & \\
\hline 11 & F, 79 & fall & a1 & closed grade 0 & dynamic & 8 & 1 & 28 & $\begin{array}{l}9 \text { degr. } \\
\text { varus }\end{array}$ \\
\hline 12 & $\mathrm{M}, 19$ & motorcycle & a3 & open grade I & dynamic & 9 & 0 & 9 & \\
\hline 13,1 & M, 85 & pedestrian & a3 & open grade II & dynamic & - & - & - & $\begin{array}{c}\text { nail cut } \\
\text { out after } \\
\text { new } \\
\text { trauma }\end{array}$ \\
\hline 14 & F, 58 & fall & a1 & closed grade 0 & dynamic & 12 & 0 & 35 & \\
\hline 15 & $\mathrm{M}, 37$ & sport & a3 & closed grade I & dynamic & 1 & 0 & $\begin{array}{c}17 \\
7 \text { degr. }\end{array}$ & $\begin{array}{c}\text { superfi- } \\
\text { cial infec- } \\
\text { tion, } \\
\text { valgus }\end{array}$ \\
\hline 16 & M, 20 & pedestrian & a3 & open grade 2 & dynamic & 4 & 0 & 19 & \\
\hline 17 & $\mathrm{M}, 31$ & car & b2 & closed grade II & dynamic & ? & $?$ & $?$ & \\
\hline 18 & F, 48 & fall & a1 & closed grade 0 & dynamic & 9 & 0 & 32 & \\
\hline 19 & $\mathrm{M}, 19$ & moped & b2 & open grade I & dynamic & 15 & 0 & 31 & \\
\hline 20 & $M, 33$ & fight & a1 & closed grade 0 & dynamic & 2 & 0 & 40 & \\
\hline 21 & F, 65 & pedestrian & c1 & open grade I & dynamic & 3 & 0 & $?$ & \\
\hline 22 & M, 35 & fall & c3 & closed grade 1 & static & 9 & 0 & 30 & $\begin{array}{l}10 \text { degr. } \\
\text { exorota- } \\
\text { tion }\end{array}$ \\
\hline 23 & M, 27 & motorcycle & b1 & closed grade 0 & dynamic & $?$ & ? & $?$ & \\
\hline 24 & M, 23 & sport & a2 & closed grade I & dynamic & 1 & 0 & 13 & \\
\hline 25,1 & $M, 29$ & $\begin{array}{c}\text { occupa- } \\
\text { tional }\end{array}$ & a1 & closed grade I & dynamic & 4 & 0 & 20 & \\
\hline 25,2 & & & a2 & closed grade I & dynamic & 4 & 0 & 20 & \\
\hline 26 & F, 82 & bicycle & c3 & closed grade III & static & & $?$ & complica & $\begin{array}{l}\text { deep in- } \\
\text { fection } \\
\text { tions }\end{array}$ \\
\hline 27 & $M, 21$ & sport & a2 & closed grade 0 & dynamic & $\begin{array}{c}\text { died of } \\
6\end{array}$ & $\begin{array}{c}\text { cerebral } \\
0\end{array}$ & $\begin{array}{c}\text { complica } \\
22\end{array}$ & \\
\hline 28 & M, 16 & sport & a1 & closed grade I & dynamic & 1 & 0 & 22 & \\
\hline
\end{tabular}


Table 4. Data on patients with tibial non-unions treated with the Telescopic Locking Nail

\begin{tabular}{|c|c|c|c|c|c|c|c|}
\hline case & $\begin{array}{l}\text { sex } \\
\text { age } \\
\text { years }\end{array}$ & $\begin{array}{l}\text { time from } \\
\text { trauma to } \\
\text { operation } \\
\text { months }\end{array}$ & $\begin{array}{l}\text { indication } \\
\text { previous treatment }\end{array}$ & $\begin{array}{c}\text { mode of } \\
\text { interlocking } \\
\text { nailing }\end{array}$ & $\begin{array}{c}\text { time till } \\
\text { full } \\
\text { weightbearing } \\
\text { weeks }\end{array}$ & $\begin{array}{l}\text { time till } \\
\text { radiological } \\
\text { union } \\
\text { weeks }\end{array}$ & complications \\
\hline$\overline{29}$ & F, 17 & 7 & brace & dynamic & 7 & 6 & \\
\hline 30 & F, 28 & 12 & unreamed tibia nail & dynamic & 4 & 24 & \\
\hline 31 & F, 24 & 4 & $\begin{array}{l}\text { ext. fixator and } \\
\text { brace }\end{array}$ & dynamic & $?$ & $?$ & \\
\hline 32 & F, 74 & $>12$ & $\begin{array}{l}\text { Grosse-Kempf nail, } \\
\text { broken nail }\end{array}$ & compression & 10 & 60 & \\
\hline 33 & F, 21 & 8 & $\begin{array}{l}\text { plate fixation, } \\
\text { broken plate }\end{array}$ & compression & 8 & 19 & \\
\hline 34 & F, 54 & 6 & $\begin{array}{l}\text { ext. fixator and } \\
\text { brace }\end{array}$ & dynamic & 6 & 30 & \\
\hline 35 & M, 33 & 4 & $\begin{array}{l}\text { infected non-union } \\
\text { plate fixation, } \\
\text { broken plate }\end{array}$ & compression & 8 & 34 & $\begin{array}{l}\text { deep infection, } \\
\text { TLN removed } \\
\text { after union }\end{array}$ \\
\hline 36 & F, 34 & 5 & plate fixation & dynamic & 4 & 24 & \\
\hline 37 & M, 38 & 5 & unreamed tibia nail & dynamic & 2 & 36 & \\
\hline 38 & $\mathrm{M}, 17$ & 3 & brace & dynamic & 4 & 20 & $\begin{array}{l}\text { superficial in- } \\
\text { fection }\end{array}$ \\
\hline 39,1 & $M, 34$ & 9 & $\begin{array}{l}\text { infected non-union } \\
\text { plate fixation, ext. } \\
\text { fixator, bone graft }\end{array}$ & dynamic & - & - & $\begin{array}{l}\text { deep infection, } \\
\text { TLN removed } \\
\text { before union }\end{array}$ \\
\hline 39,2 & $\mathrm{M}, 35$ & & infected TLN & dynamic & 5 & 52 & \\
\hline 13,2 & M, 85 & 4 & $\begin{array}{l}\text { infected non-union } \\
\text { TLN, ext. fixator }\end{array}$ & dynamic & 26 & 39 & $\begin{array}{l}\text { deep infection, } \\
\text { TLN re- } \\
\text { moved } \\
\text { after union }\end{array}$ \\
\hline 40 & M, 27 & 7 & ext. fixator & compression & 5 & 35 & \\
\hline 41 & M, 28 & 3 & brace & compression & 4 & 8 & \\
\hline 42 & $M, 16$ & 3 & brace & dynamic & 1 & 24 & \\
\hline 43 & F, 35 & 5 & ext. fixator & dynamic & 4 & 20 & \\
\hline 44 & $M, 18$ & 2 & brace & compression & 1 & 12 & \\
\hline 45 & M, 26 & $>12$ & plate fixation & dynamic & 1 & 6 & \\
\hline 46 & M, 25 & 12 & Grosse-Kempf nail & compression & 4 & 30 & \\
\hline 47 & F. 30 & 6 & $\begin{array}{l}\text { ext. fixator } \\
\text { and brace }\end{array}$ & & 17 & 20 & \\
\hline
\end{tabular}


Post-operative management.

After recovery, patients immediately started with exercises for joint mobilization and muscle strengthening under the supervision of a physical therapist. In case of dynamic osteosynthesis and when the general condition enabled mobilization, partial weightbearing was started the first day after operation to a level at which the patient did not perceive any pain at the fracture site. Patients were then allowed to increase their weight bearing as tolerate. Some patients with acute fractures were thus fully weightbearing within one week postoperatively. In case of static osteosynthesis full weightbearing was postponed until there was callus formation at the fracture site on $\mathrm{X}$-ray examination.

Follow up was performed at regular visits in the outpatient department. Complaints of localized pain around the fracture and insertion sites of nail and locking bolts were noted. Time lapses till partial and full weightbearing were noted. During physical examination signs of infection and recovery of hip, knee and ankle function were assessed for. Rotation and limb length were analyzed by comparing to the uninjured leg. X-rays were examined for varus, valgus, ante- or recurvation deformities and fracture union. A fracture was considered to be united radiologically when the fracture gap was filled with structured callus on both antero-posterior and lateral X-rays. 


\section{Results}

\section{Femur}

\section{Acute fractures}

The results of treatment with the TLN of acute femoral fractures these cases are listed in Table 1. Of two of these patients were no post-operative data: one patient was repatriated shortly after operation and the other patient never came to the outpatient department for examinations after discharge. The mean follow -up period of the remaining patients was 12 months (range 4-17 months).

The mean operation time was 145 minutes (range 60-240 minutes). Twelve osteosyntheses were dynamic, four were statically locked. After exclusion of two multitrauma patients the mean hospital stay was 10 days (range 3-15 days).

For acute femoral fractures, the union rate after osteosynthesis with a TLN was 100 percent. The mean time lapse until radiological union for these cases was 31 weeks (range 12-48 weeks). One patient had a varus deformity of 15 degrees, with no clinical consequences, yielding a malunion rate of 6.3 percent. In two cases there was shortening of the affected limb of 1 and $1.5 \mathrm{~cm}$. respectively. In two cases where comminuted fractures were locked dynamically no shortening of the affected limb was measured. There was one superficial infection of a locking bolt incision without any clinical consequences. There were no deep infections (infection rate 0 percent). The mean time lapse until full weightbearing was 7 weeks (range 1-18 weeks). Of half of the patients with acute femoral fractures there were data on functional outcome after the rehabilitation process. One of these patients had a disturbed walking pattern, the other patients had no functional impairments.

\section{Non- and mal-unions}

The results after TLN osteosynthesis of femoral non- and malunion are listed in Table 2 .

The mean follow-up period for these eight cases was 16 months (range 6-23 months).

The mean operation time was 160 minutes (range $80-300$ minutes), this included the time needed for removal of previous osteosynthetic materials. The mean hospital stay was 7 days (range 4-19 days). Patients were fully weightbearing after a mean period of 5 weeks (range 1-13 weeks).

Two of the six cases of femoral non-union did not unite after primary osteosynthesis with a TLN and needed re-operation with nail exchange. In the first case (nr. 17) the TLN was changed for a long Gamma nail (Howmedica, Kiel, Germany), one week post-operatively, because the proximal femur fractured during osteosynthesis with TLN. The second case (nr. 20) was a 48 year old male patient had sustained a distal femoral fracture and an ipsilateral fracture of the femoral neck after a car accident during childhood. The femoral neck fracture resulted in an arthrodesis of the hip joint 4 years later. Because of shortening of the limb the patient had undergone an osteotomy for bone lengthening 25 years later. This osteotomy did not unite for 13 years in spite of repeated surgery. This patient was treated with a TLN. Because of the arthrodesis of the hip a retrograde insertion of the nail was performed, through the knee joint. After this procedure the $95 \mathrm{~kg}$. weighing patient was allowed full weightbearing. Nine months after the operation the proximal locking bolt broke, three months after this the nail broke while the non-union was not yet united. This was the 
only nail breakage ever observed with the TLN. The TLN was now replaced by a custom made orthinox nail with a diameter of $12 \mathrm{~mm}$. This nail was also introduced distally. After 25 weeks the non-union united.

The other cases of femoral non- and mal-unions united after an average period of 52 weeks (range 25-72 weeks). There were two cases of superficial infections of locking bolt incisions without any clinical consequences.

$\underline{\text { Tibia }}$

\section{Acute fractures}

The results of 29 osteosyntheses with the TLN for acute tibial fractures are listed in Table 3.

Of four patients with acute tibial fractures complete follow-up was not possible: one patient died of post-traumatic cerebral complications, two patients were repatriated after operation and one further patient did not return for examinations after discharge. The mean follow-up period for the remaining patients was 10 months (range 4-20 months)

The majority of tibial fractures was treated dynamically, only two of twenty-nine osteosyntheses were static. The mean operation time was 92 minutes (range 60-180 minutes). There was one peroperative complication: in case $\mathrm{nr} 4$ the proximal tibia fractured during nail insertion. This 89 year old patient was mobilised with a roller a few days after operation and the fracture healed uneventfully.

The mean hospital stay was 10 days (range 3-47 days).

In one case the TLN broke out, two weeks postoperatively (case nr. 13.1). This patient had a distal tibial fracture and was partially weightbearing. After a fall on the affected leg the TLN broke out of the distal tibia. The TLN was then exchanged for an external fixator. The other acute tibial fractures united after an average period of 23 weeks (range 9-36 weeks), the union rate was thus 96 percent.

There were two cases of malunion (malunion rate 6.9 percent). In the first case (nr.11), a 79 year old female patient who sustained her tibial fracture after a fall because of a cerebral stroke, a varus deformity of 9 degrees was accepted. The patient is fully weightbearing, using a walking-stick. In the other case of mal-union (nr.15) a distal tibial fracture in a 37 year old male patient united with 7 degrees of valgus, which did not cause any functional problems. Two patients were having rotational deformities after tibial osteosynthesis, 15 degrees endorotation and 10 degrees exorotation respectively.

One deep infection occurred after infection of the fasciotomy wound in an 82 year old female patient (case nr.26). This patient sustained a c3 fracture in a road traffic accident. One month after the trauma she died because of cerebral complications. The infection rate for acute tibial fractures was thus 3.5 percent.

Due to poor soft tissue coverage locking bolts in the tibia tend to cause more complaints than in femoral osteosyntheses. In three cases locking bolts were removed after union of the fracture because of complaints of pain.

Mean time lapse until full weightbearing without crutches was 6 weeks (range 1-26 weeks).

Of five patients there were no data concerning the functional outcome, one patient had 20 degrees loss of dorsiflexion of the foot, the 23 other patients had no functional deficits. 
Ten percent of the patients complained about knee pain at the insertion site of the nail, $70 \%$ did not have these complaints and in $20 \%$ of the cases there was no information on post-operative knee pain.

\section{Non-unions}

Of one patient with a tibial non-union follow-up was incomplete. The mean follow-up period of the remaining 21 cases was 12 months (range 6-24 months). The mean operation time was 90 minutes (range 60-120 minutes). The mean hospital stay was 5 days (range $3-8$ days).

All tibial non-unions united after an average period of 25 weeks (range 6-60 weeks). One of these cases needed a nail exchange with a TLN before union was achieved (case $\mathrm{nr}$.39).In another case a cancelous bone graft had to be applied (case $\mathrm{nr} 30$ ). Three deep infections occurred after osteosynthesis in pre-existent infected pseudarthrosis (cases nr.13.2, 35 and 39.1). In case 13.2 the patient was previously treated with a TLN for a grade II open a3 fracture (case 13.1). This nail cut out after a new, adequate trauma two weeks postoperatively and was replaced for an external fixator. After this procedure an osteïtis developed, which was treated by drainage and insertion of gentamycine beads at the fracture site. Three months later the infection seemed to be subsided and a new TLN was placed. Also after this osteosynthesis a persistent low grade infection occurred. Two and a half month later, there was enough radiological callus formation to remove the TLN and patient was further mobilized with a brace. Four months later there was full consolidation of the fracture without any sign of infection and the brace was removed. The other two cases of deep infection occurred when infected non-unions after plate fixation were treated by intramedullary nailing with the TLN In one case (nr.39.1) the TLN was combined with a cancelous bone graft and a free latissimus dorsi flap for soft tissue coverage. The deep infection persisted and the implant had to be removed 4 months later. The intramedullary canal was debrided by reaming and gentamycine beads were inserted. Five months later the infection subsided and a second TLN was placed.The nonunion united uneventfully without any sign of infection. In the last case of an infected non-union treated with a TLN (nr. 35) the infection persisted. An abces of the wound of the proximal locking bolt had to be drained one month postoperatively. Three months later, there were still signs of a deep infection, while the fracture was radiologically united. The implant was removed, the medullary canal was reamed and gentamycine beads were inserted. No sign of infection has occurred since then and the patient is without complaints. In one further case there was a superficial wound infections that did not need further treatment.

In two cases, locking bolts were removed because of complaints of pain after the non-union was united. 


\section{Discussion}

Because of the excellent union rates, low malunion and infection rates locked intramedullary nailing is nowadays the method of choice for the treatment of fractures of femoral and tibial shaft. The possibility of early weightbearing and the lack of need for postoperative immobilization in plaster casts promote optimal functional results. With the introduction of a new intramedullary nail our purpose was to keep the good qualities of locked intramedullary nailing while adding certain characteristics to facilitate a dynamic treatment of fractures.

In this first series, the Telescopic Locking Nail has been used for many indications, as we wanted to learn about the limitations of this new implant. The variations in fracture pattern, the inclusion of closed as well as open injuries of both femur and tibia and the use of the method in acute injuries as well as in non-unions constitute so broad an experience that it is difficult to compare our results to results achieved in other studies exactly.

Rates of union of more than 96 per cent after intramedullary nailing of femoral and tibial shaft fractures have been reported routinely $4,5,7,18,28,32,33$. In the treatment of acute femoral and tibial fractures we found union rates of 100 and 96 percent respectively. The time till union occurs seems longer in our series than in others. In several publications the time till union is between 12 and 26 weeks after nailing of acute femoral fractures ${ }^{4,7,18,32}$, in our study the average time till consolidation was 31 weeks. For tibial fractures treated with the TLN the time till union was 23 weeks, compared to 15 to 18 weeks found by other authors ${ }^{7,28,29,33}$. Our criterium for union was that the fracture gap should be filled with structured callus, and not the presence of only bridging callus. The appearance of bridging callus is an important sign when static nailing systems are used, because this indicates the moment that dynamisation is possible. We believe that bridging callus is only a relative criterium in the process of bony union in patients who are fully weightbearing without pain at the fracture site after dynamic interlocking nailing.

An important item in the use of locked intramedullary nails is, whether a osteosynthesis should be dynamised after static interlocking. In his three part publication ${ }^{17,18,19}$ Brumback pleaded for static interlocking in type III and IV fractures (classification according to Winquist ${ }^{4}$ ) and in cases were there is concern over the stability of the dynamic stabilization. In 10.5 percent of the cases were a dynamic femoral nailing was performed, there was shortening or rotational instability. Brumback also concluded that static interlocking did not inhibit fracture healing. Moreover, it did not increase the risk for refracture after nail removal (stress-shielding) or the risk for fracture at the site of the locking bolts when the nail remained in situ (stress-riser). The Telescopic Locking Nail sheds a new light upon this matter, because this implant is an interlocked nail with dynamic properties. The TLN is always locked both proximally and distally and thus provides rotational stability. After interlocking the surgeon has to decide whether to leave the nail in a dynamic mode or render it in a static fashion with the distraction screw, the range of dynamisation can be chosen between 0 and $2.5 \mathrm{~cm}$. Various animal studies showed the importance of cyclic dynamic loading, better bony regeneration after less rigid fixation and a beneficial effect of dynamisation on the quality of early bone healing ${ }^{20,21,22,23}$. Also clinical experience with functional bracing of fractures of tibial and femoral shaft ${ }^{9}$ and with dynamic external fixators ${ }^{10}$ indicate that controlled movement between the fractured parts is beneficial. 
Another advantage of the Telescopic Locking Nail is that, after proximal locking, the implant can be lengthened up to $2.5 \mathrm{~cm}$., which makes the nail suitable for every length of femur and tibia. This, combined with the fact that the holes for the distal locking bolts are near the tip of the nail, makes this implant especially suitable for the use in distal femoral and tibial fractures. This is illustrated in case 3, page 116.

The last years small diameter unreamed nails are increasingly being used in the treatment of femoral and tibial shaft fractures. The application of these nails, especially in the case of severe soft tissue damage is supposed to be associated with lower infection rates compared to reamed intramedullary osteosynthesis ${ }^{24,25,26,27}$. In several clinical studies however the same infection rates were found for reamed and unreamed nailing of tibial fractures with severe soft tissue damage $e^{25,26,28}$. In a prospective randomized study on patients with Tscherne C1 fractures Court- Brown et al. showed that reamed nailing is associated with a significantly lower time to union and a reduced requirement for a further operation ${ }^{29}$. The smaller diameters of nail and locking bolts of unreamed nails have an important drawback of less mechanical stability: nail and locking bolt breakage are frequently seen, full weightbearing is only possible after callus formation and nail exchange is performed in more cases ${ }^{30}$. The TLN has a $9 \mathrm{~mm}$ diameter and a circular cross-section so strong locking bolts with a core diameter of $4.5 \mathrm{~mm}$ can be used. This makes the implant stable enough to allow immediate weightbearing. Although the patients in this series were fully weightbearing without the help of crutches after a relative short period we did not encounter nail or locking bolt breakage but in one exceptional case. The diameter of $9 \mathrm{~mm}$ makes reaming necessary in young individuals who have a narrow medullary canal, but the nail can be used without reaming in older patients and in patients with comminuted fractures.

Because of its telescopic construction, the Telescopic Locking Nail is necessarily straight. The lack of an anteversion bend does not have important consequences in femoral nailing. Due to its relative flexibility the nail will follow the axis of medullary canal (also see case 1, page 114). In a few cases we saw a slight recurvation of the femur of less than 3 degrees after femoral nailing with the TLN but this did not have any consequences for functional outcome. The point of insertion of the nail in the femur is the medial aspect of the greater trochanter. Winquist claimed that the piriform fossa is the correct entry point because the use of a more lateral entry point would lead to comminution of the fracture site in the medial part of the femoral cortex ${ }^{4}$. We however did not encounter this problem. For easier introduction of this straight nail in the tibia we have chosen the insertion point somewhat more proximal, on the ventral edge of the tibial plateau. An anatomical analysis of Girgis ${ }^{31}$ showed that the distance between this point and the tibial attachment of the anterior cruciate ligament is $15 \mathrm{~mm}$, so there is a save margin with regard to reaming and nail insertion. During osteosynthesis with the TLN the synovial cavity of the knee was never opened. On 23 out of 29 cases of acute tibial fractures there were data concerning knee pain in the area of nail insertion. In only 13 percent of these cases anterior knee pain was reported. Alho ${ }^{33}$ and Hooper ${ }^{34}$ also find relatively low incidence of anterior knee pain after tibial nailing, 15 percent and 21 percent $^{34}$ respectively. Orfaly $^{35}$ and CourtBrown $n^{29,36}$ however consider knee pain as an important problem as they report incidences of 41 to 58 percent. In these series nails had to be removed because of troublesome knee pain in 26 to 46 percent of the cases ${ }^{35,36}$. In our series not a single nail was removed prematurely due to knee complaints. A possible reason for this is that 
with a more proximal and dorsal entrypoint there is less irritation of the patellar tendon and the nail is not protruding through the anterior cortex. Furthermore the nail length can exactly be adapted to the length of the tibia, so the proximal end of the nail is always in level with the tibial plateau. Also during weightbearing there will be no nail protrusion because of the telescope mechanism.

In the treatment of acute femoral and tibial fractures the complication rate was very low. Only in the treatment of difficult cases like long lasting and septic non-unions we encountered serious complications which required re-intervention.

Our first experiences with the Telescopic Locking Nail show that this new locking nail system is effective in the treatment of fractures and non-unions of femur and tibia. Compared to other interlocking nails it has three interesting distinctive features: the ability to choose for a dynamic configuration without loosing rotational stability, the fact that the same nail can be used for femur and tibia and the fact that the nail can be adapted to every length of femur or tibia, which makes it very applicable in distal fractures. 


\section{References}

1. Bucholz, RW and Jones, A. Current concepts review fractures of the shaft of the femur. J Bone Joint Surg 73-A:1561, 1991

2. Küntscher, G. Praxis der Marknagelung. Stuttgart, Schattauer, 1962.

3. Maatz, R., Lentz, W., Arens, W. et al (eds): Intramedullary nailing and other intramedullary osteosyntheses. Philadelphia, Saunders/Schattauer, 1986

4. Winquist, RA, Hansen, ST and Clawson, DK. Closed intramedullary nailing of femoral fractures. J Bone Joint Surg 66-A:529, 1984

5. Klemm, KW and Börner, M. Interlocking nailing of complex fractures of the femur and tibia. Clin Orthop 212:89, 1986

6. Olerud, S and Karlstrom, G. The spectrum of intramedullary nailing of the tibia. Clin Orthop 212:101, 1986

7. Kempf, I, Grosse, A, Taglang, G. et al. L'enclouage centro-médullaire avec verrouillage des fractures récentes du fémur et du tibia. Étude statistique à propos de 835 cas. Chirurgie 117:478, 1991

8. Watson, JT. Current concepts review; Treatment of unstable fractures of the shaft of the tibia. J Bone Joint Surg 76-A:1575, 1994

9. Sarmiento, A. Functional bracing of tibial and femoral shaft fractures. Clin Orthop 82:2, 1972

10. Bastiani, de G, Aldegheri, R and Brivio, LR. The treatment of fractures with a dynamic axial fixator. J Bone Joint Surg [Br] 66-B:538, 1984

11. Pennig, D. Zur Biologie des Knochens und der Knochenbruchheilung. Unfallchirurg 93:488, 1990

12. Inhofe, P.D. Biomechanical considerations in intramedullary fixation of lowerextremity fracture. Orthop Rev 21:945, 1992

13. Baker, SP, O'Neill, B, Haddon, $\mathrm{W}$ et al. The injury severity score: A method for describing patients with multiple injuries and evaluating emergency care. J Trauma 14:187, 1974

14. Müller, ME, Nazarian, S, Koch, $P$ et al. The comprehensive classification of fractures of long bone. Berlin-Heidelberg-New York, Springer-Verlag, 1990

15. Oestern, HJ and Tscherne, H Pathophysiologie und Klassifikation des Weichteilschadens. Unfallheilkunde 162:1, 1983

16. Gustilo, RB and Anderson, JT. Prevention of infection in the treatment of one thousand and twenty-five open fractures of long bones. J Bone Joint Surg 58-A:453-458, 1976

17. Brumback, RJ, Reilly, JP, Poka, A et al. Intramedullary nailing of femoral shaft fractures. Part I: Decision-making errors with interlocking fixation. J Bone Joint Surg 70-A: 1441, 1988

18. Brumback, RJ, Uwagie-Ero, S, Lakatos, RP et al. Intramedullary nailing of femoral shaft fractures. Part II: Fracture-healing with static interlocking fixation. J Bone Joint Surg 70-A:1453, 1988

19. Brumback, RJ, Ellison, TS, Poka, A et al. Intramedullary nailing of femoral shaft fractures. Part III: Long-term effects of static interlocking fixation. J Bone Joint Surg 74-A:106, 1992

20. Wolf, JW, White, AA, Panjabi, MM et al. Comparison of cyclic loading versus constant compression in the treatment of long-bone fractures in rabbits. J Bone Joint Surg 63-A: 805, 1981 
21. Heitemeyer, U, Claes, L and Hierholzer, G. Die Bedeutung der postoperativen Stabilität für die ossäre Reparation einer Mehrfragmentfraktur. Unfallchirurg 93:49, 1990

22. Georgiadis, GM, Minster, GJ and Moed, BR. Effects of dynamization after interlocking tibial nailing: An experimental study in dogs. J Orthop Trauma 4:323, 1990

23. Grundnes, $\mathrm{O}$ and Reikerås, $\mathrm{O}$. Mechanical effects of function on bone healing. Nonweight bearing and exercise in osteotomized rats. Acta Orthop Scand 62:163, 1991

24. Krettek, C, Haas, N, Schandelmaier, P et al. Der unaufgebohrte Tibianagel (UTN) bei Unterschenkel-schaftfrakturen mit schwerem Weichteilschaden. Erste klinische Erfahrungen. Unfallchirurg 94:579, 1991

25. Whittle, AP, Russell, TA, Taylor, JC et al. Treatment of open fractures of the tibial shaft with the use of interlocking nailing without reaming. J Bone Joint Surg 74-A: 1162, 1992

26. Tornetta III, P, Bergman, M, Watnik, $\mathrm{N}$ et al. Treatment of grade-IIIB open tibial fractures. A prospective randomised comparison of external fixation and non-reamed locked nailing. J Bone Joint Surg 76-B: 13, 1994

27. Chapman, M. The role of intramedullary fixationin open fractures. Clin Orthop 212: 26, 1986 28. Court-Brown CM, McQueen MM, Quaba AA et al: Locked intramedullary nailing of open tibial fractures. J Bone Joint Surg 73B:959, 1991

29. Court-Brown, C, Will, E and McQueen, M. Reamed or unreamed nailing for closed fractures. J Bone Joint Surg 78-B: 580, 1996

30. Hutson, J, Zych, G and Cole, J. Mechanical failures of intramedullary nails applied without reaming. Clin Orthop 315: 129, 1995

31. Girgis, F, Marshall, J and AI Monajem, A. The cruciate ligaments of the knee joint. Clin Orthop 106:216, 1975

32. Christie, J, Court-Brown, C, Kinninmonth, AWG et al. Intramedullary locking nails in the management of femoral shaft fractures. J Bone Joint Surg 70B:206, 1988

33. Alho, A, Ekeland, A, Strømsøe, $\mathrm{K}$ et al. Locked intramedullary nailing for displaced tibial shaft fractures. J Bone Joint Surg 72-B: 805, 1990

34. Hooper, GJ, Keddell, RG and Penny, ID Conservative management or closed nailing for tibial shaft fractures. J. Bone Joint surg 73-B: 83, 1991

35. Orfaly, R, Keating, JF and O'Brien, PJ. Knee pain after tibial nailing: does the entry point matter? J Bone Joint Surg 77-B: 976, 1995

36. Court-Brown, CM, Christie, J and McQueen, MM. Closed intramedullary tibial nailing. J. Bone Joint Surg 72-B: 605, 1990 


\section{Chapter VI}

THE TREATMENT OF ACUTE FEMORAL SHAFT FRACTURES WITH THE TELESCOPIC LOCKING NAIL

A multicenter experience 


\section{Introduction}

Locked intramedullary nailing has become the standard treatment for almost every type of fracture of the femur located between the lesser trochanter and the femoral condyles $^{1}$. As the femur is surrounded with a thick, well-vascularized soft tissue layer, open fractures of the femur can safely be treated with intramedullary nails. In contrast to open tibial fractures, contamination and soft tissue injury seldom lead to complications in open femoral fractures $\mathrm{s}^{2,3}$.

Most femoral locking nail systems manufactured nowadays have similar design characteristics: an antecurvation bend and proximal and distal locking holes. Some femoral nails have small diameters to allow unreamed insertion. Other femoral nailing systems were especially designed for retrograde insertion.

The Telescopic Locking Nail (TLN) has been designed for interlocking nailing of femur and tibia. Its unique design features are the fact that the nail is straight and that it is a modular nailing system, provided with a telescoping tube. Its telescopic design gives the possibility for cyclic dynamic loading at the fracture site while rotational and angular stability is maintained. The Telescopic Locking Nail is a modular nailing system, consisting of an inner nail and an outer tube, the telescope part. The nail is assembled intra-operatively. After nail insertion and proximal and distal locking, a dynamic, compression or static mode can be chosen, depending on the fracture type.

The TLN can be used in both femur and tibia, as there are no differences in design of the TLN for these bones.

In 1999 we presented the first clinical results with the TLN in a heterogeneous patient group ${ }^{4}$. In this study we present the clinical and long-term results of treatment of acute femoral fractures with the Telescopic Locking Nail. 


\section{Patients and Methods}

The Telescopic Locking Nail was introduced in the Netherlands in 1994. In six hospitals in the Netherlands the TLN became available and it was used by the surgeon's preference, mostly beside the nailing system that was already in use. In the period from January 1994 until January 1998, 59 acute femoral fractures in 56 patients were treated with the Telescopic Locking Nail.

The indication for intramedullary osteosynthesis in these patients was an acute fracture of the femoral shaft. Patients with delayed unions and nonunions nailed during that period were not included in this study group. There were 38 males and $18 \mathrm{fe}-$ males with a mean age of 37 years (range 14 - 92 years). The mechanisms of injury were as follows: motor vehicle accident (15 patients), motorcycle accident (6), moped/bicycle accident (15), occupational accident (4), fall (15) and one shotgun injury.

\section{Table 1}

Fracture characteristics and soft tissue injury (of 59 femoral fractures treated with the Telescopic Locking Nail)

\begin{tabular}{|c|c|c|c|}
\hline Specification & Subspecification & Number of cases & Percentage of cases \\
\hline \multirow[t]{3}{*}{ Fracture Pattern } & A & 25 & 43 \\
\hline & B & 22 & 37 \\
\hline & C & 12 & 20 \\
\hline \multirow[t]{2}{*}{ Length Stability } & Stable & 51 & 86 \\
\hline & Unstable & 8 & 14 \\
\hline \multirow[t]{3}{*}{ Fracture Localization } & Proximal $1 / 3$ & 2 & 3 \\
\hline & Mid $1 / 3$ & 45 & 76 \\
\hline & Distal 1/3 & 12 & 21 \\
\hline \multirow[t]{9}{*}{ Soft Tissue Injury } & Closed & 47 & 80 \\
\hline & Grade 0 & 27 & \\
\hline & Grade 1 & 10 & \\
\hline & Grade 2 & 7 & \\
\hline & Grade 3 & 3 & \\
\hline & Open & 12 & 20 \\
\hline & Grade 1 & 5 & \\
\hline & Grade 2 & 5 & \\
\hline & Grade 3 & 2 & \\
\hline
\end{tabular}


All fractures were classified according to the AO/ASIF classification of fractures. Soft tissue injury was classified according to the Oestern-Tscherne classification ${ }^{5}$ in case of closed fracture and according to the Gustilo-Anderson ${ }^{6}$ classification in case of open fracture. Fracture specifications are shown in table 1 . The majority of the fractures $(90 \%)$ were treated within 24 hours after trauma, the remainder of the fractures were treated with a delay ranging from 2 to 19 days, mostly after fracture stabilisation with an external fixation.

\section{Surgical Technique}

For surgery, the patients were positioned supine on a fracture table. Profylactic antibiotics were given intravenously. Before draping, the fracture was reduced under image intensification. Medial to the tip of the greater trochanter, the medullary canal was opened with an awl. After insertion of a guide wire, the medullar canal of the femur was reamed beyond the isthmus up to a diameter of $11 \mathrm{~mm}$. The proximal part of the femur was further reamed up to $13 \mathrm{~mm}$ to accommodate the wider telescope part of the nail. The distal metaphysis of the femur was not reamed.

After measuring the length of the medullar canal, a nail was chosen that was up to $25 \mathrm{~mm}$ shorter than the measured length. The Telescopic Locking Nail was then inserted in its shortest manner, with its telescopic mechanism blocked.

The proximal locking bolts were inserted first. After deblocking of the telescopic mechanism, the inner nail was driven forward by using a small hammer under fluoroscopic control until its tip was at the desired position in the distal fragment. In doing so, the implant always had the exact length of the medullar canal, which made this nail very suitable for distal fractures.

After this procedure, the distal locking bolts were inserted, by using the free hand technique. After proximal and distal locking, the aiming device was removed. In this way the nail provides rotational stability but permits cyclic dynamic compression at the fracture site during weight bearing. This dynamic configuration was applied in fractures were there was enough cortical contact between the main fragments. In some cases where there was diastasis of the fracture, the compression screw was be inserted in the top of the nail to compress the fracture elements. With the compression screw inserted cyclic dynamic compression is still possible. When there was concern over the axial stability of the osteosynthesis, i.e. in fractures with a comminution zone of more than $2 \mathrm{~cm}$ long, the distraction screw was inserted in the top of the nail. This blocks the telescope mechanism and provides a static interlocked osteosynthesis. In this study the distraction screw was used 10 times, the other 49 cases were locked dynamically either without (35 cases) or with compression screw (14 cases).

Postoperatively patients were encouraged to fully weight bear as soon as their other injuries allowed them to. The time lapse till full weight bearing was noted.

After discharge patients were seen at regular intervals at the outpatient department. Control radiographs were examined for union and alignment. A fracture was considered united when the fracture gap was filled with structured callus on both anteroposterior and lateral radiographs. The time lapse till fracture union and signs of malunion were noted. During physical examination functional deficits of knee and 
hip, leg length differences and rotational deformities were assessed. Patients were discharged from further follow up when they were fully ambulating without pain and when their fracture was united on control radiographs.

For inclusion in the study, follow-up of at least 6 months was required, unless fracture healing was documented to have occurred when the follow-up period was less than 6 months. 


\section{Results}

Ten patients were lost for follow-up. Two of these patients died five days postoperatively due to their neurologic injuries, four of these patients lived abroad and another four patients lived in nursing homes due to dementia. Of the 56 patients treated with the TLN for a femoral shaft fracture, 46 patients with 49 femoral fractures met the follow-up criteria. The mean follow-up period for this group of patients was 15 months (range 5-35 months).

All femoral fractures united after a mean period of 25 weeks (range 12-72 weeks). In one case of open femoral fracture there was a nail exchange due to infection before union was achieved. The primary union rate was therefore $98 \%$, the secondary union rate was $100 \%$. In six cases locking bolts were removed, not for dynamization but because of complaints of pain. These interventions took place after union of the fracture.

Patients with closed femoral fractures were fully weight bearing after a mean period of 8 weeks (range 1-36 weeks); for open fractures this was 10 weeks (range 3-24 weeks)

There were no nail or locking bolt breakages. In one case their was post-operative shortening of the femur due to injudicious use of the compression screw in a length unstable fracture (see case 5 , page 118).

Infections requiring intravenous antibiotics, surgical drainage, or both, developed in two cases for an infection rate of $4 \%$. Both were deep infections. One of these infections developed in a 21 year old man who fell from a height and sustained a grade 2 open femoral fracture. Three months after nailing with a TLN a deep infection occurred for which the nail was exchanged after reaming. This fracture united uneventfully thereafter and the patient was without signs of infection when last seen.

The other deep infection occurred in a 26 year old man. Nine months after nailing with a TLN because of a closed fracture, the nail was removed and the medullary canal was reamed. By then, the fracture had already healed. No sign of infection occurred thereafter.

Analysis of angulation on radiographs of healed femoral fractures revealed two cases with a varus or valgus, both less than 5 degrees $(4 \%)$. Six cases showed recurvatum of less than 5 degrees $(12 \%)$, two cases healed with 8 and 10 degrees recurvatum respectively $(4 \%)$. There were no procurvatum deformities. In all there were two cases with angular deformity in either plane of more than 5 degrees $(4 \%)$. Radiological results are shown in table 2.

Patients were assessed for rotational deformities post-operatively by physical examination. In one patient this revealed an exorotation of 15 degrees.

On examination for leg length discrepancy two patients showed a shortening of the operated leg of 1 and 2 centimeters respectively. In the first patient this was a C2type fracture that was nailed dynamically. The $2 \mathrm{~cm}$ shortening in the other patient was the result of the wrongly use of the compression screw in a length unstable fracture (see case 5, page 118). No correctional procedures were performed when femoral fractures had healed after nailing with the TLN.

In 39 patients the functional outcome of the affected limb could be assessed. Hip flexion and extension were unaffected, in two patients there was an extension deficit of the knee of more than 5 degrees.

In 50 of the 59 cases the TLN was removed routinely after fracture healing. 


\section{Table 2}

Results of treatment of femoral fractures with the Telescopic Locking Nail (of 49 cases in follow-up)

\begin{tabular}{|c|c|c|c|}
\hline Specification & Subspecification & $\begin{array}{c}\text { Closed Frac- } \\
\text { tures } \\
\mathrm{N}=38\end{array}$ & $\begin{array}{c}\text { Open Fractures } \\
N=11\end{array}$ \\
\hline $\begin{array}{l}\text { Mean time lapse till radiological } \\
\text { union } \\
\text { (weeks) }\end{array}$ & & 25 & 25 \\
\hline $\begin{array}{l}\text { Mean time lapse till full weight- } \\
\text { bearing } \\
\text { (weeks) }\end{array}$ & & 8 & 10 \\
\hline $\begin{array}{l}\text { Alignement } \\
\text { (number of cases) }\end{array}$ & $\begin{array}{l}\text { Varus }>5^{\circ} \\
\text { Valgus }>5^{\circ} \\
\text { Recurvatum }>5^{\circ} \\
\text { Procurvatum }>5^{\circ} \\
\text { Rotation }>10^{\circ} \\
\text { Shortening }>1 \mathrm{~cm}\end{array}$ & $\begin{array}{l}0 \\
0 \\
1 \\
0 \\
1 \\
1\end{array}$ & $\begin{array}{l}0 \\
0 \\
1 \\
0 \\
0 \\
1\end{array}$ \\
\hline $\begin{array}{l}\text { Infections } \\
\text { (number of cases) }\end{array}$ & $\begin{array}{l}\text { Superficial } \\
\text { Deep }\end{array}$ & $\begin{array}{l}0 \\
1\end{array}$ & $\begin{array}{l}0 \\
1\end{array}$ \\
\hline
\end{tabular}




\section{Discussion}

Intramedullary nailing of fractures of the femoral shaft is nowadays a generally accepted standard treatment'. While the conventional 'Küntscher nailing' was restricted to diaphysal fractures ${ }^{7}$, the introduction of locked nailing has extended the spectrum of indications to include the entire femoral shaft and all other fracture types $^{8-12}$.

Since the development of the interlocking nail, many different nailing systems evolved for locked intramedullary nailing of the femur. The main differences between the modern nailing systems are concerning the nail diameter and the material of which the nail is manufactured.

The Telescopic Locking Nail is a different and unique treatment modality for shaft fractures of the lower extremity. The biomechanical properties of this nail allow for movement of the longitudinal axis while maintaining rotational and angular stability. In a previous study we showed that treatment of fractures and non-unions of femur and tibia is feasible ${ }^{4}$. In this series we studied a more circumscribed group of patients with acute femoral fractures in a multicenter setting. The primary union rate in this series was $98 \%$, only in one case a nail exchange was performed before union was achieved, because of infection. Numerous authors have documented these high union rates treating femoral shaft fractures with reamed intramedullary nailing ${ }^{8-18}$.

Initially, the treatment of open femoral fractures with immediate reamed intramedullary nailing was controversial, because of the risk of infection ${ }^{19}$. Vast clinical experience with reamed nailing in open femoral fractures has proven the efficacy and safety of this method ${ }^{2,3}$. Infection rates of approximately 1 percent can be expected after femoral nailing ${ }^{12,17,20,21}$. The infection rate in this study was 4 percent. The deep infections that occurred in two cases subsided after nail removal, debridement and antibiotics.

Although that patients were encouraged to full weightbearing after operation, no locking bolt or nail breakages were observed, demonstrating the excellent biomechanical performance of this implant.

The femoral shaft and its endosteal canal, although straight in the anteroposterior plane, form a gentle curve (convex anteriorly) in the lateral view. Most femoral locking nails have an antecurvation bend to follow this curve. The Telescopic Locking Nail is straight. This explains why a small amount of recurvatum was seen in 16 percent of the cases. Only in two cases this was more than 5 degrees ( 8 and 10 degrees respectively). This small amount of recurvation due to the shape of the TLN is not expected to have clinical consequences.

Another unique design parameter of the Telescopic Locking Nail is its Telescope mechanism. It was developed to give the nail the possibility of movement over the longitudinal axis while maintaining rotational and angular stability. Actually, dynamization of the nail, which is the result of cyclic dynamic loading, can be observed on postoperative radiographs in some cases, after the patient has been weightbearing. In the early days of the interlocking nail the majority of nailings were performed with locking bolts only on one site of the fracture, to achieve a dynamic fracture fixation. When static interlocking had to be performed because of a length unstable fracture pattern, the osteosynthesis was frequently "dynamized" later, to promote fracture union. The main problem with these dynamic or dynamized intramedullary osteosyntheses is the fact that fracture fixation is unstable. Axial loading can then lead to 
shortening of the femur. But also torsional and angular forces can lead to loss of reduction and therefore to non- or malunions. Therefore Brumback pleaded for static interlocking of all femoral shaft fractures, after he demonstrated that statically interlocked femoral shaft fractures united in 98 percent of the cases without the need for dynamization 22,23 . The Telescopic Locking Nail has always to be locked proximally and distally so rotational and angular stability is warranted. Hereafter the surgeon can decide to make the osteosynthesis static or dynamic, depending on the fracture pattern. In 83 percent of the cases in this series a dynamic configuration was chosen. In only 2 cases shortening occurred. Interestingly, in one of these two cases the surgeon had decided to make the nail static, but mistakenly used the compression screw for this. As the patient started weightbearing, the nail shortened, as it had unintentionally been programmed to do, leading to a shortening of the operated femur of 2 centimeter (see case 5 , page 118). Overall, the malunion rate was low (4 percent) and no correction osteotomies had to be performed after fracture healing, while in the majority of cases a dynamic configuration of the Telescopic Locking Nail was chosen.

Because of its telescope mechanism the length of the TLN can exactly be adjusted to the length of the medullary canal. After proximal locking the inner nail can be driven forward until the distal locking holes are below the fracture, while the top of the nail remains in level with its insertion point. In case of very distal fractures this can be advantageous (see figure case 6, page 119).

The TLN has a circular cross section of $9 \mathrm{~mm}$. Because of this diameter and circular cross section medullary canal has to be reamed up to 10 to 11 millimeters to allow for easy nail insertion. The last decade there has been increasing concern about the systemic pulmonary effects of reamed intramedullary nailing of the femur. This has lead to an increased use of unreamed femoral nails ${ }^{21}$. However, conflicting evidence exist with regard to the beneficial or deleterious effects of reaming. Some studies show that early reamed intramedullary fixation improved pulmonary morbidity ${ }^{24}$, whereas others state that reamed nailing causes a further diminution of pulmonary function in the polytraumatised patient ${ }^{25}$. Unreamed femoral nailing has been associated with shorter operation time and diminished blood loss compared to reamed nailing. These advantages do however not offset the disadvantages: longer union time, higher reintervention rate and higher rates of screw or nail breakage $e^{26-28}$. Reamed interlocking nailing is still the standard treatment for femoral fractures. Further studies have to find out if subgroups of patients exist who could benefit from unreamed nailing.

In this study we did not observe any nail or locking bolt breakages, although patients were encouraged to start weight bearing as soon as possible, regardless of the mode of interlocking (static or dynamic). As other authors stated, early weight bearing after statically locked reamed intramedullary nailing of length unstable fractures is possible and does not preclude screw or locking bolt breakage ${ }^{29,30}$. In these studies the diameters of the nails used varied from 12 to 14 millimeter. The Telescopic Locking Nail has a diameter of 9 millimeter, a wall thickness of 1 millimeter and a circular cross-section. This allows for strong locking bolts with a core diameter of 4.5 millimeter to be used. In a biomechanical study Gabler at al showed that these bolts have a better biomechanical performance than the fully threaded locking bolts with smaller core diameters used in other nailing systems ${ }^{21}$. 
The Telescopic Locking Nail is a universal locking nail system. The nail is available in only one diameter ( 9 millimeter) and there are no differences for right or left side. Although not mentioned in this paper the TLN can be used for both antegrade and retrograde nailing of the femur. Exactly the same nail and instrumentation set is used for tibial nailing. Our experience is that this has made intramedullary nailing of the femur and tibia a more standard and simple procedure for both surgeon and theatre staff. Different nail lengths are available in steps of 2.5 centimeter; the length difference between these steps can be adjusted with the telescope mechanism, so the desired nail length is always available. This can be cost effective because fewer nails have to be in stock.

In this multicenter study the Telescopic Locking Nail has shown to be a reliable implant for the treatment of acute femoral fractures. Open and closed, length stable and unstable fractures of the femoral shaft were treated successfully, with results comparable to other locking nail systems. In the majority of the cases a dynamic osteosynthesis could be performed. This did not lead to high rates of shortening or malunion. While patients were ambulating in an early stage postoperatively, no implant failure was seen. Future prospective randomized trials will have to confirm our observations. 


\section{References}

1. Brumback, RJ. The rationales of interlocking nailing of the femur, tibia, and humerus. Clin Orthop, 1996; (324): p. 292-320.

2. Brumback, RJ, Ellison Jr., PS, Poka, A, Lakatos, R, Bathon, GH and Burgess, AR. Intramedullary nailing of open fractures of the femoral shaft. $J$ Bone Joint Surg Am, 1989; 71(9): p. 1324-31.

3. O'Brien, PJ, Meek, RN, Powell, JN and Blachut, PA. Primary intramedullary nailing of open femoral shaft fractures. J Trauma, 1991; 31(1): p. 113-6.

4. Goessens, ML, Van de Wildenberg, FL, Eggink, GJ and Stapert, JW. Treatment of fractures of femur and tibia with the telescopic locking nail: design of a new implant and the first clinical results. J Trauma, 1999; 46(5): p. 853-62.

5. Oestern, HJ and Tscherne, H. [Physiopathology and classification of soft tissue lesion]. Hefte Unfallheilkd, 1983; 162: p. 1-10.

6. Gustilo, RB and Anderson, JT. Prevention of infection in the treatment of one thousand and twenty- five open fractures of long bones: retrospective and prospective analyses. J Bone Joint Surg [Am], 1976; 58(4): p. 453-8.

7. Küntscher, G. Praxis der Marknagelung. 1962, Stuttgart: Schattauer.

8. Benirschke, SK, Melder, I, Henley, MB, Routt, ML, Smith, DG, Chapman, JR and Swiontkowski, MF. Closed interlocking nailing of femoral shaft fractures: assessment of technical complications and functional outcomes by comparison of a prospective database with retrospective review. J Orthop Trauma, 1993; 7(2): p. 118-22.

9. Christie, J, Court-Brown, C, Kinninmonth, AW and Howie,CR. Intramedullary locking nails in the management of femoral shaft fractures. J Bone Joint Surg Br, 1988; 70(2): p. 206-10.

10. Kempf, I, Grosse, A and Beck, G. Closed locked intramedullary nailing. Its application to comminuted fractures of the femur. J Bone Joint Surg Am, 1985; 67(5): p. 709-20.

11. Klemm, K.W., Borner, M. Interlocking nailing of complex fractures of the femur and tibia. Clin Orthop, 1986; (212): p. 89-100.

12. Winquist, RA, Hansen Jr, ST and Clawson, DK. Closed intramedullary nailing of femoral fractures. A report of five hundred and twenty cases. J Bone Joint Surg Am, 1984; 66(4): p. 529-39.

13. Sojbjerg, JO, Eiskjaer, S and Moller-Larsen, F. Locked nailing of comminuted and unstable fractures of the femur. J Bone Joint Surg Br, 1990; 72(1): p. 23-5.

14. Thoresen, BO, Alho, A, Ekeland, A, Stromsoe, K, Folleras, G and Haukebo, A. Interlocking intramedullary nailing in femoral shaft fractures. A report of forty-eight cases. J Bone Joint Surg Am, 1985; 67(9): p. 1313-20.

15. Wiss, DA, Fleming, CH, Matta, JM and Clark, D. Comminuted and rotationally unstable fractures of the femur treated with an interlocking nail. Clin Orthop, 1986; (212): p. 35-47.

16. Wiss, DA, Brien, WW and Stetson, WB. Interlocked nailing for treatment of segmental fractures of the femur. J Bone Joint Surg Am, 1990; 72(5): p. 724-8.

17. Wolinsky, PR, McCarty, E, Shyr, Y and Johnson, K. Reamed intramedullary nailing of the femur: 551 cases. J Trauma, 1999; 46(3): p. 392-9. 
18. Zuckerman, JD, Veith, VG, Johnson, KD, Bach, AW, Hansen, ST and Solvik, S. Treatment of unstable femoral shaft fractures with closed interlocking intramedullary nailing. J Orthop Trauma, 1987; 1(3): p. 209-18.

19. Chapman, MW. The role of intramedullary fixation in open fractures. Clin Orthop, 1986; (212): p. 26-34.

20. Jenny, JY, Jenny, G and Kempf, I. Infection after reamed intramedullary nailing of lower limb fractures. A review of 1,464 cases over 15 years. Acta Orthop Scand, 1994; 65(1): p. 94-6.

21. Krettek, C, Rudolf, J, Schandelmaier, P, Guy, P, Konemann, B and Tscherne, H. Unreamed intramedullary nailing of femoral shaft fractures: operative technique and early clinical experience with the standard locking option. Injury, 1996; 27(4): p. 233-54.

22. Brumback, RJ, Reilly, JP, Poka, A, Lakatos, RP, Bathon, GH, Burgess and AR. Intramedullary nailing of femoral shaft fractures. Part I: Decision- making errors with interlocking fixation. J Bone Joint Surg Am, 1988; 70(10): p. 1441-52.

23. Brumback, RJ, Uwagie-Ero, S, Lakatos, RP, Poka, A, Bathon, GH and Burgess, AR Intramedullary nailing of femoral shaft fractures. Part II: Fracturehealing with static interlocking fixation. J Bone Joint Surg Am, 1988; 70(10): p. 1453-62.

24. Bone, LB, Johnson, KD., Weigelt, J and Scheinberg, R. Early versus delayed stabilization of femoral fractures. A prospective randomized study. J Bone Joint Surg Am, 1989; 71(3): p. 336-40.

25. Pape, HC, Auf'm'Kolk, M, Paffrath, T, Regel, G, Sturm, JA and Tscherne, H. Primary intramedullary femur fixation in multiple trauma patients with associated lung contusion--a cause of posttraumatic ARDS? J Trauma, 1993; 34(4): p. 540-7; discussion 47-8.

26. Clatworthy, MG, Clark, DI, Gray DH and Hardy, AE. Reamed versus unreamed femoral nails. A randomised, prospective trial. J Bone Joint Surg Br, 1998; 80(3): p. 485-9.

27. Giannoudis, PV, Furlong, AJ, Macdonald, DA and Smith, RM. Reamed against unreamed nailing of the femoral diaphysis: a retrospective study of healing time. Injury, 1997; 28(1): p. 15-8.

28. Shepherd, LE, Shean, CJ, Gelalis, ID, Lee, J and Carter, VS. Prospective randomized study of reamed versus unreamed femoral intramedullary nailing: an assessment of procedures. J Orthop Trauma, 2001; 15(1): p. 28-32; discussion 32-3.

29. Arazi, M, Ogun, TC, Oktar, MN, Memik, R and Kutlu, A. Early weight-bearing after statically locked reamed intramedullary nailing of comminuted femoral fractures: is it a safe procedure? J Trauma, 2001; 50(4): p. 711-6.

30. Brumback, RJ, Toal Jr, TR, Murphy-Zane, MS, Novak, VP and Belkoff, SM. Immediate weight-bearing after treatment of a comminuted fracture of the femoral shaft with a statically locked intramedullary nail. J Bone Joint Surg Am, 1999; 81(11): p. 1538-44.

31 Gabler, C, Tschegg, EK, Greitbauer, M, Stanzl-Tschegg, S, Wozasek, GE, Laube, W and Vecsei, V. [Fatigue stability of locking screws for unreamed tibial intramedullary nailing]. Unfallchirurg, 1999; 102(1): p. 29-34. 


\section{Chapter VII}

\section{THE TREATMENT OF ACUTE TIBIAL FRACTURES WITH THE TELESCOPIC LOCKING NAIL}

A prospective multicenter study 


\section{Introduction}

Locked intramedullary nailing is nowadays accepted as the treatment of choice for unstable tibial fractures. Since the introduction of intramedullary nailing of the tibia, many nailing systems have been developed. Most of these nails have more or less the same design features. The main difference between tibial nails nowadays is whether they are inserted with or without prior reaming, depending mainly on the diameter of the used nail. While the interlocking nail was still in an early stage of development, other methods besides intramedullary nailing evolved and became of great importance. In the late nineteen sixties Sarmiento realized the importance of cyclic dynamic loading for fracture healing ${ }^{1}$. His method of functional bracing is nowadays well accepted as the treatment of choice for stable fractures of the tibial shaft, with excellent results. Some time later De Bastiani developed the dynamic external fixator, also based on the premise that cyclic loading at the fracture site is beneficial to fracture healing ${ }^{2}$. In experimental animal studies these observations were confirmed $^{3-5}$.

Following the abovementioned developments the Telescopic Locking Nail was designed. The TLN is an intramedullary locking nail that provides the possibility of cyclic dynamic loading at the fracture site while maintaining rotational and angular stability.

The Telescopic Locking Nail is a modular nailing system, consisting of an inner nail and an outer tube, the telescope part. The nail is assembled intra-operatively. After nail insertion and proximal and distal locking, a dynamic, compression or static mode can be chosen, depending on the fracture type.

The TLN can be used in femur and tibia, as there are no differences in design of the TLN for these bones.

In 1999 we presented the first clinical results with the TLN in a heterogenous patient group ${ }^{6}$. In this study we present the clinical and long term results of treatment of acute tibial fractures with the Telescopic Locking Nail. 


\section{Materials and Methods}

In a prospective nonrandomized multicenter study, 74 acute tibial fractures were treated with the Telescopic Locking Nail in seven hospitals in the Netherlands from February 1994 until January 1996. Indications for intramedullary osteosynthesis were a displaced unstable fracture of the tibial shaft or loss of reduction of a conservatively treated fracture. The majority of the fractures $(70 \%)$ were treated within 24 hours after trauma; the remainder of the fractures was treated with a delay ranging from 2 to 41 days, mostly after loss of reduction of the fracture in a plaster cast. Patients with delayed unions and nonunions nailed during that period were excluded from this study group. There were $\mathbf{5 2}$ males and 22 females with a mean age of 35 years (SD 14 years). The mechanism of injury was as follows: motor vehicle accident (3 patients), motorcycle accident (7), moped/bicycle accident (18), pedestrian (15), occupational accident (2) and fall (5). Three of these patients were polytraumatized. Associated injuries of the affected limb included one acetabular fracture, two femoral fractures, one fracture of the lateral tibial plateau and six mono- or bimalleolar fractures of the ankle.

All fractures were classified according to the $A O$ classification of fractures. Soft tissue injury was classified according to the Oestern-Tscherne classification in case of closed fracture and according to the Gustilo-Anderson classification in case of open fracture. Fracture specifications are shown in table 1.

Table 1

Preoperative conditions

\begin{tabular}{cccc}
\hline Specification & Subspecification & Number of cases & Percentage of cases \\
\hline Gender & Male & 52 & 70 \\
& Female & 22 & 30 \\
Age & Mean \pm SD (years) & $35 \pm 14$ & \\
Fracture pattern & A & & \\
& B & 36 & 49 \\
Fracture localization & C & 31 & 39 \\
& Proximal 1/3 & 9 & 12 \\
& Mid 1/3 & 2 & 3 \\
Distal 1/3 & 31 & 42 \\
& & 41 & 55 \\
& Cloft tissue damage & & 42 \\
& Grade 1 0 & 31 & 19 \\
& Grade 2 & 14 & 8 \\
& Grade 3 & 6 & 5 \\
& Open: Grade 1 & 4 & 11 \\
& Grade 2 & 8 & 12 \\
& Grade 3a & 9 & 3 \\
\hline
\end{tabular}




\section{Technique}

Open fractures were treated with initial irrigation and debridement of the wound followed by immediate nailing. Traumatic wounds were not closed primarily. In the three cases with a preoperative compartment syndrome a four-compartment fasciotomy was carried out. During induction of anesthesia a first dose of cephalosporin antibiotic was given. Antibiotics were continued for 24 hours postoperatively. Either a fracture table or a radiolucent standard table was used for tibial nailing according to the preference of the surgeon in each of the participating clinics. Advantages and disadvantages of each method have been well delineated by Krettek et $\mathrm{al}^{7} \mathrm{At}$ the authors institution a standard radiolucent operation table is preferred. To maintain reduction of the fracture peroperatively we use a carbonfiber distractor. The proximal pin for this distractor is positioned from the anteromedial to the posterolateral aspect of the tibial head so there is no interference with the nail. The distal pin is inserted through the calcaneus. Together with this distractor a towel sling can be used to correct varus or valgus deformity. For proper nail insertion, there should always be the possibility for maximal flexion of the knee, regardless of which reduction technique is used. The Telescopic Locking Nail is a straight nail and is not provided with a proximal Herzog bend as other tibial nails. For this reason the medullar canal should be entered as close as possible to the anatomical axis of the tibia. The entry point for the Telescopic Locking Nail is therefore more proximal and posterior than the entry point for conventional nails (figure 8.1, page 95). This point can be reached via a transverse incision between the tibial tuberosity and the apex of the patellar tendon or a longitudinal incision over or medial to the patellar tendon. At the authors' institution a transverse incision is preferred because the scar if this incision heals well with less keloid formation. Advantage of the longitudinal incision is that skin and patellar tendon is more easily protected during reaming and nail insertion. After the incision is made the patellar tendon can either be split longitudinally or retracted laterally. The center of the medullar canal is visualized using fluoroscopy and then the medullar canal is opened with an awl. A bulb tipped guide wire is then introduced in the medullar canal. There is taken care of that the tip of the guide wire is centrally oriented in the distal metaphysis, especially in case of distal fractures. Over the guide wire the medullary canal is reamed up to $11 \mathrm{~mm}$. In case of a comminuted fracture the reamer is not used when passing the communition zone. In many cases the TLN can be inserted without reaming the full length of the medullar canal. The proximal $12 \mathrm{~cm}$ of the medullar canal is reamed up to a diameter of $13 \mathrm{~mm}$ to accommodate the telescope part of the nail, which has a diameter of $12 \mathrm{~mm}$. After reaming the guide wire is exchanged for one without a bulb at the tip. Over this guide wire the nail is inserted in its shortest fashion until the top of the nail is in level with the tibia plateau. Through the aiming device two proximal locking bolts are inserted. These bolts go through both the locking holes of the outer tube and the locking sleeve of the inner nail. After unlocking the telescope mechanism on the aiming device the inner nail can now be driven forward until the nail tip reaches the subchrondral bone in the distal tibia. Thus the nail always has the exact length of the medullar canal. This makes the TLN very suitable for distal fractures. With the distal locking holes being near the tip of the nail distal locking bolts can be inserted below fractures with a distance of three or more centimeters from the tibio-talar joint. The distal locking bolts can be inserted by using the free hand technique or by using a radiolucent drill. After proximal and distal locking, the aiming device is removed. In this way the nail pro- 
vides rotational stability but permits cyclic dynamic compression at the fracture site during weight bearing. We use this dynamic configuration in fractures were there is enough cortical contact between the main fragments. When there is diastasis of the fracture the compression screw can be inserted in the top of the nail to compress the fracture elements. With the compression screw inserted cyclic dynamic compression is still possible. When there is concern over the axial stability of the osteosynthesis, i.e. in fractures with a comminution zone of more than $2 \mathrm{~cm}$ long, the distraction screw is inserted in the top of the nail. This blocks the telescope mechanism and provides a static interlocked osteosynthesis. In this study the distraction screw was used 12 times, the other 62 cases were locked dynamically either without (47 cases) or with compression screw (15 cases). In seven tibia nailings additional fixation measures were taken for 1 lateral tibia plateau fracture and 6 bi- or monomalleolar fractures. Postoperatively no plaster casts or braces were used. Patients were encouraged to bear full weight as soon as their other injuries allowed them to do so, also in case of fractures that were treated with static interlocking nailing. After discharge patients were seen at the outpatient department at regular intervals. Specially developed follow up forms were used for registration of per-operative and postoperative data. Variables that were registered were: complaints of pain, signs of infection, knee and ankle function, rotation deformities and limb shortening, the time lapse between operation and the start of full weight bearing without the help of crutches. On biplane radiographs the anatomical result of the osteosynthesis was assessed. Varus/valgus and ante-/recurvation deformities were measured. The time lapse between operation and radiological union of a fracture was noted. Fracture union was defined radiologically as the filling of the fracture gap with cortical bone on both frontal and lateral radiographs.

In 1999 we conducted an inquiry via telephone to asses the long term results. Any residual complaint of the formerly injured leg was noted, special attention was given to knee complaints. We also documented whether patients had returned to their former jobs end sporting activities. 


\section{Results}

Patients were in follow-up until nail removal or until union of the fracture and restoration of function of the limb. One 69-year-old patient died two weeks postoperatively due to pre-existent congestive heart failure; of 73 patients follow-up data were available for analysis. For these patients the mean follow-up period was 12.6 months (SD 4.0 months). Of all the closed tibia fractures treated with the Telescopic Locking Nail $98 \%$ united without further re-interventions; for open tibia fractures the primary union rate was $83 \%$. In two cases locking bolts were removed to promote union, in two other cases nail exchange was necessary before union of the fracture. The secondary union rate, after minor or major re-interventions was $100 \%$ for both closed and open tibia fractures. Before radiological union of the fracture patients were already ambulating without assistive devices after a median period of 3 weeks for closed fractures and 6 weeks for open fractures. Radiologically, closed tibia fractures united after a median period of 18 weeks, open fractures after 22 weeks.

$\underline{\text { Table } 2}$

Results

\begin{tabular}{|c|c|c|c|}
\hline Specification & Subspecification & Closed fractures & Open fractures \\
\hline $\begin{array}{l}\text { Median time lapse till radio- } \\
\text { logical union and range } \\
\text { (weeks) }\end{array}$ & & $18(7-50)$ & $22(12-80)$ \\
\hline $\begin{array}{l}\text { Malalignment (number of } \\
\text { cases) }\end{array}$ & $\begin{array}{l}\text { Varus }>5^{\circ} \\
\text { Valgus }>5^{\circ} \\
\text { Antecurvation }>10^{\circ} \\
\text { Retrocurvation }>10^{\circ} \\
\text { Rotation }>10^{\circ} \\
\text { Shortening }>1 \mathrm{~cm} .\end{array}$ & $\begin{array}{l}3 \\
2 \\
0 \\
0 \\
0 \\
1\end{array}$ & $\begin{array}{l}0 \\
0 \\
0 \\
0 \\
0 \\
0\end{array}$ \\
\hline $\begin{array}{l}\text { Median time lapse till weight- } \\
\text { bearing and range (weeks) }\end{array}$ & $\begin{array}{l}\text { Partial } \\
\text { Full }\end{array}$ & $\begin{array}{c}1(0-9) \\
3(0-15)\end{array}$ & $\begin{array}{c}1(0-6) \\
6(6-29)\end{array}$ \\
\hline $\begin{array}{l}\text { Functional deficits } \\
\text { (number of cases)l }\end{array}$ & $\begin{array}{l}\text { Knee flexion } \\
\text { Knee extension } \\
\text { Ankle flexion } \\
\text { Ankle extension }\end{array}$ & $\begin{array}{l}0 \\
3 \\
0 \\
1\end{array}$ & $\begin{array}{l}0 \\
0 \\
0 \\
0\end{array}$ \\
\hline $\begin{array}{l}\text { Infections } \\
\text { (number of cases) }\end{array}$ & $\begin{array}{l}\text { Superficial } \\
\text { Deep }\end{array}$ & $\begin{array}{l}0 \\
3\end{array}$ & $\begin{array}{l}1 \\
2\end{array}$ \\
\hline $\begin{array}{l}\text { Reinterventions before union } \\
\text { (numberof cases) }\end{array}$ & $\begin{array}{l}\text { Minor } \\
\text { Major }\end{array}$ & $\begin{array}{l}0 \\
1\end{array}$ & $\begin{array}{l}2 \\
1\end{array}$ \\
\hline
\end{tabular}

Malunion was defined as varus or valgus angulation of more than 5 degrees, anteroposterior angulation of more than 10 degrees, or shortening of more than 1 centimetre. There were five malunions, which gives a malunion rate of $7 \%$. 
Three patients had a varus deformity of 6,10 and 11 degrees respectively, two patients had a valgus deformity of 6 and 8 degrees respectively and one patient had a combination of a varus deformity of 6 degrees and a shortening of the tibia of 1.5 centimetres. Malrotation was evaluated by comparing the amounts of external and internal rotation of the injured extremity with those of the uninjured extremity. There were no rotational deformities.

Range of motion of knee, ankle and subtalar joints was normal except in three patients. Two of these patients had limited extension of the knee of 5 and 10 degrees respectively. In the latter case this was caused by protrusion of the nail 1 centimetre above the tibia plateau. One patient had a limited dorsoflexion of the ankle joint due to a compartment syndrome. Of the 74 patients $23(31 \%)$ had knee pain after the osteosynthesis with the TLN. In 7 cases this pain subsided after nail removal.

In this study there were six infections, in three cases after closed fractures and in another three cases after open fractures. Of these postoperative infections, five were deep and one was superficial. The superficial wound infection was treated by drainage and antibiotics. Of the five deep infections four were low-grade infections. In three of these cases the fractures united uneventfully. Treatment of the infection in these cases consisted of removal of the nail and debridement of the medullar canal after the fracture had united. In these patients no signs of infection were seen thereafter. The two other cases with deep infection needed re-intervention for infection treatment. One of these patients had a grade 3 closed fracture, which was primarily treated with an external fixator. One week after trauma the external fixator was exchanged for a TLN. Three months later a serious infection occurred and the TLN was removed, the medullar canal was reamed and gentamycine beads were left behind after which the fracture was again stabilized with an external fixator. After a second re-intervention with cancelous bone grafting the fractures united without any sign of infection. The other patient who needed re-intervention had a grade 2 open fracture of the tibia after a motorcycle accident, which was treated by immediate nailing with a TLN. A low-grade infection localized around the distal locking bolts and a delayed union of the fracture developed. The nail was then exchanged for a second TLN after debridement of the medullar canal, together with bone grafting and fibulotomy. After this, the fracture united without signs of infection.

Secondary procedures, which could be performed under local anaesthesia only, were defined as minor re-interventions. In two cases statically locked nails were dynamized by removing locking bolts under local anaesthesia. There were two patients with major re-interventions, were a change of treatment was performed because of infection. Both cases were previously mentioned. The (major) re-intervention rate in this study was $3 \%$.

There were no post-operative compartment syndromes. One patient had a temporary peroneal nerve palsy, which subsided spontaneously after three months.

No nail breakages were observed; in one case there was a broken locking bolt. This was the only distal locking bolt in an osteosynthesis with TLN. This patient was fully weight bearing after 3 weeks. Ten weeks postoperatively the distal locking bolt broke. This did however not influence union or alignment. 
Of 61 patients the TLN was removed after union of the fracture. This was done after a mean period of 15 months postoperatively (range 3-58 months).

When the data were analyzed according to the criteria of Johner and Wruhs there were 53 excellent $(73 \%), 11$ good $(14 \%), 6$ fair $(8 \%)$ and $3(4 \%)$ poor results (also see table 3$)^{8}$.

\section{Table 3}

Evaluation of Final Results according to classification of Johner and Wruhs

\begin{tabular}{|c|c|c|c|c|}
\hline & $\begin{array}{l}\begin{array}{l}\text { Excellent } \\
\text { (Left }=\text { Right) }\end{array} \\
\end{array}$ & Good & Fair & Poor \\
\hline Nonunion, infection & None & None & None & Yes \\
\hline Neurovascular disturbances & None & Minimal & Moderate & Severe \\
\hline \multicolumn{5}{|l|}{ Deformity } \\
\hline Varus/valgus & None & $2-5^{\circ}$ & $6-10^{\circ}$ & $>10^{\circ}$ \\
\hline Anteversion/retroversion & $0-5^{\circ}$ & $6-10^{\circ}$ & $11-20^{\circ}$ & $>20^{\circ}$ \\
\hline Rotation & $0-5^{\circ}$ & $6-10^{\circ}$ & $11-20^{\circ}$ & $>20^{\circ}$ \\
\hline Shortening & $0-5 \mathrm{~mm}$ & $6-10 \mathrm{~mm}$ & $11-20 \mathrm{~mm}$ & $>20 \mathrm{~mm}$ \\
\hline \multicolumn{5}{|l|}{ Mobility } \\
\hline Knee & Full & $>80 \%$ & $>75 \%$ & $<75 \%$ \\
\hline Ankie & Full & $>75 \%$ & $>50 \%$ & $<50 \%$ \\
\hline Subtalar & $>75 \%$ & $>50 \%$ & $<50 \%$ & \\
\hline Pain & None & Occasional & Moderate & Severe \\
\hline Gait & Normal & Normal & Mild Limp & $\begin{array}{l}\text { Significant } \\
\text { Limp }\end{array}$ \\
\hline Strenuous activities & Possible & Limited & Severely limited & Impossible \\
\hline Study results & $53(73 \%)$ & $11(14 \%)$ & $6(8 \%)$ & $3(4 \%)$ \\
\hline
\end{tabular}


The three poor results were attributable to one valgus deformity of 11 degrees and two infected non-unions that needed re-intervention.

Long term results were analyzed by interviewing patients over telephone. This interview was carried out after a mean period of 47 months postoperatively (range 39-60 months). The results of this analysis are listed in table 4.

\section{Table 4}

Long term follow-up results

\begin{tabular}{lcc}
\hline Specification & Number of patients & Percentage of patients \\
\hline Knee pain when: & 25 & $33 \%$ \\
kneeling down & 14 & $19 \%$ \\
sitting on heels & 12 & $16 \%$ \\
walking stairs & 16 & $22 \%$ \\
running & 12 & $16 \%$ \\
no information & & \\
& & \\
Sporting activities: & 26 & $35 \%$ \\
resumed on former level & 18 & $24 \%$ \\
not resumed or below former level & 19 & $26 \%$ \\
no previous activities & 11 & $15 \%$ \\
no information & & \\
& & \\
Professional activities: & 54 & $73 \%$ \\
resumed on former level & 6 & $8 \%$ \\
not resumed or below former level & 7 & $9 \%$ \\
no previous activities & 7 & $9 \%$ \\
no information & & \\
\hline
\end{tabular}




\section{Discussion}

The Telescopic Locking Nail is a different and unique treatment modality for diaphysal fractures of the lower extremity. The biomechanical properties of this nail allow for movement over the longitudinal axis while maintaining rotational and angular stability. In a previous study we showed that treatment of fractures and non-unions of femur and tibia with this new locking nail is feasible ${ }^{6}$. In this series we studied a more circumscribed group of patients with acute fractures of the tibia. The primary union rate was $98 \%$ and $83 \%$ for closed and open fractures respectively. The time to union was 18 weeks for closed and 23 weeks for open fractures. These figures compare favorably to other published reports on reamed intramedullary nailing of the tibia $^{9}$. An important finding is that patients were fully weight bearing without assistive devices after a relative short period of time.

Minor differences exist in available interlocking nails for the tibia. Virtually all tibial nails have some form of proximal Herzog bend and an anterior curve at the tip or a tapered tip to facilitate the insertion of the nail. Because of three distinctive design parameters the Telescopic Locking Nail takes in a unique place between other available tibial nailing systems.

Firstly, because of its telescope mechanism the TLN is a straight nail. As we pointed out in the paragraph on operation technique this has consequences for the insertion point. This is at the ventral edge of the tibial plateau, so more proximal and posterior to the conventional entry-point. Advantage of this entry-point is that it is more in line with the longitudinal axis of the medullary canal diminishing the stress to the anterior cortex during nail insertion ${ }^{10}$. A possible disadvantage could be that the articular surface of the tibial plateau, menisci, or anterior cruciate ligament are damaged, causing knee complaints ${ }^{11}$. In a previous study on measurements on knee MRI's we found that the distance between the proximal entry point and the tibial attachment of the anterior cruciate ligament is 12.2 millimeter, which is long enough to ensure safe application of this entry-point ${ }^{12}$. Anterior knee pain is an important complication of intramedullary osteosynthesis of the tiba and is occurring in $51 \%$ to $78 \%$ of all tibial nailings ${ }^{13-15}$. In our series the incidence of knee pain after nailing was $31 \%$. Of our patients $33 \%$ experienced pain when kneeling down, a much lower figure than in series where conventional nails and insertion point were used. Also in a previous study we reported a incidence of knee pain as low as $13 \%$ after osteosynthesis with the $\mathrm{TLN}^{6}$. We have two explanations for this finding. Firstly, because of the more proximal and posterior insertion point the nail does not protrude through the anterior cortex of the proximal tibia. Secondly, the nail length can be adapted to every length of tibia so the proximal end of the nail can always be in level with the tibial plateau. Furthermore, when the nail is inserted in the dynamic mode it will not protrude cranially as other interlocking nails do, when the oval locking hole is used for dynamic interlocking. These factors contribute to the fact that there is less chance of the nail impinging on the patellar ligament.

The fact that the TLN is a straight nail makes it less suitable for very proximal tibial fractures. When intramedullary nailing is performed for these fractures, probably a proximal Herzog bend is needed to overcome anterior bowing deformity ${ }^{16}$. 
Furthermore, as a straight nail the TLN has no antecurvation nor Herzog bend. The TLN is provided with only one nail diameter of 9 millimeter. This gives the unique opportunity of using the same nail for the femur and the tibia (Goessens 1999).

The second distinctive design feature of the TLN is its telescope mechanism. As the tibia has the highest non-union rates of any long bone it is important to optimize the potential for fracture healing. Brumback stated it is better to dynamically stabilize tibial fractures ${ }^{17}$. Dynamic interlocking with conventional tibial interlocking nails means that locking holes on either proximal or distal side of the fracture are not used, which leads to rotational instability, especially in cases where small diameter nails are being used. The Telescopic Locking Nail can be used in the dynamic mode in case of a transverse, short oblique or spiral fracture. Cyclic dynamic compression at the fracture side is then possible, while rotational stability is maintained. In case of length unstable fractures, the TLN can be used in the static mode so that length stability is guaranteed. In $84 \%$ of the cases in this study the fracture was dynamically locked. In some cases dynamization of the osteosynthesis was visible on control Xrays (see case 7 , page 120). In only two cases locking bolts were removed to promote union. In a series of one hundred thirty-four acute unstable fractures Wiss et.al. described using static interlocking in $46 \%$ of the cases. Of these statically interlocked osteosyntheses almost one third had to be dynamized later to promote union $^{18}$.

A possible disadvantage of the telescope mechanism of the TLN could be that shortening can occur when the osteosynthesis is dynamic in case of a length unstable fracture. In only one case shortening of more than one centimeter was observed in a patient who was considered to have a length stable fracture and in whom a dynamically locked osteosynthesis was performed.

Case 8, page 121 illustrates an additional advantage of the telescope mechanism in the treatment of distal tibial fractures with intramedullary nailing. As mentioned earlier the length of the nail can always exactly be adapted to every length of tibia through the telescope mechanism. This makes it possible to ensure that the tip of the nail is in the subchondral bone above the tibio-talar joint, while the top of the nail remains in level with the surface of the tibial plateau. In this way we treated distal metafysal tibial fractures without the need for sawing of the distal tip of the nail or driving the nail deep into the proximal tibia.

Thirdly, the TLN has a circular cross section of $9 \mathrm{~mm}$. This allows for strong locking bolts with a core diameter of 4.5 millimeter to be used. In a biomechanical study Gabler at al showed that these bolts have a better biomechanical performance than the fully threaded locking bolts with smaller core diameters used in other nailing systems $^{19}$. Because of the diameter and circular cross section of the TLN the medullary canal has to be reamed up to 10 to 11 millimeters to allow for easy nail insertion. There has been much concern about the possible harmful effect of reaming ${ }^{20}$. Especially for the treatment of fractures with extensive soft tissue injury unreamed nailing systems were developed. Unreamed insertion of the nail was thought to spare the delicate endosteal blood supply of the cortex and reaming would in contrast be associated with cortical necrosis and infections. The unreamed nails became increasingly popular for the treatment of virtually all unstable tibial fractures. This was associated with increasing numbers of implant failures, like bolt or nail breakage ${ }^{21}$. 
Higher malunion rates were observed and the number of re-interventions needed to achieve union had risen with the increased use of unreamed nails ${ }^{22,23}$. Because of these drawbacks reamed nailing is nowadays the preferred treatment for unstable closed tibial fractures. Recent publications however show that also in case of open fractures reamed nailing has the advantage of the possibility to insert larger and stronger nails, without the disadvantage of higher infection rates ${ }^{24}$.

Because of the biomechanical advantages we support the use of a strong nail in both open and closed tibial fractures. Reaming of the medullary canal up to 10 or 11 millimeters to allow for easy insertion of the TLN did not lead to unacceptable high infection rates. Furthermore patients were fully weightbearing in an early stage during fracture healing, while the number of broken bolts and the malunion rate remained low.

In this multicenter study the Telescopic Locking Nail has shown to be a reliable implant for the treatment of tibial shaft fractures. We found indications that the three distinctive design parameters of the TLN provide advantages above conventional tibial nailing systems with regard to: knee complaints, the treatment of distal fractures and fatigue strength. Future prospective randomized trials will have to confirm our observations. 


\section{References}

1. Sarmiento, A. Functional bracing of tibial fractures. Clin Orthop, 1974; 105(0): p. 202-19.

2. De Bastiani, G, Aldegheri, R and Renzi Brivio, L. The treatment of fractures with a dynamic axial fixator. J Bone Joint Surg [Br], 1984; 66(4): p. 538-45.

3. Grundnes, $\mathrm{O}$ and Reikeras, $\mathrm{O}$. Effects of instability on bone healing. Femoral osteotomies studied in rats. Acta Orthop Scand, 1993; 64(1): p. 55-8.

4. Georgiadis, GM, Minster, GJ and Moed, BR. Effects of dynamization after interlocking tibial nailing: an experimental study in dogs. J Orthop Trauma, 1990; 4(3): p. 323-30.

5. Heitemeyer, U, Claes, L, Hierholzer, G and Korber, M. Significance of postoperative stability for bony reparation of comminuted fractures. An experimental study. Arch Orthop Trauma Surg, 1990; 109(3): p. 144-9.

6. Goessens, ML, Van de Wildenberg, FJ, Eggink, GJ and Stapert, JW. Treatment of fractures of femur and tibia with the telescopic locking nail: design of a new implant and the first clinical results. J Trauma, 1999; 46(5): p. 853-62.

7. Krettek, C, Schandelmaier, $\mathrm{P}$ and Tscherne, H. Nonreamed interlocking nailing of closed tibial fractures with severe soft tissue injury. Clin Orthop, 1995; (315): p. 34-47.

8. Johner, R and Wruhs, $\mathrm{O}$. Classification of tibial shaft fractures and correlation with results after rigid internal fixation. Clin Orthop, 1983; (178): p. 7-25.

9. Court-Brown, CM. Reamed tibial nailing in Edinburgh (1985-1995). Bull Hosp Jt Dis, 1999; 58(1): p. 24-30.

10. Carr, JB, Sobba, DB and Bear, LL. Biomechanics of rigid tibial nail insertion sites. Am J Orthop, 1996; 25(8): p. 553-6.

11. Hernigou, $\mathrm{P}$ and Cohen, D. Proximal entry for intramedullary nailing of the tibia. The risk of unrecognised articular damage. J Bone Joint Surg Br, 2000; 82(1): p. 33-41.

12. Goessens, MLMJ, Sijbers, R, Harbers, JS and Stapert, JWJL. Application of a proximal entrypoint for intramedullary nailing of the tibia. Osteosynthese Int, 2001; 9: p. 101-04.

13. Orfaly, R, Keating, JE and O'Brien PJ Knee pain after tibial nailing: does the entry point matter? J Bone Joint Surg Br, 1995; 77(6): p. 976-7.

14. Sala, F, Binda, M and Lovisetti, G. Anterior gonalgic syndrome after intramedullary nailing: ultrasound and radiologic study. Chir Organi Mov, 1998; 83(3): p. 271-5.

15. Court-Brown, CM, Gustilo, $T$ and Shaw, $A D$. Knee pain after intramedullary tibial nailing: its incidence, etiology, and outcome. J Orthop Trauma, 1997; 11(2): p. 103-5.

16. Lang, GJ, Cohen, BE, Bosse, MJ and Kellam, JF. Proximal third tibial shaft fractures. Should they be nailed? Clin Orthop, 1995; (315): p. 64-74.

17. Brumback, RJ. The rationales of interlocking nailing of the femur, tibia, and humerus. Clin Orthop, 1996; (324): p. 292-320. 
18. Wiss, DA and Stetson, WB. Unstable fractures of the tibia treated with a reamed intramedullary interlocking nail. Clin Orthop, 1995; (315): p. 56-63.

19. Gabler, C, Tschegg, EK, Greitbauer, M, Stanzl-Tschegg, S, Wozasek, GE, Laube, W and Vecsei, VV. [Fatigue stability of locking screwfor unreamed tibial intramedullary nailing]. Unfallchirurg, 1999; 102(1): p. 29-34.

20. Klein, MP, Rahn, BA, Frigg, R, Kessler, S and Perren, SM. Reaming versus non-reaming in medullary nailing: interference with cortical circulation of the canine tibia. Arch Orthop Trauma Surg, 1990; 109(6): p. 314-6.

21. Hutson, JJ, Zych, GA, Cole, JD, Johnson, KD, Ostermann, P, Milne, EL and Latta, L. Mechanical failures of intramedullary tibial nails applied without reaming. Clin Orthop, 1995; (315): p. 129-37.

22. Court-Brown, CM, Will, E, Christie, J and McQueen, M. Reamed or unreamed nailing for closed tibial fractures. A prospective study in Tscherne C1 fractures [see comments]. J Bone Joint Surg Br, 1996; 78(4): p. 580-3.

23. Blachut, PA, O'Brien, PJ, Meek, RN and Broekhuyse, HM. Interlocking intramedullary nailing with and without reaming for the treatment of closed fractures of the tibial shaft. A prospective, randomized study. J Bone Joint Surg Am, 1997; 79(5): p. 640-6.

24. Keating, JF, O'Brien, PJ Blachut, PA, Meek, RN and Broekhuyse, HM. Locking intramedullary nailing with and without reaming for open fractures of the tibial shaft. A prospective, randomized study. J Bone Joint Surg Am, 1997; 79(3): p. 334-41. 


\section{Chapter VIII}

\section{APPLICATION OF A PROXIMAL ENTRY POINT FOR}

INTRAMEDULLARY NAILING OF THE TIBIA

Osteosynthese Int, 2001; 9: p 101-104 


\section{Introduction}

Intramedullary osteosynthesis is widely accepted as a treatment of choice for tibial diaphyseal fractures. The operative technique for most intramedullary nailing systems has been well been established ${ }^{1,2}$. In most cases when reamed intramedullary nailing is performed, the entry point for the tibial nail is selected between the tibial tuberosity and the anterior margin of the tibial plateau. The reasons for this are the easy accessibility of the points mentioned and the margin of safety with regard to the knee joint. The commonly used tibial nails are provided with a proximal Herzog bend to facilitate nail introduction through this entry point.

In this paper we describe the application of a new entry point for the recently developed Telescopic Locking Nail (TLN) (Howmedica, Kiel, Germany). This third generation nailing system incorporates a unique sliding component to create the possibility of static or dynamic locked nailing, as well as the opportunity for compression or distraction. Because of its telescopic facility, this nail is necessarily straight, and not provided with the conventional proximal Herzog bend. Its straight design requires a more proximal entry point, located at the anterior margin of the tibial plateau, which is closer to the anatomical axis of the tibia. The proximal telescope part has a diameter of $12 \mathrm{~mm}$. To allow for easy insertion of the nail the proximal part of the tibia has to be reamed up to $13 \mathrm{~mm}$. This study aims to determine the distance from this proximal entry point to the anterior cruciate ligament and to compare the insertion axis between the conventional and the new entry point. 


\section{Anatomical considerations and operative technique}

The anterior aspect of the tibial plateau also referred to as the area intracondylaris anterior $^{3}$ is an intracapsular, extrasynovial space in front of the anterior cruciate ligament. The anterior cruciate ligament (ACL) is attached to a fossa in front of and lateral to the anterior tibial spine. At this attachment the ACL passes beneath the transverse meniscal ligament and a few fascicles may blend with the anterior attachment of the lateral meniscus. Ventrally the ACL is covered with synovial membrane. The medial border of the area intracondylaris anterior is confined by the attachment of the anterior horn of the medial meniscus; the posterolateral border is formed by the anterior horn of the lateral meniscus. On the surface of the area intracondylaris anterior lies the base of the infrapatellar fat pad which fills the intracapsular space behind the patellar ligament. A deep infrapatellar bursa covers the ventral aspect of the tibial head from the anterior rim of the tibial plateau until the attachment of the patellar ligament at the tibial tuberosity.

Figure 8.1 shows the entry point that is used for conventional nails and the entry point we use for insertion of the Telescopic Locking Nail.

Both entry points can be reached via a transverse or longitudinal incision after which the patellar tendon is split longitudinally or retracted laterally.

The conventional entry point is found just above the tibial tuberosity in the midline between the lateral and medial tibial condyles, the new entry point for the TLN is located at the anterior edge of the tibial plateau in the midline between the lateral and medial tibial condyles.

Figure 8.1

Schematic view of the entry point for conventional nails (A) and the entry point for the Telescopic Locking Nail (B).

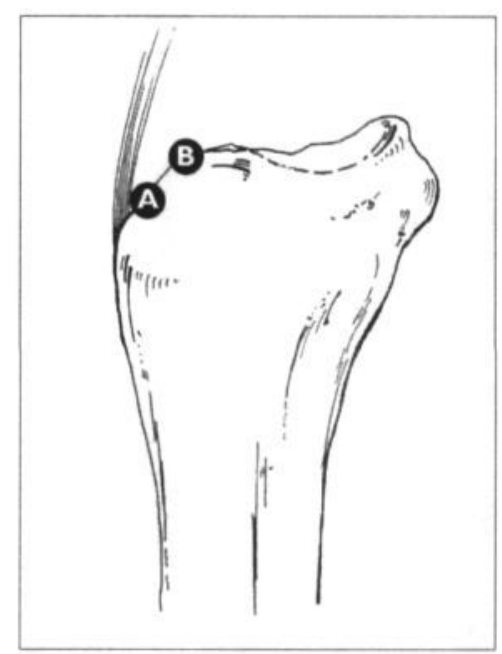




\section{MRI study}

To measure the distance between the new entry point and the knee joint cavity we studied 50 MRI's, randomly selected from all knee MRI's performed in 1994 and 1995 in the University Hospital Maastricht. A 1.5-Tesla superconducting magnet (Gyroview, Philips Eindhoven, the Netherlands) was used to acquire the MRI.

The criteria for inclusion were:

- $\quad$ age between 20 and 60 years

- $\quad$ the anterior cruciate ligament was clearly visible

- $\quad$ good resolution of the T2 weighted midsagittal view

After inclusion, the MRI's of 27 male patients (mean age 39 years) and 23 female patients (mean age 38 years) were examined. The distance between the anterior edge of the tibial plateau and the anterior border of the tibial attachment of the ACL to the tibia was measured using electronic mensural equipment (see figure 8.2). Measurements were done on an illuminated electronic plate with $\mathrm{x}, \mathrm{y}$ coordinate fields, which was connected to a converter (Summagraphics, Fairfield, U.S.A.). After conversion into ASCII characters the data were transmitted to a computer, which produced the measured distance in millimeters. Each measurement was carried out five times; the average of these five measurements was used for statistical analysis.

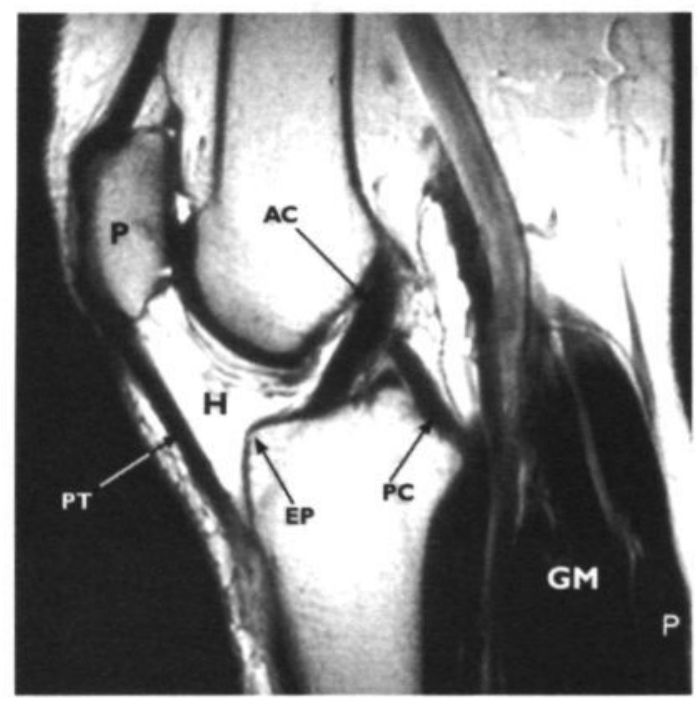

Figure 8.2

Example of MRI of the knee, midsagittal view ( $P=$ patella, $P T=$ patellar tendon, $H=H o f f a ' s$ infrapatellar fat pad, $A C=$ anterior cruciate ligament, $P C=$ posterior cruciate ligament, $G M=$ gastrocnemius muscle, $E P=$ entry point for Telescopic Locking Nail). The distance between EP and the tibial attachment of the anterior cruciate ligament was measured.

\section{Plain film radiography study}

For measurement of the insertion angle of an intramedullary nail plain film radiographs were examined. Forty plain films were randomly selected from all plain films of the tibia performed in 1994 and 1995 in the University Hospital Maastricht. The selection criteria for these radiographs were:

age between 20 and 60 years

both knee and ankle joint should be visible on lateral view

good lateral view, i.e. the fibular shaft should be projected behind the tibial shaft 
with an open space between them and the head of the fibula should be projected over the proximal tibia with only a small part revealed.

The insertion angle was defined as the angle between the anatomical axis of the tibia and a line between the entry point and a point at one third of the anatomic axis of the tibia (see fig 8.3). The angles were measured with a ruler and a triangle with scale divisions of $1 \mathrm{~mm}$ and 1 degree respectively. For each plain film radiograph, the insertion angles were measured for the conventional and new entry point.

Figure 8.3

Procedure for estimating the anatomical axis of the tibia. Points $X 1$ and $X 2$ are the located in the middle of the tibial plateau and in the middle of the distal tibial joint surface on lateral view. Line $L$ between these points is divided in three equal parts (points $X 3$ and $X 4$ ). Perpendicular lines are drawn through points $X 3$ and $X 4$. On these lines the middle of the tibial shaft was indicated (points M1 and M2). The line through points M1 and M2 is the anatomical axis.

It is estimated that when a nail is inserted in the tibia its tip reaches the posterior cortex when it has arrived at point M1. Lines drawn between point $A$ and $M 1$ and Point $B$ and $M 1$. The angles between these lines and the anatomical axis are then considered to be the insertion angle for conventional nails and the Telescopic Locking Nail respectively.

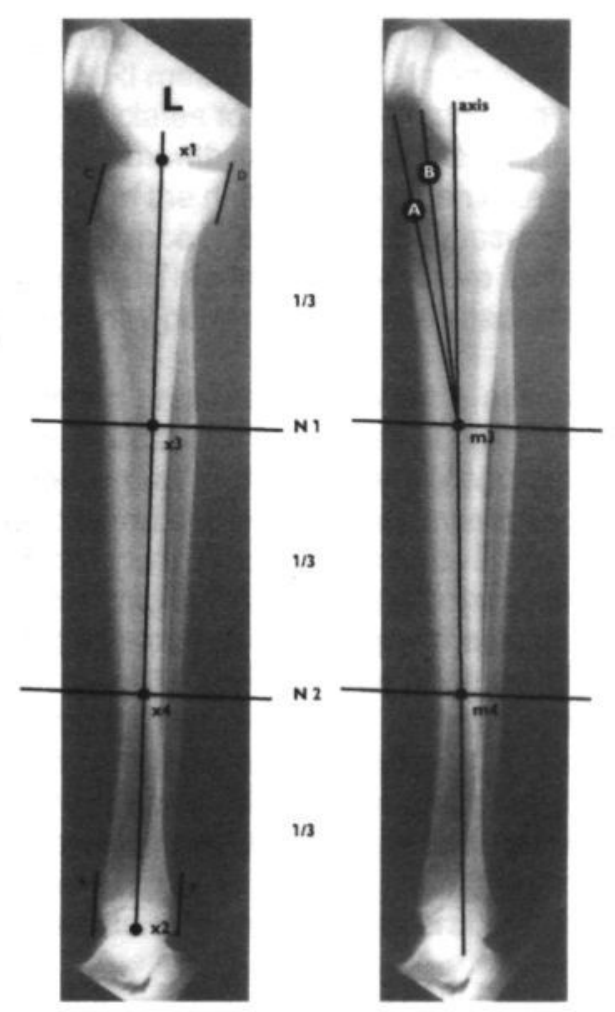




\section{Results}

A mean distance of $12.2 \mathrm{~mm}$ was found between the new entry point and the anterior cruciate ligament (range $7.4 \mathrm{~mm}-18.3 \mathrm{~mm}$ ). For male patients this distance was 13.1 $\mathrm{mm}$ and for female patients $11.2 \mathrm{~mm}$.

The mean insertion angle for the new entry point was 4.7 degrees (range 2 to 9 degrees) and for the conventional entry point 9.3 degrees (range 4 to 14 degrees). 


\section{Discussion}

The use of MRI has proved to be a validated method for making accurate osseous measurements of the knee. Herzog and associates found no statistically significant differences between MRI measurements and direct measurements made on cadaveric knees in a study on intracondylary notch measurement ${ }^{4}$. Although cortical bone generates no signal on MR images the margins of the cortex were easily defined because of adjacent fat that generates high signal intensity. In randomly selected knee MRI's we measured an average distance of $12.2 \mathrm{~mm}$ between the anterior edge of the tibial plateau and the anterior cruciate ligament. In a study on the tibial attachment area of the anterior cruciate ligament Stäubli and Rauschning found this distance to be $14 \mathrm{~mm}$ in cadaveric knees, $12.1 \mathrm{~mm}$ in cryosectional anatomy measurements and 15.2 and 13.4 $\mathrm{mm}$ for male and female persons respectively in MRI measurements ${ }^{5}$. In an older anatomical study on cadaveric knees, Girgis and associates found this distance to be 15 $\mathrm{mm}^{6}$. For the TLN the entry point is drilled up to $13 \mathrm{~mm}$ with its center located on the anterior edge of the tibial plateau, the posterior border of the drilled hole is then located 6.5 $\mathrm{mm}$ behind the anterior margin. In practice this distance is even less because the drill has the tendency to move ventrally during reaming. This means that there is a save margin between the posterior border of the drilled entry point and the tibial attachment of the anterior cruciate ligament.

In a recent study, Hernigou and Cohen stated that a proximal entry point is associated with a higher risk of damaging intra-articular structures. The structures at risk were the anterior horn of the medial meniscus, the anterior part of the lateral plateau and the ligamentum transversum. They estimated the location of the so-called "sweet spot" by measurements on human cadaver tibiae. According to their measurements the location of this ideal entry point depends on the tibial length, the proximal nail diameter, the proximal angle of the nail and whether the approach to the entry point is medial, lateral or anterior. In a retrospective radiological analysis of 30 patients who underwent tibial nailing, they found eight patients at risk for damage to intra-articular structures, which was confirmed in four ${ }^{7}$. In this study we focused on the distance between the proximal entry point and the anterior cruciate ligament. The clear visibility of the anterior tibial attachment of the anterior cruciate ligament on midsagittal view MRI of the knee allows for accurate measurements. As mentioned previously the anterior tibial attachment of the anterior cruciate ligament is closely related to the anterior horns of the lateral and medial menisci and to the ligamentum transversum.

Anterior knee pain is a frequent complication of intramedullary nailing of the tibia. It remains however unclear whether damage to the intracapsular structures near the entry point are responsible for this. Orfaly et al. found incidence of $56 \%$ of knee pain after tibial nailing with the reamed Grosse-Kempf nail while using the conventional entry point ${ }^{8}$. We however found much lower figures of knee problems in a previous study. In only $13 \%$ of 29 acute tibial fractures treated with the TLN knee complaints were noted ${ }^{9}$. In these cases the proximal entry point was used.

The method of measurements of the insertion angles on plain film radiographs may result in small inaccuracies, due to the fact that various tangent constructions were carried out by hand. This was however not expected to influence the outcome of the measurements when taken over the complete tibial length. The insertion axis through the proximal entry point was significantly smaller, so closer to the anatomical axis of the tibia, then through the conventional entry point. An advantage of this would be that an in- 
tramedullary nail is more easily inserted through the more proximal entry point because the nail does not have to bend that much to follow the medullary canal and that there is less chance of perforating the posterior cortex.

Also other authors have advocated a more proximal and posterior entry point. They suggested that, in case of a fracture of the proximal one third of the tibia, a more proximal and posterior entry point would overcome anteversion malalignment and posterior displacement ${ }^{10,11}$.

In our experience the use of a more proximal entry point for tibial nailing with the Telescopic Locking Nail is save with regard to the intracapsular structures of the knee joint. MRI measurements of the distance between this entry point and the tibial attachment of the anterior cruciate ligament seem to confirm this. The proximal entry point has the advantage of the insertion axis of the nail being closer to the anatomical axis of the tibia. 


\section{References}

1. Court-Brown, CM. An Atlas of Closed Nailing of the Tibia and the Femur. Springer-Verlag, New York, Berlin, Heidelberg 1991

2. Müller,ME, Allgöwer, M, Schneider, R and Willeneger, H. Manual of Internal Fixation. Springer-Verlag, Berlin, Heidelberg, New York, Tokyo 1991

3. Jacobsen K. Area Intercondylaris Tibiae: Osseous Surface Structure and Its Relation to Soft Tissue Structures and Applications to Radiography. J Anat 1974; 117: 605-618

4. Herzog, RJ, Silliman, JF, Hutton, K, Rodkey, WG and Steadman, JR. Measurements of the Intercondylar Notch by Plain Film Radiography and Magnetic Resonance Imaging. Am J Sports Med 1994; 22: 204-210

5. Staubli, HU and Rauschning, W. Tibial Attachment Area of the Anterior Cruciate Ligament in the Extended Knee Position. Anatomy and Cryosections in Vitro Complemented by Magnetic Resonance Arthrography in Vivo. Knee Surg Sports Traumatol Arthrosc1994; 2: 138-146

6. Girgis, FG, Marshall, JL and Monajem, A. The Cruciate Ligaments of the Knee Joint. Anatomical, Functional and Experimental Analysis. Clin Orthop 1975; 216 231

7. Hernigou, P and Cohen, D. Proximal Entry for Intramedullary Nailing of the Tibia. The Risk of Unrecognised Articular Damage. J Bone Joint Surg Br 2000; 82: 3341

8. Orfaly, R, Keating, JE and O'Brien, PJ Knee Pain after Tibial Nailing: Does the Entry Point Matter? J Bone Joint Surg Br 1995; 77: 976-977

9. Goessens, ML, Van de Wildenberg, FJ, Eggink, GJ and Stapert, JW. Treatment of Fractures of Femur and Tibia with the Telescopic Locking Nail: Design of a New Implant and the First Clinical Results. J Trauma 1999; 46: 853-862

10. Benirschke, SK, Henley, MB and Ott, J.W. Proximal One-Third Tibial Fracture Solutions. Orthop. Trans. 1995; 18: 1055-1060

11. Lang, GJ, Cohen, BE, Bosse, MJ and Kellam, JF. Proximal Third Tibial Shaft Fractures. Should They Be Nailed? Clin Orthop 1995; 64-74 


\section{Chapter IX}

OSTEOLYSIS OF THE TIBIA AT THE JUNCTION OF THE TELESCOPIC LOCKING NAIL 


\section{Introduction}

The Telescopic Locking Nail (TLN) has been designed as an intramedullary nail that permits cyclic dynamic loading at the fracture site while weightbearing and can also be used for static interlocking or for compression between fracture elements ${ }^{1}$. The TLN is a two piece modular nail, which is assembled intra-operatively. It consists of an inner nail of $9 \mathrm{~mm}$ diameter on which a $12 \mathrm{~mm}$ outer tube (telescope part) is mounted. After proximal and distal locking the inner nail can move over a maximal distance of $2,5 \mathrm{~cm}$ in the telescope part when used in the dynamic mode. All components of the Telescopic Locking Nail are made of $316 \mathrm{~L}$ stainless steel.

Since 1992 the TLN has been used for osteosynthesis of the tibia. At routine followup radiographs of some patients we noticed an area of radiolucency next to the junction of the modular intramedullary nail, suggesting osteolysis. One of these nails was than removed routinely and showed severe corrosion at the junction. This observation and similar experiences in other hospitals, using the TLN system, made us decide to investigate this phenomenon.

Peri-implant osteolysis is most commonly associated with total hip replacement. Both wear particles of polyethylene as metal corrosion products from modular taper junctions seem to be etiological factors in the process of osteolysis.

In a case report Jones and Marsh firstly described junction-related osteolysis of the femur in a patient who was treated with a modular intramedullary nail ${ }^{3}$. Recently the same authors published a study on osteolysis in thirty-two femoral fractures or nonunions treated with the same intramedullary modular nail ${ }^{2}$.

To our knowledge, there is no published report on osteolysis occurring after intramedullary nailing in the tibia.

In this study we wanted to determine the incidence of osteolysis around the junction of the TLN and the correlation between the occurrence of osteolysis and clinical problems or complaints after intramedullary nailing of the tibia with the TLN. 


\section{Patients and methods}

To investigate the incidence of osteolysis after tibial nailing with the TLN we retrospectively reviewed the radiographs of 154 consecutive patients who were treated with a Telescopic Locking Nail for a tibial fracture. Two of the nails were exchanged during the course of treatment, resulting in 156 nails. Of these 156 nails, 100 were implanted in our hospital, the other 56 were implanted in six other hospitals in the Netherlands. Thirty patients were excluded for several reasons. Seventeen were excluded because the follow-up period was less than 80 days. Of five patients living abroad there were no radiographs available. Seven patients were excluded because the serial radiographs of the tibia were not complete. As the serial radiographs of one patient showed a screw-aperture next to the junction, due to a former external fixator, this case was also excluded. This left 126 tibial nails in 124 patients for inclusion in our study. There were 89 males and 35 females with a mean age of 38 years (range of $13-80$ years). The mean follow-up period of the serial radiographs was 317 days (range of $80-1265$ days).

The radiographs of included patients were evaluated by two observers (M.G. and J.v.d.B.). The amount of osteolysis was measured and the site of appearance was noted. Osteolysis was defined as an area of radiolucency next to the junction of the modular nail. The width of the area of osteolysis was measured from the outer border of the telescope part to the most distant extent of the radiolucency along a line perpendicular to the axis of the nail. The length was measured from the most distant extents along a line parallel to the axis of the nail. The width and length were then recorded in millimeters. The time of occurrence of osteolysis was registered in days following the day of operation. The site of appearance was recorded as either ventral, dorsal, medial or lateral. Also the presence of cortical thickening or periostal reaction was noted being present or absent. The fracture was considered to be united radiologically when the fracture gap was filled with structured callus on both anteroposterior and lateral X-rays.

To investigate the correlation between the occurrence of osteolyis and the presence of clinical problems or complaints we analyzed, a group of 74 patients, a subgroup of the 154 patients mentioned above, with acute tibial fractures treated with the Telescopic Locking Nail. Of these patients we had obtained long term follow-up data during a prospective multicenter trial. With these figures we were able to compare the clinical outcomes of patients with osteolysis to the patients without osteolysis. Thirteen patients of the 74 patients were excluded for the reasons mentioned before. So 61 patients were left for comparison.

Figure 9.1 shows the composition of the study groups. 


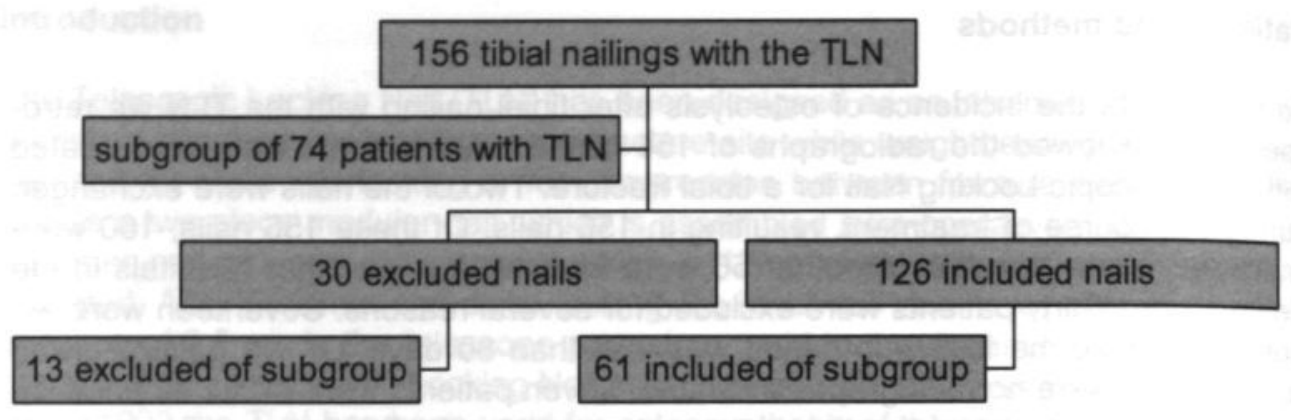

Fig. 9.1

The group showing osteolysis on the radiographs consisted of 19 patients. There were 42 patients without signs of osteolysis.

Variables between these two groups as gender, localization of the fracture, mode of interlocking, time till union, time till full weightbearing, presence of pain and occurrence of pain during exercise, were compared using the Chi square test. The groups were compared for the age at surgery using the student-T-test.

The nails of three patients showing osteolysis on their serial radiographs were removed (13 months, 14 months and 15 months after operation) because of pain in the lower leg. The nails were retrieved and analyzed by a stereo microscope to evaluate the surface of the osteosynthetic device (principally the junction). Four further nails that were routinely removed after fracture union were visually inspected. 


\section{Results}

Thirty-five of the 126 studied serial X-rays showed osteolysis at the junction of the two parts of the Telescopic Locking Nail (28\%)(also see figure 9.2). Of these 35 patients, 25 were male and 10 female, and they had a mean age of 35 years (range of $16-63$ years).

The first observation of osteolysis was made on an average of 215 days (range 82 634 days).

In all of the 35 cases, the place of appearance of osteolysis was the ventral side of the tibia. In three cases, osteolysis was found at the dorsal side as well. Osteolysis was noted medially in two cases and never laterally. The mean widths of the osteolytic lesions were $1.7 \mathrm{~mm}$ (range $0.5-7 \mathrm{~mm}$ ). The lengths of the lesions were on average $8.7 \mathrm{~mm}$ (range $3-22 \mathrm{~mm}$ ). In 6 patients periostal reaction or cortical thickening was seen on the serial radiographs. Four times at the lateral side of the junction, one time at the medial side. One patient had periostal reaction or cortical thickening at both sides of the junction. The first periostal reaction and cortical thickening were observed on the radiographs at a mean of 304 days (range $170-438$ days). The first observation of osteolysis always preceded the periostal reaction and the cortical thickening. Of the 35 patients, 8 patients had serial radiographs consisting of 4 or more consecutive radiographs on which osteolysis was seen. Of these 8 cases of osteolysis, only one was progressive in the course of time. Four were stable. Four of the osteolytic spots diminished in the course of time. One of them even vanished completely. Of two patients, showing osteolysis on their radiographs, radiographs of

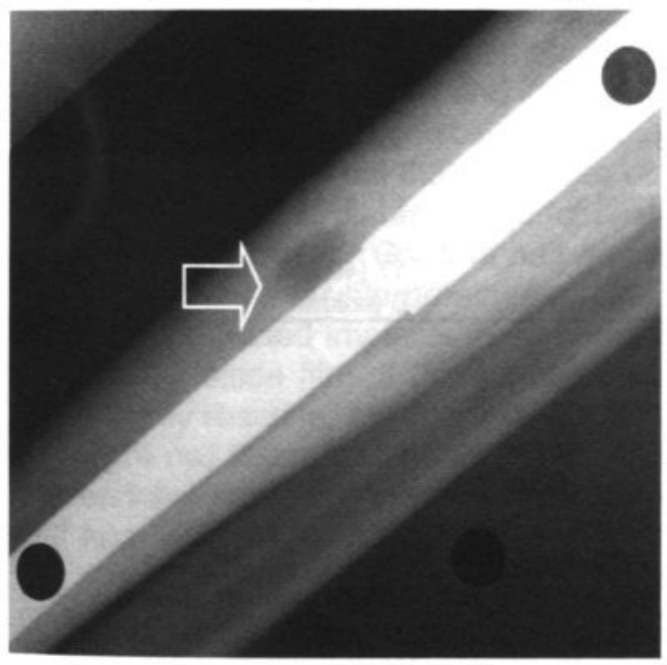
the tibia were available after their TLN had been removed. In one case, the osteolytic area diminished in the course of 9 months. The osteolytic lesion of the other patient disappeared completely. In figure 9.2 an example of osteolysis after osteosynthesis with a TLN is given.

\section{Figure 9.2}

Osteolysis of the tibia after intramedullary nailing with the TLN. The osteolytic spot is located at the ventral side of the junction of inner nail and telescope tube.

Of the subgroup of 61 patients in whom we compared the clinical outcomes between patients with and without osteolysis the results are listed in Table 1. With the numbers available, no statistical differences could be found between the group of patients with and without osteolysis after osteosynthesis with the TLN with regard to gender, mean age, localization of the fracture, mode of interlocking(static, dynamic or with compression), mean period until union, mean period until full weightbearing and percentage of patients who perceived pain in the injured leg. 
Inspection of seven retrieved nails revealed deep surface corrosion damages and residues at the contact surfaces between nail, tube and adjoining surfaces, mainly at the ventral site of the nail. The corroded areas inside the tube corresponded to the corroded areas of the nail. All other parts of the assembled nail showed no corrosive attack. With the means of the stereo microscope material abrasion was clearly visible with partially deep corrosive dimples. The deepest material abrasion was found at the transition from covered to non covered section of the nail.

Table 1.

Comparison between patients with and without osteolysis

\begin{tabular}{llll}
\hline & $\begin{array}{l}\text { Osteolysis } \\
(n=19)\end{array}$ & $\begin{array}{l}\text { no osteolysis } \\
(n=42)\end{array}$ & n.s. \\
\hline Male (\%) & 37 & 29 & n.s. \\
Age (yrs) & 31 & 36 & \\
$\begin{array}{l}\text { Localization of fracture (\%) } \\
\quad \text { Proximal }\end{array}$ & 0 & 0 & n.s. \\
$\quad$ Midshaft & $10(52 \%)$ & $17(40 \%)$ & n.s. \\
Distal & $9(48 \%)$ & $25(60 \%)$ & n.s. \\
Mode of interlocking (\%) & & $9(21 \%)$ & n.s. \\
$\quad$ Static & $3(16 \%)$ & $26(62 \%)$ & n.s. \\
Dynamic & $9(47 \%)$ & $7(17 \%)$ & n.s. \\
Time until union (wks) & $7(27 \%)$ & 18.7 & n.s. \\
Time until full weightbearing (wks) & 23.0 & 6.4 & n.s. \\
Knee or lower leg pain & 4.8 & $14(33 \%)$ & $17(40 \%)$ \\
Pain during exercise & $8(42 \%)$ & $6(\mathrm{unknown})$ & \\
\hline
\end{tabular}




\section{Discussion}

The occurrence of osteolysis after intramedullary nailing has been described by Jones and co-workers in a case report and later in study on thirty-two femoral nailings with a modular femoral nail ${ }^{2,3}$. To our knowledge osteolysis after tibial nailing has never been described before. In treating tibial fractures with the Telescopic Locking Nail, also a modular interlocking nail, we noticed that in some cases osteolysis occurred around the junction between the two parts of the nail. This prompted us to further investigate this phenomenon with special interest to the incidence and clinical sequelae of osteolysis.

Of 126 studied serial X-rays thirty-five revealed osteolysis, yielding an incidence of osteolysis of 28 percent. However, if we would have included only patients with a follow-up time of their postoperative radiographs of 400 days or more, the incidence of osteolysis would be 46 percent. So, the incidence of osteolysis is high and occurrence of osteolysis seems to be progressive in the course of time. With a mean width of 1.7 millimeters and a mean length of 8.7 millimeters the area of the osteolytic spots is rather small but in a few cases large osteolytic defects were seen. In 27 studied patients with modular femoral nails, Jones et al. found 19 cases where osteolysis was seen on postoperative radiographs (70 percent). The mean time they fist observed osteolysis was thirteen months. The mean width of the osteolytic lesions they measured was 2.5 millimeters ${ }^{2}$.

The location of the osteolytic spots, mainly on the ventral side of the tibia, at the height of the junction of the Telescopic Locking Nail, corresponds to the location of the corrosive area of the assembled nail. The fact that the corrosive areas were found on both tube and nail and its characteristics of these areas as seen by stereo microscope, the kind of corrosion can be categorized as crevice corrosion. Crevice corrosion is a side effect that has been observed at various osteosynthetic materials such as screws and plates, the junctions between hip screw and plate or nail in the Dynamic Hip Screw or Gamma nail respectively, and taper junctions between head and neck in modular hip prostheses ${ }^{4}$. It can occur especially at the contact surface between connected implants in combination with micro movements. Due to fretting, the passive oxide film of the contact area is fractured and the underlying material, being highly reactive, than spontaneously oxidizes. As the Telescopic Locking Nail is a straight nail it tends to bend a little (recurvation) in order to adapt to the shape of the medullary canal of the tibia. Therefore the strongest fretting forces between nail and tube with micro movements will be at the ventral side of the junction between nail and tube. Nail analysis shows that this is the indeed the area where material abrasion is found and where corrosion occurs.

The finding that osteolysis occurs in all cases at the ventral side of the junction of the assembled nail, and the finding that this is also the side where material abrasion and corrosion occurs, suggest that these processes are related.

Implant related osteolysis has repeatedly been reported. Periprosthetic osteolysis in total joint replacements constitutes a major problem in contemporary hip arthroplasty. The etiology of periprosthetic osteolysis is multifactorial. Particulate debris from polyethylene components and bone cement have mostly been implicated in this process, as these particles incite a local macrophage mediated resorption of bone ${ }^{5,9}$. On the other hand, also corrosion products and metallic debris, generated by modu- 
lar connections, have been described as possible causative agents of osteolysis, as osteoclastic bone resorption is more extensive in the presence of metal particles ${ }^{10,11}$. Bending and torsional tests of metal/ metal modular connections showed that dynamic loads can release large numbers of debris particles from taper junctions of modular hip prostheses ${ }^{7,12}$. Gilbert et al found significant corrosion in up to one third of taper junctions of retrieved modular hip prostheses ${ }^{4}$. Jones et al. found large amounts of corrosion particles in tissue around the nail taper junctions, where as no metal debris was found in a control group with one piece intramedullary nails ${ }^{2}$. Their modular femoral nail was also made of $316 \mathrm{~L}$ stainless steel.

There is evidence that both corrosion products and metal debris can cause osteolysis, respectively through a cellular response from macrophages and through a stimulation of osteoclast formation, both leading to bone resorption ${ }^{10,11,13}$.

As Jones et al. state, it is an interesting observation that osteolysis occurs without the presence of polyethylene and polymethylmethacrylate, both substances most frequently being implicated as the causative agents of osteolysis after total hip replacement. These observations with modular intramedullary nails provide additional evidence, that metal debris and corrosion products could be important etiological Factors in the occurrence of osteolysis with the use of modular hip prostheses. In this study we found no relation between the presence of osteolysis and clinical outcome. All acute fractures united uneventfully, regardless of the presence of osteolysis. No differences could be detected between patients with and without osteolysis regarding to weightbearing and pain perceived in the injured leg. In their study Jones et al. found no significant differences between patients treated with modular femoral nails and a control group treated with one piece femoral nails, regarding the thigh pain, scored on a visual analog scale. The patients with the more severe osteolytic lesions however, did have significant higher scores for thigh pain than the patients in the control group ${ }^{2}$.

In summary, we conclude that focal osteolysis is an important phenomenon after intramedullary osteosynthesis of the tibia with the Telescopic Locking Nail. Its etiology has to be sought in the release of corrosion products at the junction of inner nail and telescope part. Whether osteolysis has important clinical sequelae has remains unclear. Future studies have to answer this question. Those studies should also include implants like the Dynamic Hip Screw and the Gamma-nail were the phenomenon might also be present but not as clearly visible as in the proximal part of the tibia. The appearance of osteolysis after fixation with modular implants could however be a drawback for the widespread use of these implants. 


\section{References}

1. Goessens, ML, Van de Wildenberg, FJ, Eggink, GJ and Stapert, JW. Treatment of fractures of femur and tibia with the telescopic locking nail: design of a new implant and the first clinical results. J Trauma, 1999; 46(5): p. 853-62.

2. Jones, DM, Marsh, JL, Nepola, JV, Jacobs, JJ, Skipor, AK, Urban, RM, Gilbert, JL and Buckwalter, JA. Focal Osteolysis at the Junctions of a Modular Stainless-Steel Femoral Intramedullary Nail. J Bone Joint Surg, 2001; 83(4): p. 537-.

3. Jones, DM and Marsh, JL. Osteolysis of the femur at the junction of a modular intramedullary nail. A case report. lowa Orthop J, 1998; 18: p. 136-41.

4. Gilbert, JL, Buckley, CA and Jacobs, JJ. In vivo corrosion of modular hip prosthesis components in mixed and similar metal combinations. The effect of crevice, stress, motion, and alloy coupling. J Biomed Mater Res, 1993; 27(12): p. 1533-44.

5. Huo, MH, Salvati, EA, Lieberman, JR, Betts, F and Bansal, M. Metallic debris in femoral endosteolysis in failed cemented total hip arthroplasties. Clin Orthop, 1992; (276): p. 157-68.

6. Jasty, M, Bragdon, C, Jiranek, W, Chandler, H, Maloney, W and Harris, WH. Etiology of osteolysis around porous-coated cementless total hip arthroplasties. Clin Orthop, 1994; (308): p. 111-26.

7. Manley, MT and Serekian, P. Wear debris. An environmental issue in total joint replacement. Clin Orthop, 1994; (298): p. 137-46.

8. Willert, HG, Bertram, $\mathrm{H}$ and Buchhorn, GH. Osteolysis in alloarthroplasty of the hip. The role of ultra-high molecular weight polyethylene wear particles. Clin Orthop, 1990; (258): p. 95-107.

9. Jacobs, JJ, Gilbert, JL and Urban, RM. Corrosion of metal orthopaedic implants. J Bone Joint Surg Am, 1998; 80(2): p. 268-82.

10. Kadoya, Y, Kobayashi, A and Ohashi, H. Wear and osteolysis in total joint replacements. Acta Orthop Scand Suppl, 1998; 278: p. 1-16.

11. Lee, SH, Brennan, FR, Jacobs, JJ, Urban, RM, Ragasa, DR and Glant, TT. Human monocyte/macrophage response to cobalt-chromium corrosion products and titanium particles in patients with total joint replacements. J Orthop Res, 1997; 15(1): p. 40-9.

12. Bobyn, JD, Tanzer, M, Krygier, JJ, Dujovne, AR and Brooks, CE. Concerns with modularity in total hip arthroplasty. Clin Orthop, 1994; (298): p. 27-36.

13. Jacobs, JJ, Urban, RM, Gilbert, JL, Skipor, AK, Black, J, Jasty, M and Galante, JO. Local and distant products from modularity. Clin Orthop, 1995; (319): p. 94-105. 


\section{Chapter X}

CLINICAL CASES 


\section{Case 1}

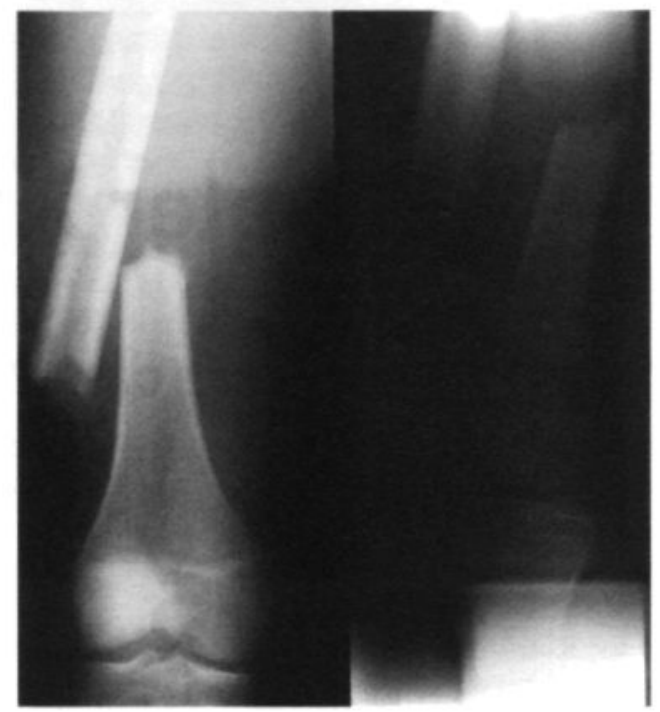

a

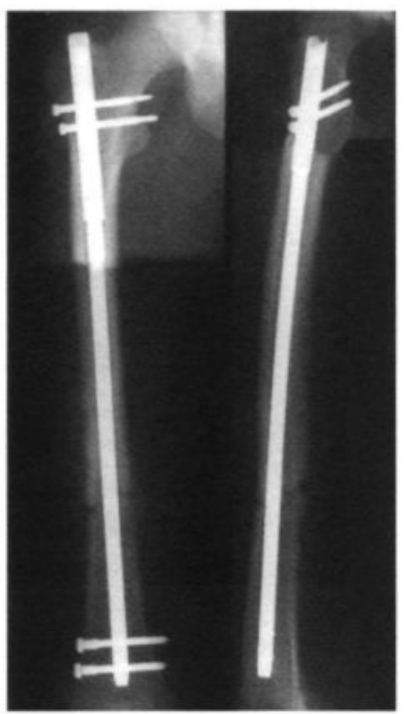

b

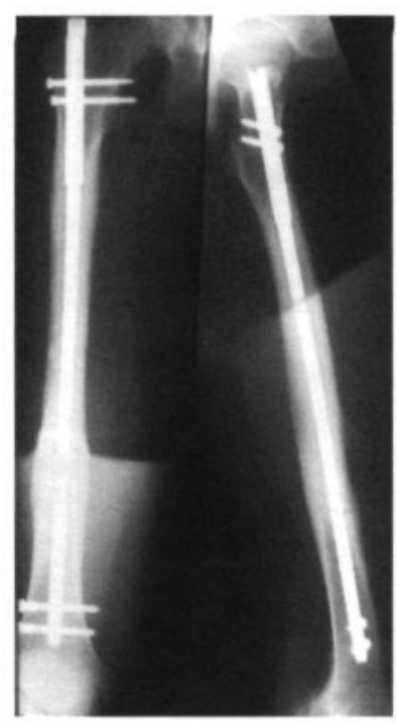

c 1.a

16 year old male multitrauma patient with grade III open, type A3 fracture of the femoral shaft.

1.b

Immediate osteosynthesis is performed with a $T L N$ in the dynamic mode. The top-lock has not been used in this case. Note that the straight nail bends a little to follow the antecurvation of the femur.

1.c

Consolidation of the fracture after 30 weeks. This patient was already fully weightbearing after three weeks. 


\section{Case 2}

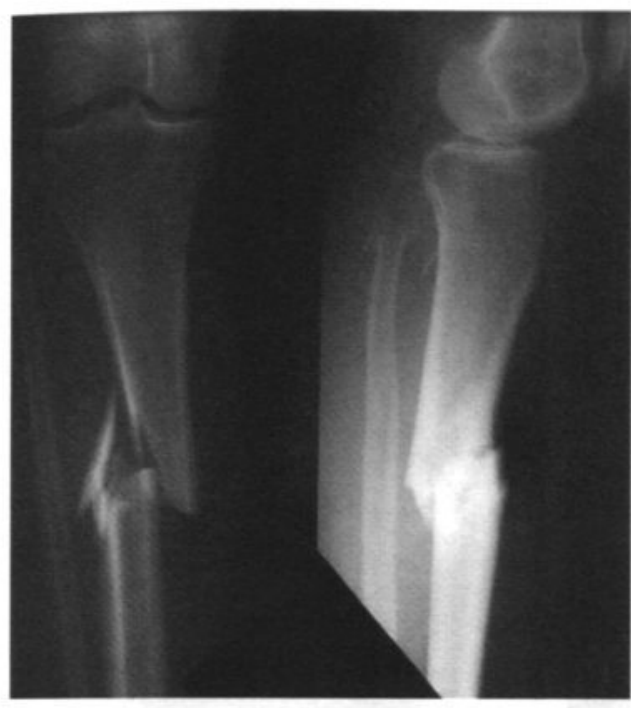

a

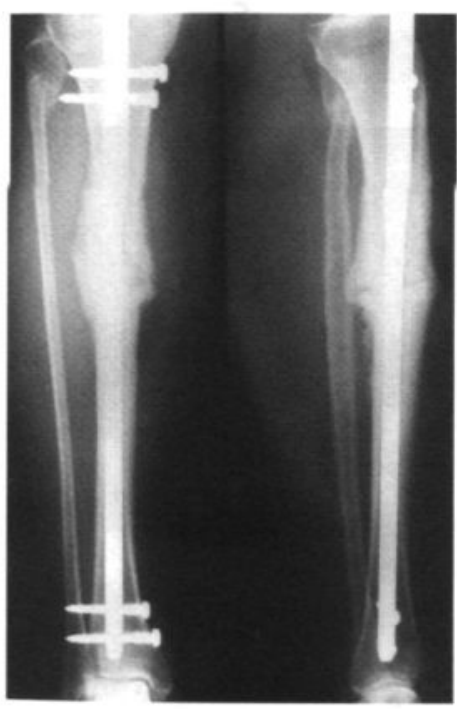

c

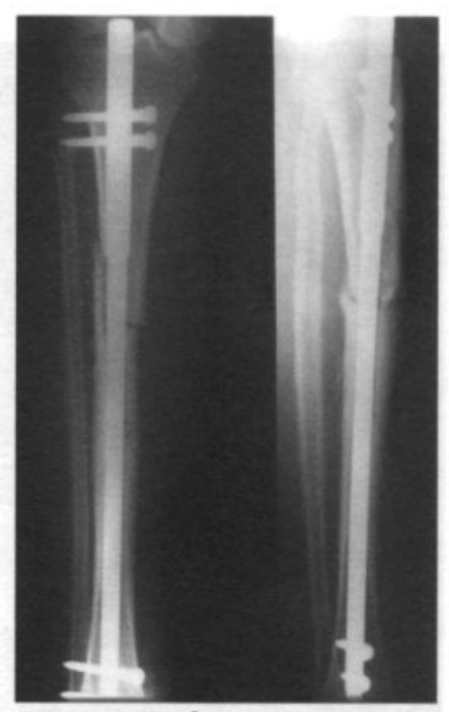

b

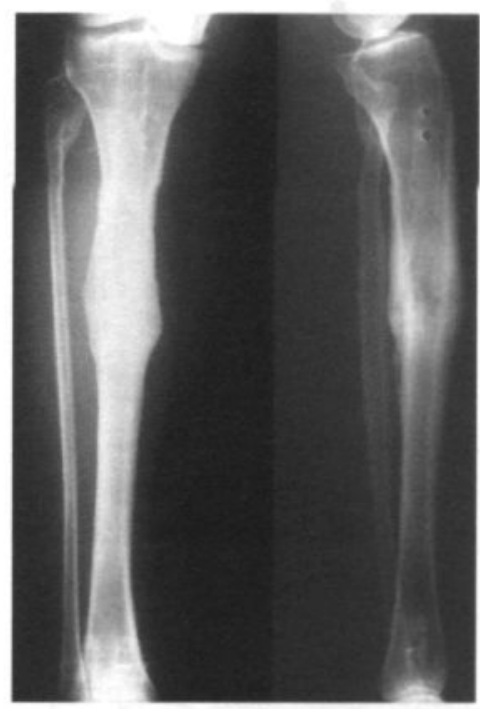

d

2.a

59 year old female patient with a grade II open, type B1 fracture of the tibial shaft and proximal fibular fracture.

2.b

Immediate osteosynthesis with a TLN in the dynamic mode.

2.c

Consolidation after 14 weeks.

2.d

After nail removal, one and a half year after osteosynthesis. 
Case 3

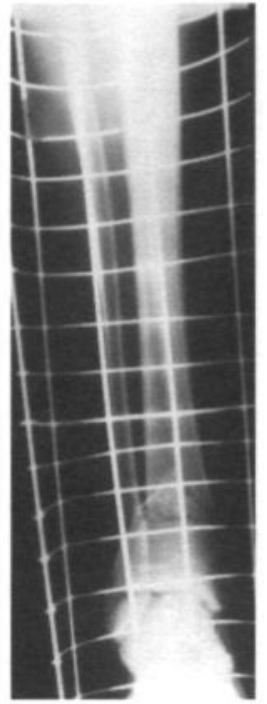

a

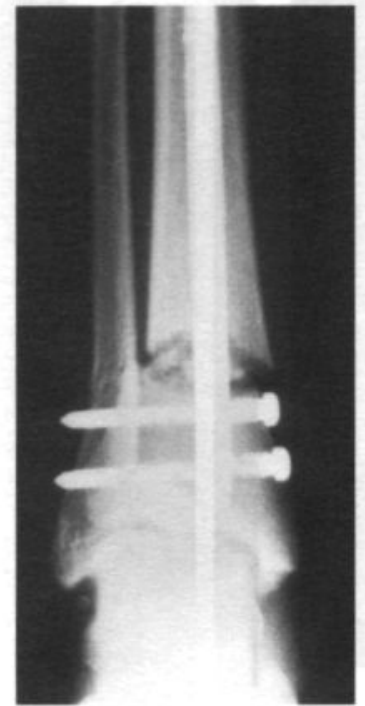

b

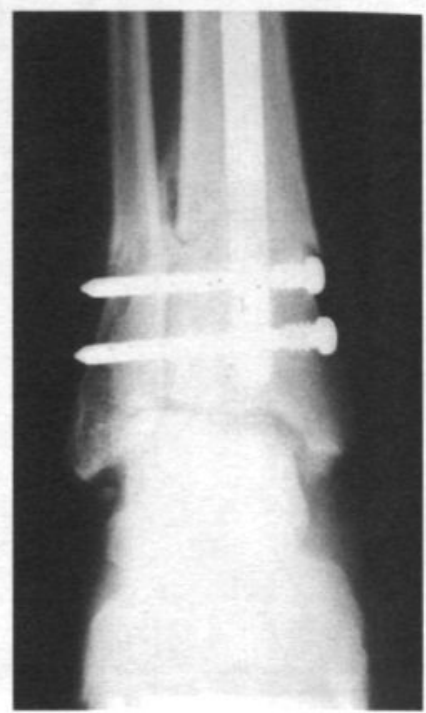

c

3.a

17 year old male patient with distal tibial fracture, closed, type A3.

3.b

Osteosynthesis with TLN one month post trauma because of malalignment in plaster cast. After proximal locking the inner nail was driven forward with its tip just into the subchrondal bone of the distal tibia. After this, the distal locking bolts could be inserted just below the level of the fracture.

The TLN was used in a dynamic mode.

3.c

Two months postoperatively. At this time the patient was fully weightbearing. The fracture elements are compressed under cyclicdynamic loading.

3.d

Six months post-operatively: full consolidation of the fracture.

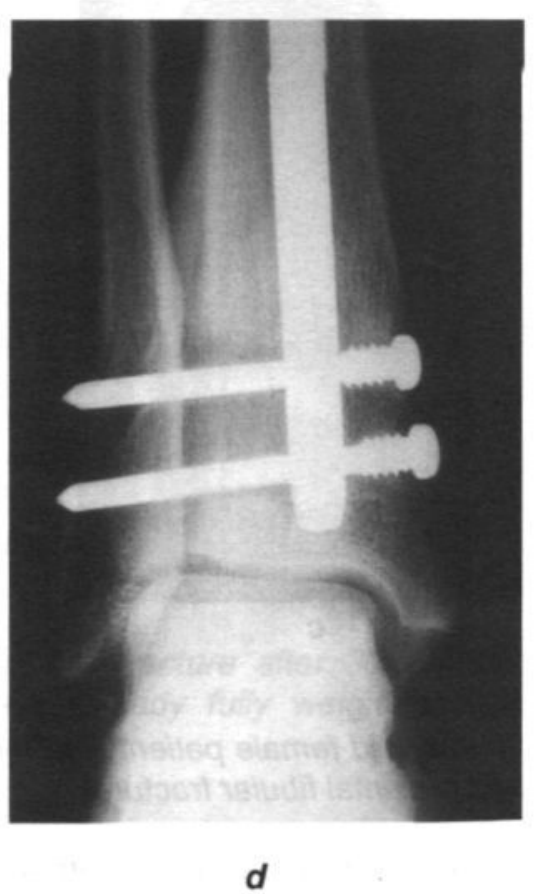


Case 4

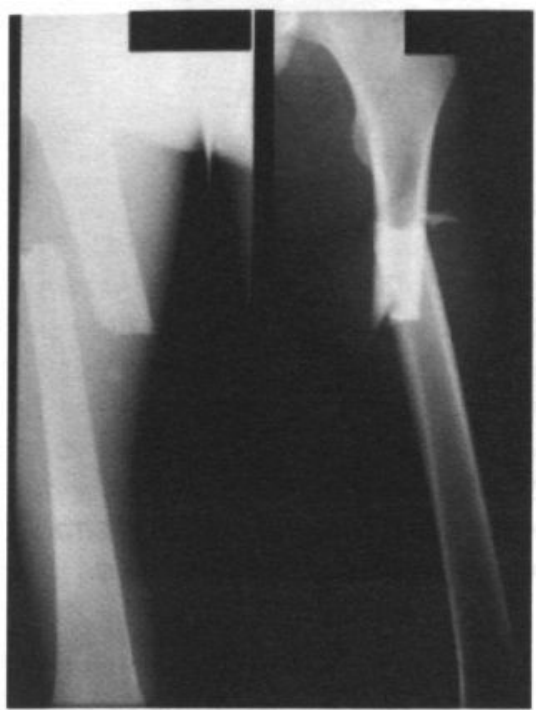

a

4.a

Femoral fracture, transverse type, length stable

4.b

Post-operative radiographs after fixation with Telescopic Locking Nail in dynamic mode 4.c

Consolidation of the fracture

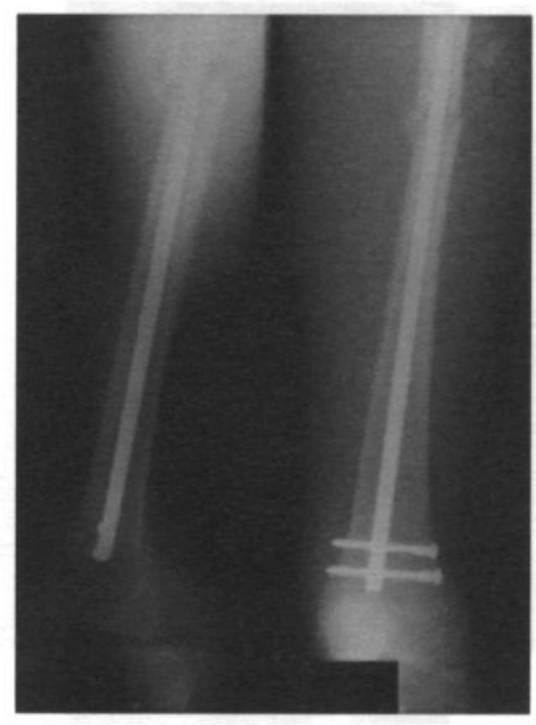

b

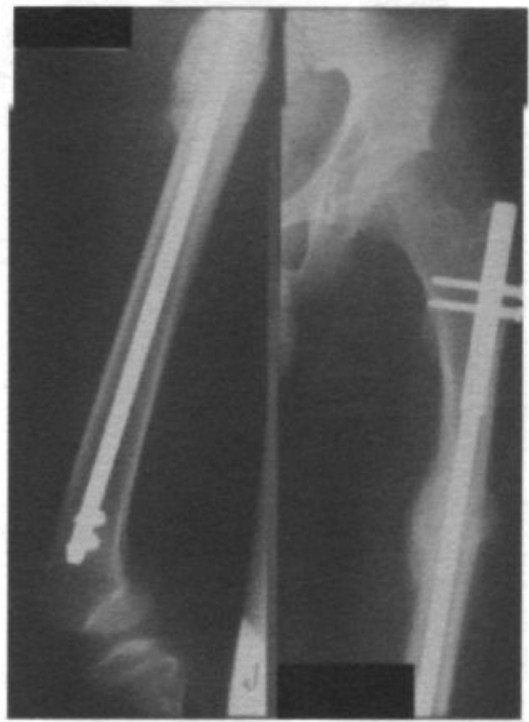

c 


\section{Case 5}

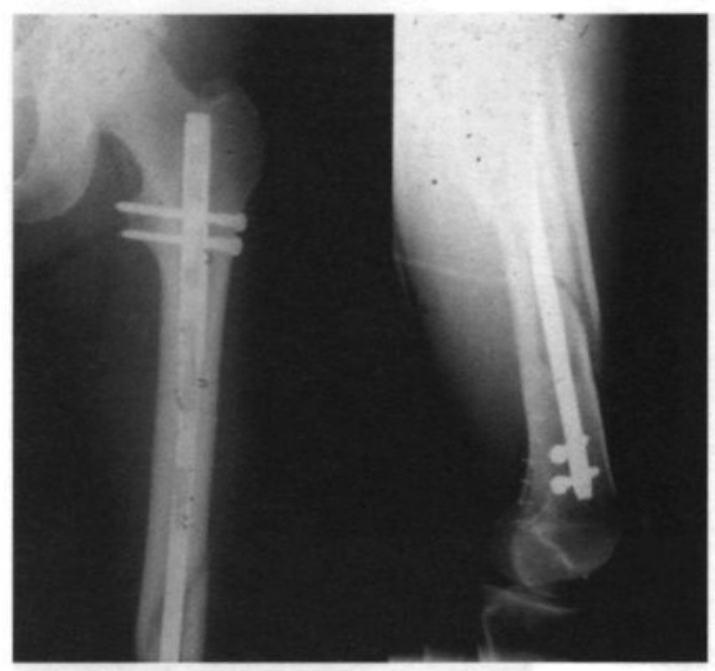

a

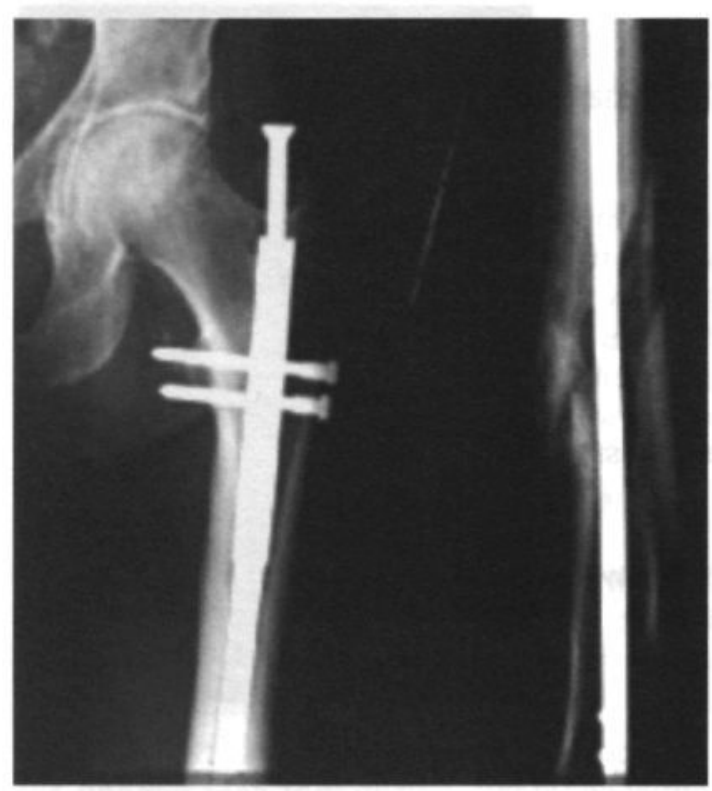

b 5.a

Post-operative radiographs. The operating surgeon judged this fracture to be length unstable and wanted to make a static osteosynthesis. Close inspection on the tip of the nail already reveals that mistakenly the compression screw has been used instead of the distraction screw that should be used.

\section{5.b}

After the patient started weight bearing the nail "dynamizes" as it was unintentionally programmed to do. Due to shortening the compression screw comes out of the top of the nail. 


\section{Case 6}

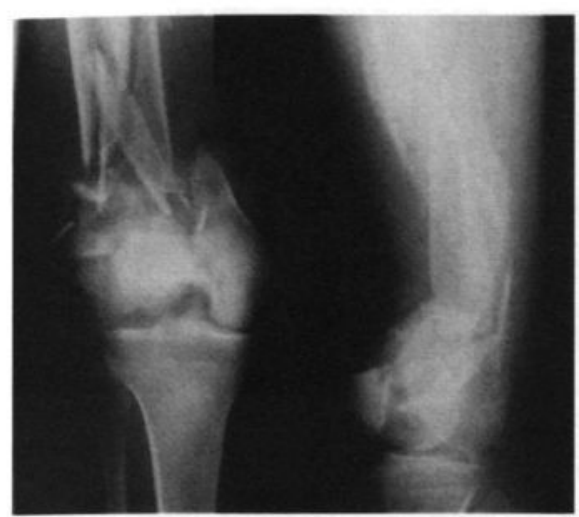

a

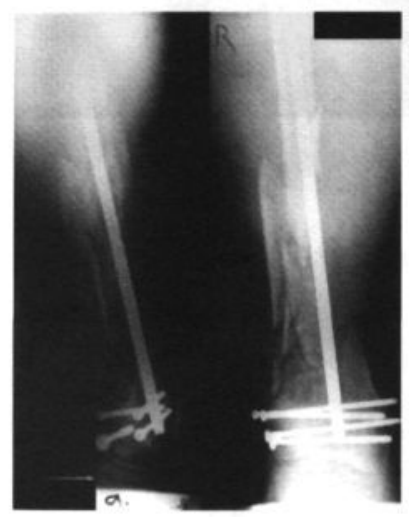

c

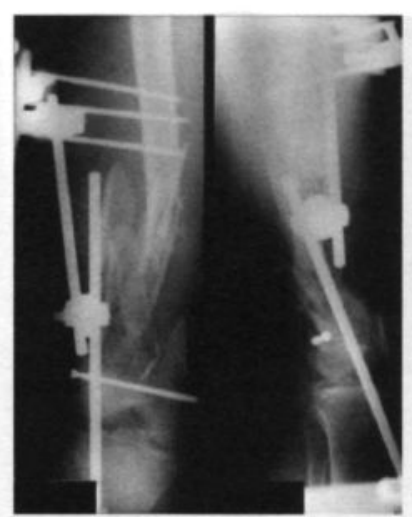

b

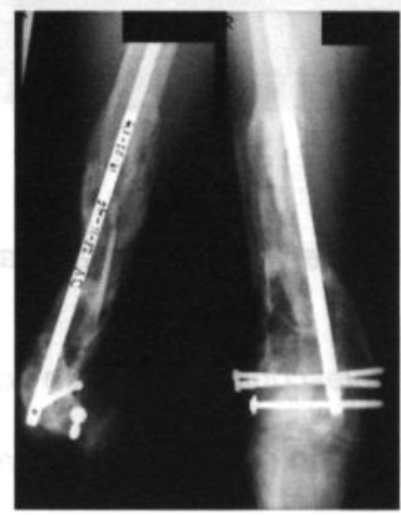

$\boldsymbol{d}$

\section{6.a}

An example of a distal femoral fracture 6.b

Temporary fixation with external fixation and reconstruction of condylar block 6.c

After proximal locking the inner nail is driven forward until the tip of the nail with the two locking holes is distal to the fracture

6.d

Consolidation of the fracture. 
Case 7

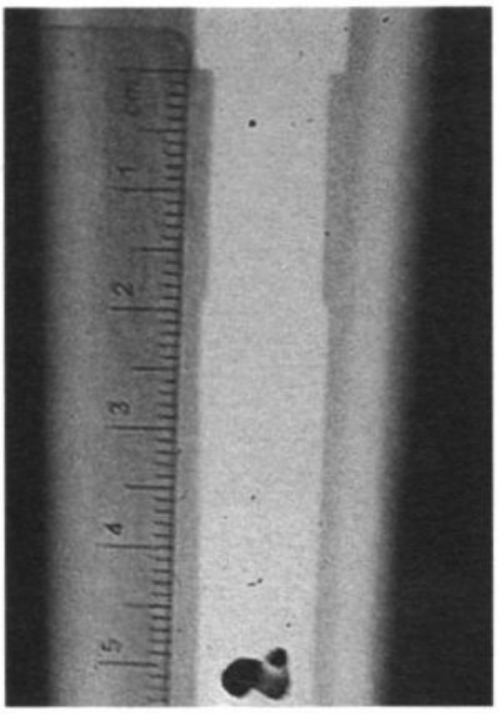

a

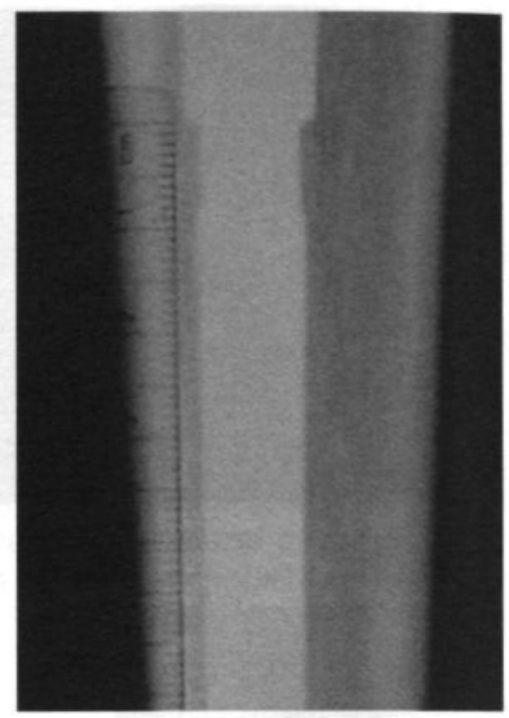

b

Clinical observation of dynamization of the Telescopic Locking Nail.

7.a

"Open" telescope mechanism postoperatively.

7.b

Dynamization of 10 millimeters after weight bearing 
Case 8

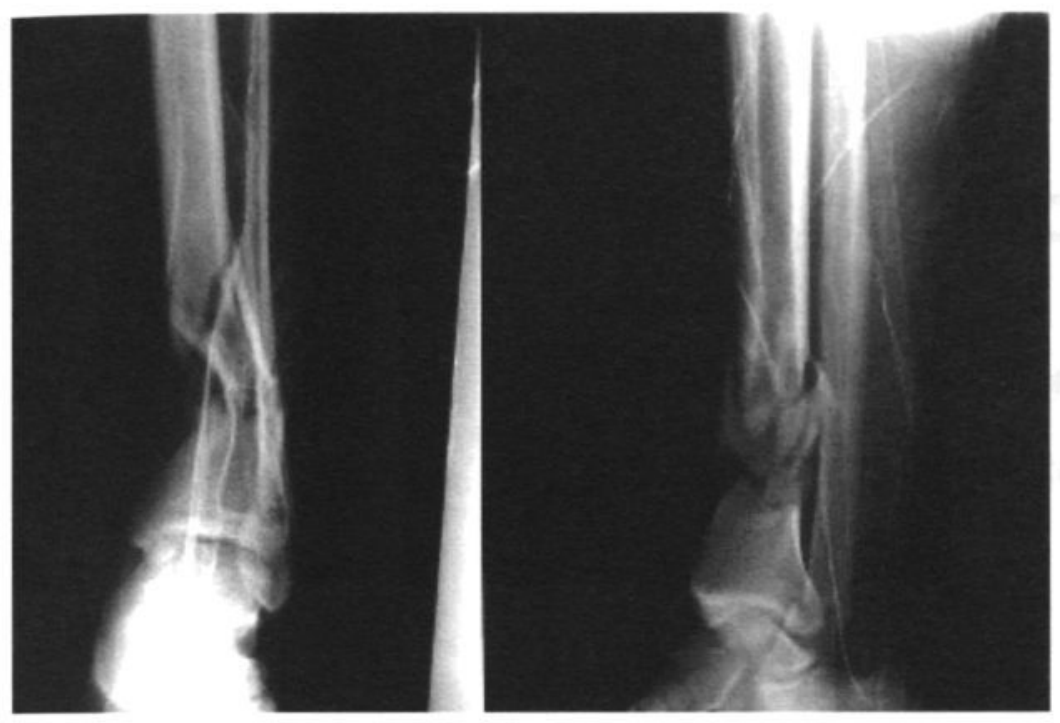

a

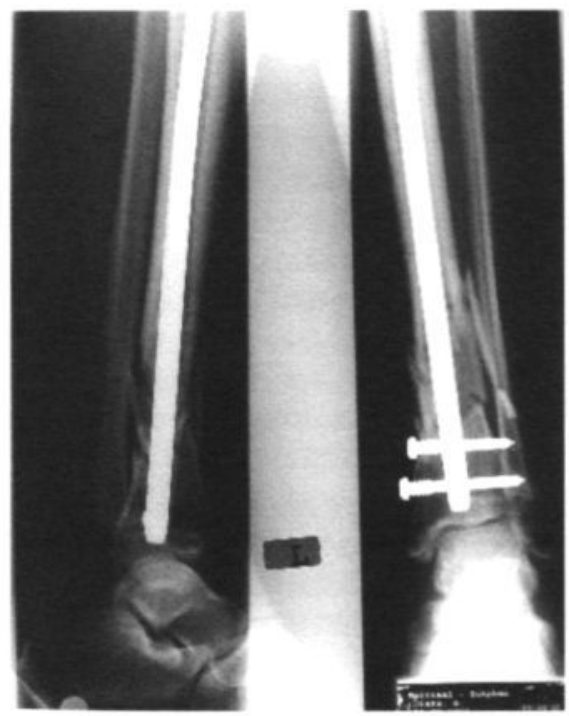

b

8.a

An example of a distal tibial fracture treated with the TLN

8.b

After proximal locking the inner nail is driven forward until its tip reaches the subchrondal bone above the ankle joint. The distal locking bolts can be inserted just below the fracture. 


\section{ChapterXI}

\section{SUMMARIES AND CONCLUSIONS}

SAMENVATTING EN CONCLUSIES 
Chapter 1 gives a general introduction on the subject of this thesis: the development of the Telescopic Locking Nail and the clinical results of femoral and tibial fracture treatment with this newly designed interlocking nail.

In Chapter 2 a historical review of intramedullary osteosynthesis is given. Intramedullary fixation techniques are believed to have been used already in the 16 th century by the Aztecs in Mexico.

In Europe intramedullary nailing started halfway the 19 century, but methods of fixation used were inadequate and lacked stability. With the advent of asepsis and better anesthetics operative fracture treatment, also intramedullary fixation, became more common at the beginning of the $20^{\text {th }}$ century. Instead of ivory or autologous bone, metal implants were introduced. In 1940 Küntscher introduced closed intramedullary nailing. The success of his method was appreciated and closed intramedullary became popular for treatment of long bone fractures. Because Küntscher nailing depended on impingement of the nail in the medullary canal, only length stable fractures in or near the isthmus of the medullary canal were suitable for this method. From 1970 the interlocking nail was developed. With these nails the range of indications for intramedullary nailing expanded to virtually all types of fractures of the shaft of long bones. With the further development of the interlocking nail this method has become the standard treatment modality of long bone fractures at the end of the $20^{\text {th }}$ century.

Chapter 3 explains why and how the Telescopic Locking Nail was developed from drawing table to final design, based on the premise, that the implant should permit:

- minimal invasive operation technique

- $\quad$ cyclic dynamic loading at the fracture site

- $\quad$ the application of compression between the fracture fragments

- $\quad$ early weight bearing

- $\quad$ the use of one universal locking nail system for femur, tibia and humerus

That the TLN has an excellent fatigue strength was shown during dynamic biomechanical testing. The TLN was capable of withstanding 900.000 cycles of ascending load without any sign of plastic deformation.

Chapter 4 describes the instrumentation set of the TLN and the operation technique. This is somewhat different from conventional locking nail systems due to the TLN's unique design.

In chapter 5 a study is described which was carried out to evaluate the first clinical experiences with the Telescopic Locking Nail in a single center setting. Seventy-one consecutive patients were treated with the TLN, 24 patients with femoral and $47 \mathrm{pa}-$ tients with tibial fracture or non-union. Functional outcome, complication rate and union rate were comparable to other interlocking nail systems. 
Chapter 6 describes a multi center study on acute femoral fractures.

Fifty-nine acute femoral shaft fractures in 56 patients were treated with the TLN. There were 25 type A, 22 type B and 12 type C fractures; 47 fractures were closed, 12 were open. Of these fractures 83 percent was locked in a dynamic mode.

Forty-nine patients met the follow-up criteria. The primary union rate was 98 percent, infection rate 4 percent and malunion rate 4 percent. After a median period of 8 weeks patients were fully weight bearing. No locking bolt or nail breakages were observed. In two cases there was leg shortening post-operatively.

Results of treatment of acute femoral fractures with the TLN are comparable to those of other nailing systems. The distinctive design characteristics of the TLN: straight nail and telescope mechanism, did not lead to higher complication or malunion rates.

Advantages are its applicability in both femur and tibia, its fatigue strength and its adjustability to every desired nail length.

Chapter 7 concerns a multicenter study on acute tibial fractures. In a prospective multicenter trial 74 acute tibial fractures were treated with the Telescopic Locking Nail. There were 36 simple fractures, 31 fractures with wedge fragment and 9 comminuted fractures. There were 55 closed and 19 open fractures.

Seventy three patients were in follow-up. All fractures united after a mean period of 18 weeks for closed fractures and 22 weeks for open fractures. In two cases there was a change of treatment before union was achieved. Patients were fully weight bearing after a 3 weeks for closed fractures and after 6 weeks for open fractures. One locking bolt broke. The malunion rate was $7 \%$. Five patients developed deep infections, two of these had to be re-operated to treat the infection. Three patients had deficits in knee or ankle function. In 33 percent of the cases patients perceived knee pain. The results were classified as excellent in 73 percent, good in 14 percent, fair in 8 percent and poor in 4 percent.

The results of treatment of acute tibial fractures with the Telescopic Locking Nail are comparable to those of other nailing systems. The distinctive design parameters of the TLN seem to provide advantages above conventional tibial nailing systems with regard to knee complaints, the treatment of distal tibial fractures and fatigue strength.

Chapter 8 addresses the issue of the use of a proximal entrypoint for tibial nailing.

Locking nails used for the treatment of tibial fractures are inserted at the ventral edge of the proximal tibia, below the tibial plateau and above the tibial tuberosity. With the introduction of the Telescopic Locking Nail we started to use an insertion point which lies more proximally and dorsally than the conventional point of insertion. The aim of this study was to determine the distance between this new entry point and the intracapsular structures of knee joint cavity and to compare the angle of insertion between the conventional and new entry point.

On 50 randomly selected knee MRI's the distance between the new entry point and the knee joint cavity was measured electronically. Forty randomly selected lateral plain radiographs of the tibia were used to determine the insertion axis via both insertion points. 
A mean distance of 12.2 millimeter $(7.4-18.3 \mathrm{~mm})$ was found between the new entry point and the knee joint cavity. This distance is safe with regard to the risk of opening the knee joint.

The insertion angle via the conventional entry point was 9.3 degrees, via the new entry point 4.7 degrees. This smaller insertion angle has advantages with regard to the risk of perforating the posterior cortex and in the treatment of proximal fractures.

Chapter 9 addresses the problem of osteolysis at the junction of the two parts of the TLN. After treating patients with tibial fractures with the Telescopic Locking Nail, we encountered the occurrence of osteolytic lesions around the junction of the nail components on postoperative radiographs. The purpose of this study was to evaluate the incidence and clinical relevance of these radiological findings.

Of 124 patients with 126 intramedullary nailings of the tibia with the Telescopic Locking Nail the postoperative radiographs were examined for the occurrence of osteolysis. The long term follow up data of a subgroup of 61 patients were used to compare clinical outcome variables, such as time till union, time till full weight bearing and pain perceived at the injured limb, between patients with and without osteolysis.

Seven retrieved nails were inspected for the presence of corrosion. The location and type of corrosion were determined.

In 35 of 126 intramedullary nailings osteolysis was found, yielding an incidence of $28 \%$. No significant differences could be found with regard to fracture union, weight bearing and pain perceived in the injured limb between the groups with and without osteolysis. On inspection of retrieved nails corrosive areas were found on both inner and outer tube at the junction of these two components. All other parts of the assembled nails were free of corrosive attack.

The occurrence of focal osteolysis in the tibia at the junction of the two components of the Telescopic Locking Nail is most likely caused by the release of corrosive materials. Whether the appearance of osteolysis has important clinical consequences remains to be investigated.

Approximately 1500 nailings of femur and tibia have been performed with the Telescopic Locking Nail in the Netherlands since 1991. Of these, 204 cases were described in this thesis. From these cases it could be concluded that the results of intramedullary nailing with the Telescoping Locking Nail are comparable to those of conventional interlocking nailing systems, with regard to union rates, mal-union rates and infection rates.

The unique design parameters of the Telescopic Locking Nail provide this locking nail system with specific advantages and disadvantages compared to conventional locking nail systems.

An obvious advantage is the fact that with the TLN the same nail is used for femur and tibia. Furthermore, the TLN is adaptable to every length of femur or tibia, due to its telescoping mechanism. This can be very helpful in treating distal femoral or tibial fractures with intramedullary nailing. Due to nail and locking bolt design, early weightbearing is possible without the risk of implant failure. In fact, locking bolt breakage was seldom observed. After tibial nailing with the TLN, knee complaints were observed less than after nailing with conventional nails, as reported in literature. 
Using a more proximal entry point in tibial nailing and the fact that the tip of the nail remains in level with the tibial plateau, when dynamization occurs, could be responsible for this.

The operative technique with the TLN system is more complex than with conventional locking nail systems. This can be regarded as a disadvantage. When the locking mode is wrongly chosen, failure of fracture fixation can occur. The telescope mechanism, which made the Telescopic Locking Nail such a unique treatment modality amongst other locking nailing systems, is responsible for the main disadvantage of the TLN system: the occurrence of osteolysis around the junction of the inner and outer nail, probably due to corrosion products which are released from the nail at this particular spot. It remains however unclear whether the occurrence of osteolysis has clinical consequences.

As was mentioned in the introduction of this thesis, the goal for modern interlocking nailing systems is to provide stable fracture fixation, allowing early functional rehabilitation of the injured limb. With the Telescopic Locking Nail this goal seems to be achieved. Comparative studies should be performed to proof whether the Telescopic Locking Nail is better in achieving this goal than conventional locking nail systems 


\section{SAMENVATTING EN CONCLUSIES}

Hoofdstuk 1 is een introductie op het onderwerp van dit proefschrift: de ontwikkeling van de Telescopic Locking Nail en de klinische ervaringen met deze nieuw ontworpen grendelpen bij de behandeling van femur- en tibiaschachtfracturen.

In hoofdstuk 2 wordt een historisch overzicht gegeven van de intramedullaire osteosynthese.

Naar verluidt werden intramedullaire fixatietechnieken al in de zestiende eeuw toegepast door de Azteken in Mexico.

In Europa begon de intramedullaire osteosynthese omstreeks het midden van de negentiende eeuw; de destijds toegepaste methoden en materialen bleken echter niet toereikend voor adequate fractuurfixatie. Met de opkomst van het principe van asepsis en van betere anesthesietechnieken kwam de intramedullaire osteosynthese aan het begin van de twintigste eeuw weer meer in zwang. In plaats van ivoren staven of autologe botspanen, werden nu metalen implantaten gebruikt. In 1940 introduceerde Küntscher de techniek van gesloten intramedullaire osteosynthese.

Zijn methode bleek succesvol en gesloten intramedullaire osteosynthese werd meer en meer toegepast, eerst in Europa later ook in het Amerikaanse continent.

Omdat de "Küntscher-pen" voor zijn stabiliteit afhankelijk was van inklemming in de mergholte, konden met deze pen alleen lengte stabiele fracturen behandeld worden, die gelokaliseerd waren in of rondom de isthmus van de mergholte.

Vanaf 1970 werd de grendelpen ontwikkeld. Dankzij het proximaal en distaal vergrendelen kon het indicatiegebied van intramedullaire osteosynthese allengs worden uitgebreid, zodat vrijwel alle fractuurtypen in de schacht van lange pijpbeenderen met een grendelpen behandeld konden worden. Dankzij de verdere doorontwikkeling van de implantaten en inbrengtechnieken is de grendelpen heden ten dage de standaard behandelingsmethode geworden voor de behandeling van schachtfracturen van de lange pijpbeenderen.

In hoofdstuk 3 wordt uitgelegd waarom en hoe de Telescopic Locking Nail werd ontwikkeld, van tekentafel tot laatste prototype. Het ontwerp van deze nieuwe grendelpen was gebaseerd op de volgende randvoorwaarden:

- een minimaal invasieve insertietechniek moest mogelijk zijn

- er moest cyclisch dynamische compressie kunnen plaatsvinden tussen de fractuurelementen tijdens belasten

- er moest compressie kunnen worden uitgeoefend tussen de fractuurelementen door het implantaat

- het implantaat moest sterk genoeg zijn om vroegtijdig belast mobiliseren mogelijk te maken zonder kans op materiaalbreuk

- het zou een universeel grendelpensysteem moeten worden voor de behandeling van zowel femur-, tibia- als humerusschachtfracturen.

Tijdens biomechanische testen van het definitieve model bleek dat de Telescopic Locking Nail over een uitstekende belastbaarheid beschikte. De TLN doorstond 900.000 cycli met toenemende belasting zonder enig teken van plastische vervorming of materiaalbreuk. 
In hoofdstuk 4 wordt de grendelpen en het instrumentarium van het Telescopic Locking Nail systeem beschreven. De operatietechniek wordt getoond, deze is enigszins afwijkend van de conventionele grendelpensystemen.

Hoofdstuk 5 bevat een studie welke de eerste klinische ervaringen met de Telescopic Locking Nail beschrijft, in één centrum door één operateur.

Een en zeventig opeenvolgende patiënten werden behandeld met de TLN, 24 patienten met een femurfractuur/pseudarthrose en 47 patiënten met tibiafractuur/pseudarthrose. Het functioneel herstel, het optreden van complicaties en fractuurgenezing waren verglijkbaar met de resultaten van conventionele grendelpensystemen.

Hoofdstuk 6 beschrijft een multicenter onderzoek over acute femurfracturen.

Negenenvijftig acute femurschachtfracturen bij 56 patiënten werden behandeld met een TLN. Het betrof 25 type A, 22 type B en 12 type $C$ fracturen; 47 fracturen waren gesloten, 12 waren open. Van al deze fracturen werd 83 procent dynamisch vergrendeld.

Bij negenenveertig patiënten werd aan de follow-up voorwaarden voldaan. De primaire union rate was 98 procent, het infectie-percentage was 4 procent, en de malunion rate was 4 procent. $\mathrm{Na}$ een mediane periode van acht weken waren patiënten volledig belast gemobiliseerd. Er werden geen schroef- of penbreuken geconstateerd. In twee gevallen was er een verkorting van het geopereerde been opgetreden in de postoperatieve fase.

De resultaten bij de behandeling van acute femurschachtfracturen met de Telescopic Locking Nail zijn vergelijkbaar met die van andere grendelpensystemen. Specifieke aspecten van het ontwerp van de TLN: het recht zijn van het implantaat en het telescoop mechanisme hebben niet tot een groter aantal complicaties of mal-union geleid. De voordelen zijn de toepasbaarheid van de zelfde pen in zowel femur als tibia, de goede belastbaarheid en de mogelijkheid om de lengte van de pen intraoperatief precies aan te passen.

Hoofdstuk 7 bevat een onderzoek over acute tibia fracturen. In een prospectieve multicenter studie werden 74 acute tibiafracturen behandeld met een Telescopic Locking Nail. Het betrof 36 type A, 31 type B en 9 type C fracturen. Er waren 55 gesloten en 19 open fracturen.

Drieënzeventig patiënten waren in follow-up. Alle fracturen consolideerden na een gemiddelde tijdsduur van 18 weken voor gesloten en 22 weken voor open fracturen. In twee gevallen was een secundaire behandeling noodzakelijk om consolidatie te bereiken. $\mathrm{Na}$ gemiddeld drie weken liepen patiënten met gesloten fracturen volledig belast, voor patiënten met open fracturen was dit zes weken.

Eenmaal trad er schroefbreuk op. In zeven procent van de gevallen trad mal-union op.

Bij vijf patiënten ontstond een diepe infectie, bij twee van deze was hiervoor reoperatie noodzakelijk. Bij drie patiënten was er een beperking van knie -of enkel functie. Drieëndertig procent van de patiënten ondervond kniepijn na de revalidatiefase. De resultaten van behandeling konden als volgt geclassificeerd worden: excellent bij 73 procent, goed in 14 procent, redelijk in 8 en slecht in 4 procent van de gevallen. 
De resultaten van behandeling van acute tibiaschachtfracturen met de Telescopic Locking Nail zijn vergelijkbaar met die van andere grendelpensystemen. Het afwijkende ontwerp van deze pen lijkt voordelen te bieden met betrekking tot het ontstaan van knieklachten, het behandelen van distale tibiafracturen en de hoge belastbaarheid.

Hoofdstuk 8 gaat over het gebruik van een proximaal insertiepunt bij intramedullaire osteosynthese van de tibia. Klassiek wordt voor het "pennen" in de tibia de pen ingebracht aan de ventrale zijde van de proximale tibia, onder het tibia plateau en boven de tuberositas tibiae. Met de introductie van de Telescopic Locking Nail werd het insertiepunt meer proximaal en dorsaal gekozen dan het conventionele insertiepunt. Het doel van deze studie was om de afstand tussen dit nieuwe insertiepunt en de intracapsulair gelegen structuren van de knie te bepalen en om de insertiehoek van de pen te vergelijken tussen het nieuwe en conventionele insertiepunt.

Op 50 steekproefsgewijs geselecteerde MRl's van de knie werd de afstand tussen het nieuwe insertiepunt en het kniegewricht elektronisch gemeten. Op veertig steekproefsgewijs geselecteerde laterale röntgenopnames van de tibia's werden de insertie-as bepaald via zowel het nieuwe als conventionele insertiepunt.

Een gemiddelde afstand van 12,2 millimeter werd gevonden tussen het nieuwe insertiepunt en het kniegewricht. Dit is een veilige afstand met het oog op het risico op beschadigen van intracapsulaire structuren.

De gemiddelde insertiehoek via het conventionele insertiepunt werd bepaald op 9,3 graden, via het nieuwe insertiepunt op 4,7 graden. Deze kleinere insertiehoek heeft voordelen met het oog op het risico op perforatie van de achterste cortex en bij de behandeling van proximale fracturen.

Hoofdstuk 9 behandelt het probleem van het ontstaan van osteolyse. Na de behandeling van tibiaschachtfracturen met de Telescopic Locking Nail werden er bij sommige patiënten osteolytische afwijkingen gezien op de postoperatieve röntgenopnames ter plaatse van de overgang binnenpen/telescoophuls. Het doel van deze studie was om de incidentie van het ontstaan van osteolyse vast te stellen en de klinische betekenis van deze afwijkingen te beoordelen.

Van 124 patiënten met 126 grendelpenosteosyntheses met de Telescopic Locking Nail werden achtereenvolgende postoperatieve röntgenopnames beoordeeld op het aanwezig zijn van voornoemde osteolytische afwijkingen. Lange termijn follow up gegevens van een subgroep van 61 patiënten werden gebruikt om variabelen zoals tijdsduur tot consolidatie, tijdsduur tot volledig belasten, pijn ter plaatse van het operatiegebied te vergelijken tussen patiënten met en zonder osteolyse.

Tenslotte werden zeven verwijderde TLN's onderzocht op de aanwezigheid van corrosie. De plaats van deze corrosie op de pen en het type corrosie werden vastgesteld.

In 35 van de 126 gevallen werd osteolyse gevonden, hetgeen leidt tot een incidentie van 28 procent. Er konden geen significante verschillen worden aangetoond met betrekking tot tijdsduur tot consolidatie, tijdsduur tot volledig belasten en postoperatieve pijnklachten in het operatie gebied. Inspectie van de verwijderde pennen liet zien dat er corrosieplekken waren aan zowel telescoophuls als binnenpen, daar waar deze met elkaar in contact zijn. Alle andere onderdelen van het implantaat waren vrij van corrosie. 
Het optreden van focale osteolyse in de tibia ter plaatse van de overgang tussen de twee componenten van de Telescopic Locking Nail, wordt meest waarschijnlijk veroorzaakt door het vrijkomen van corrosieproducten. Of het optreden van osteolyse belangrijke klinische consequenties heeft dient verder te worden onderzocht.

Ongeveer 1500 intramedullaire osteosyntheses met de Telescopic Locking Nail zijn uitgevoerd in Nederland sinds 1991. Tweehonderdenvier van deze casus werden beschreven in dit proefschrift. Hieruit kon geconcludeerd worden dat de resultaten van behandeling met de Telescopic Locking Nail vergelijkbaar zijn met andere grendelpensytemen qua tijdsduur tot consolidatie, en het voorkomen van mal-union en infecties.

Het unieke ontwerp van de Telescopic Locking Nail brengt specifieke voordelen en nadelen met zich mee in vergelijking tot conventionele grendelpensytemen.

Een belangrijk voordeel Is dat de TLN toegepast kan worden in zowel femur als tibia.

Verder is de TLN door zijn telescoop mechanisme aan elke lengte van femur of tibia aan te passen. Dit is van belang bij de behandeling van zeer distale fracturen. Pen en schroeven van het TLN systeem zijn zodanig ontworpen, dat vroegtijdig belast mobiliseren mogelijk is zonder een verhoogd risico op schroefbreuk. Schroefbreuk werd dan ook nauwelijks gezien. Na gebruik van de TLN in de tibia werden minder knieklachten geobserveerd dan wordt beschreven bij conventionele grendelpensystemen. Enerzijds het gebruik van een hoger gelegen insertiepunt en anderzijds het feit dat het proximale uiteinde op niveau van het tibiaplateau blijft na dynamiseren, zou hiervoor verantwoordelijk kunnen zijn.

De operatietechniek van het TLN systeem is complexer dan bij conventionele systemen, hetgeen als een nadeel kan worden beschouwd. Wanner voor een verkeerde wijze van vergrendelen wordt gekozen, kan dit leiden tot een instabiele fractuurfixatie. Het telescoopmechanisme, waarmee de TLN zich onderscheidt van andere systemen, is verantwoordelijk voor een belangrijk nadeel bij het gebruik van dit systeem: het optreden van osteolyse ter plaatse van de verbinding tussen binnenpen en telescoophuls, hoogst waarschijnlijk een gevolg van het vrijkomen van metaalpartikels en roestdeeltjes. Het is overigens nog niet duidelijk of het optreden van osteolyse belangrijke klinische consequenties heeft.

Zoals aan het begin van deze thesis werd vermeld is het doel van de behandeling van fracturen met de grendelpen het verschaffen van adequate fixatie van de fractuur, zodanig dat in een vroeg stadium functionele behandeling en zelfs volledig belasten mogelijk zijn, terwijl de fractuurgenezing nog in gang is. De Telescopic Locking Nail heeft aan deze doelstelling te voldoen. Vergelijkend onderzoek zal moeten uitwijzen of de TLN ook beter aan deze doelstelling voldoet dan de conventionele grendelpensystemen. 


\section{Chapter XII}

APPENDIX 


\section{FOLLOW UP FORM}




\section{KLINIEKNUMMER:}

\begin{tabular}{|c|c|c|c|c|c|c|}
\hline O Man & D Vrouw & o & Algeheel anaesthesie & D Centr.lijn & Urine Cath. & D Afdekdrape \\
\hline 0 Links & D Rechts & a & Regionaal anaesthesie & C Antibiotica ; & tijdstip : & $\ldots$ uur \\
\hline
\end{tabular}

\section{Geboortedatum}

Fractuurdatum

Opnamedatum

Operatiedatum

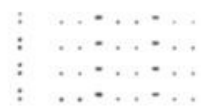

\section{AARD VAN}

HET ONGEVAL:

$$
\begin{array}{lll}
\text { 00 Onbekend } & \text { D } & 05 \text { Bromfiets } \\
01 \text { Sport voetbal } & \text { D } & 06 \text { Motor } \\
\text { 02 Sport anders } & \text { D } & 07 \text { Auto } \\
\text { 03 Voetganger } & \text { D } & 08 \text { Verkeer anders } \\
\text { D4 Fiets } & \text { D } & 09 \text { Bednif }
\end{array}
$$

\begin{tabular}{|c|c|c|c|c|c|}
\hline \multicolumn{2}{|c|}{ Lokale afwikingen: } & \multicolumn{4}{|c|}{ Nevenletsels: } \\
\hline D & 00 Onbekend & D & 00 Onbeikend & 0 & 11 Voet \\
\hline 0 & 01 Geen & D & 01 Geen & 0 & 12 Humerus \\
\hline 0 & 02 Aangeboren / polio & $\overrightarrow{0}$ & 02 Schedel & $\overrightarrow{0}$ & 99 Andere.... \\
\hline 0 & 03 Tumor / cyste & व & 03 Thorax & $\ldots$ & \\
\hline 0 & 04 Rheuma & D & 04 Buik & & \\
\hline 口 & 05 Arthrose & 0 & 05 Homolateraal & & \\
\hline 0 & 06 Osteoporose & 0 & 06 Heterolateraal & & \\
\hline$\overline{0}$ & 07 Infectie & $\overline{0}$ & 07 Bekken & & \\
\hline 0 & 08 Eerdere fractuur & 0 & 08 Fernur & & \\
\hline 0 & O9 Pseudarthrose & $\overline{\mathrm{D}}$ & 09 Tibia & & \\
\hline Q & 99 Andere......................... & $\mathrm{D}$ & 10 Fibula & & \\
\hline
\end{tabular}

\begin{tabular}{|c|c|c|c|c|}
\hline GESLOTEN FRACTUREN: & & A & $\begin{array}{c}\text { B } \\
\text { Vinder fragment }\end{array}$ & C \\
\hline Gering wekedelen letsel. & 0 & & & \\
\hline Oppervlakkige excoriatie contusie. & 1 & & & \\
\hline $\begin{array}{l}\text { Diepe gecontamineerde excoriatie, } \\
\text { begrensd wekedelen letsel. }\end{array}$ & 2 & & & \\
\hline $\begin{array}{l}\text { Uitgebreide huid en spier contusie, } \\
\text { subcutaan decollement. }\end{array}$ & 3 & & & \\
\hline
\end{tabular}

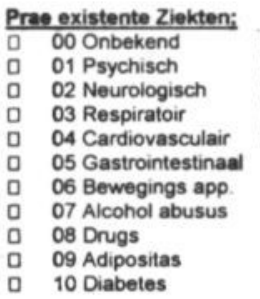

\section{PATIENTNUMMER:}

INDELING WEKEDELEN LETSEL:

Geringe contusie, matige bacteriele contaminatie.

Begrensde wekedelen contusie, matige / hevige contaminatie.

Uitgebreid wekedelen letsel, vaatzenuw letsel, hevige contaminatie.

Totale of subtotale amputatie.

\section{TLN PEN:}

Pen Lengte

........ mm

Grendels Distaal $\quad . . . . . . \quad \mathrm{mm}$

PROBLEMEN BIJ OPERATIE:

\begin{tabular}{ll}
\hline & 00 Geen \\
0 & 01 Repositie \\
0 & 02 Voerdraad \\
0 & 03 Mergholte boor \\
0 & 04 Prox. Richtapparaat \\
D & 05 Instrumentarium \\
0 & 06 Implantaat \\
0 & 07 Grendelboor \\
0 & 08 Vnje hand nichtapp. \\
0 & 99 Andere
\end{tabular}

\begin{tabular}{|c|c|c|c|}
\hline 0 & 10 & Humenus & Subcapitaal \\
\hline a & 11 & Humerus & Prox. $1 / 3$ \\
\hline ם & 12 & Humerus & Mid. $1 / 3$ \\
\hline $\overrightarrow{0}$ & 13 & Humerus & Dist. $1 / 3$ \\
\hline ס & 20 & Femur & Subtroch. \\
\hline 0 & 21 & Femur & Prox. $1 / 3$ \\
\hline व & 22 & Femur & Mid. $1 / 3$ \\
\hline D & 23 & Femur & Dist. $1 / 3$ \\
\hline 0 & 30 & Tibia & Prox $1 / 3$ \\
\hline o & 31 & Tibia & Mid. $1 / 3$ \\
\hline$\tilde{0}$ & 32 & Tibia & Dist. $1 / 3$ \\
\hline & $\begin{array}{l}x- \\
\text { (ve }\end{array}$ & $\begin{array}{l}\text { intra Lat } \\
\text { elijk and }\end{array}$ & $\begin{array}{l}\text { JA } \\
\text { tijde.) }\end{array}$ \\
\hline
\end{tabular}

Opmerkingen:
FRACTUUR LOKALISATIE:

\section{Huis}

011 Tentamen suicide

012 Spontaan fractuur

099 Andere

Bijzonderheden:
OPBOREN MERGHOLTE: ...... mm \& $\quad \ldots \ldots . . . \quad \mathrm{mm}$ $\& \quad \mathrm{~mm}$

OSTEOSYNTHESE KWALITEIT:

01 Belastingstabiel

口. 02 Oefenstabiel

03 instabiel

0 00 Onbekend

EXTRA MAATREGELEN:

C Fasciotomie $\square$ Andere.

व Redon

a Wond open

Skingraft

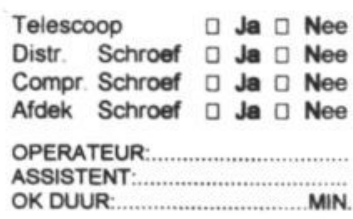

Advies nabehandeling: 
Klinieknummer :

Patientnummer:

STANDAARD REGISTRATIE FOLLOW-UP: $3,6,12,24,36,48$ WK POST TRAUMA:

(Bij complicaties om de 4 weken)

INVULLEN: $\underline{\text { Goed }}$ of $\underline{\mathrm{Ja}}=+,++,+++; \underline{\text { Slecht }}$ of $\underline{\mathrm{Nee}}=-,-,-; \quad$ Onbekend $=0 ; \quad$ N.v.t. $=\mathrm{X}$

\begin{tabular}{|c|c|}
\hline \multicolumn{2}{|c|}{ WEKEN POST OPERATIEF: } \\
\hline \multirow[t]{4}{*}{ PIJN } & : fractuur \\
\hline & heup (schouder) \\
\hline & knie (elleboog) \\
\hline & enkel \\
\hline ZWELLING & : arm/been \\
\hline \multirow[t]{3}{*}{ FUNCTIE } & : heup (schouder) \\
\hline & knie (elleboog) \\
\hline & enkel \\
\hline \multirow[t]{3}{*}{ BELASTEN } & : onbelast \\
\hline & pertieel belast \\
\hline & volledig belast \\
\hline WERKEN & : \\
\hline SPORTEN & : \\
\hline \multicolumn{2}{|c|}{ RONTGEN ONDERZOEK } \\
\hline & varus / valgus \\
\hline & ante- / recurvatie \\
\hline \multirow[t]{2}{*}{ CONSOLIDATIE: } & onrust Callus \\
\hline & fixatie Callus \\
\hline INFECTIE: & prox grendel \\
\hline diep / oppervlak & dist. grendel \\
\hline MIGRATIE: & prox grendel \\
\hline \multicolumn{2}{|r|}{ dist. grendel } \\
\hline \multicolumn{2}{|c|}{ Breuk proximaal / distaal; pen. } \\
\hline \multicolumn{2}{|c|}{ DYNAMISATIE TELESCOOP in $\mathrm{mm}$} \\
\hline
\end{tabular}

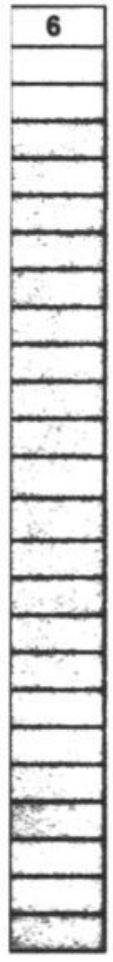

a Geen re-operatie

Datum re-operatie:

Re-operatie wegens:

D Fasciotomie sluiten envof wondbeh.

b. Infectie

Instabiliteit

D. Pen breuk

a Secundaire dislokatie

D Migratie / breuk Proximale grendel(s)

घ. Migratie / breuk Distale grendel(s)

a Verwijeren osteosynthese materiaal

- Wisselen naar ander osteosynthese

a. Andere

\section{OPMERKINGEN :}




\section{DANKWOORD}


Een ieder die betrokken was bij de totstandkoming van dit proefschrift wil ik van harte danken, in het bijzonder:

Mijn ouders die de basis hebben gelegd. Mijn moeder dank ik voor haar inspanningen en geduld gedurende mijn opvoeding. Wat zou pap trots geweest zijn.

Prof.dr. J. Stapert, mijn promotor. Beste Jouwert, jaren geleden zijn we met dit project gestart.

We hebben het allebei niet zo op met deadlines, misschien een reden waarom het allemaal wat langer geduurd heeft. Toch hadden we altijd op het laatste moment onze dia's klaar wanneer we weer eens naar een congres gingen. Zo verschijnt ook dit boekje over je "geesteskind" nog net voordat je afscheid gaat nemen, daar ben ik blij om. Bedankt voor de plezierige tijd en voor alles wat ik van je geleerd heb.

Karel Meuwissen en Eric Hoomans, mijn paranimfen. Al twintig jaar een voor allen, allen voor een. Bedankt voor onze vriendschap.

Al degenen die mij tot chirurg hebben gevormd, in het bijzonder mijn opleiders dr. W.J. Prakken en prof. dr. G. Kootstra. Ook degenen van wie ik als junior-chirurg veel heb geleerd, in het bijzonder prof. dr. G. Ramsay, dr. C.J. van der Linden en dr. P.R.G. Brink.

Mijn collega's in Maastricht die meedachten over de TLN: Jan Verbruggen, Jorrit Harbers, Paul Breedveld, Stephan van Zutphen en Gert Jan Eggink. Bedankt voor de plezierige samenwerking.

Bart de Graaf, de TLN-man van Howmedica. Jij was er vanaf het begin zeer intensief bij betrokken. Bedankt voor al je hulp.

Jacco Geuze, Rob Sijbers, Justian Hofmans en Jephta van de Bremer. Destijds als student betrokken bij de verzameling van data. Bedankt voor jullie inspanning.

Yvonne Daemen, als secretaresse van prof. dr. Stapert heb jij heel veel voor ons geregeld.

Johanna Boesten zorgde voor lijsten met namen van patiënten en stapels fotomappen.

Dames, bedankt.

Dr. B.J. Dwars, dr. A.J.H. Kerver, P.V.M. Pahlplatz, D.J. Swank, dr. R. Leemans en dr. J.P.A.M. Vroemen. "First users" van de TLN. Bedankt voor jullie hulp bij het verzamelen van gegevens voor de multicenter studies.

De Audiovisuele Dienst van het AZM. Bedankt voor de vele mooie plaatjes en voor het feit dat mijn presentaties ondanks de verstreken deadlines toch nog werden afdrukt.

Leden van de beoordelingscommissie. Dank voor het beoordelen en goedkeuren van het manuscript. 
Vivian van Oorschot. Jij verzorgde de lay-out. Dat een dikke stapel papier in zo'n korte tijd tot een mooi boekje is geworden heb ik aan jou te danken.

Robert Schreve, Alex Ponson, Jenny Ketel en Jan Staghouwer, mijn maten in Zutphen.

Bedankt voor jullie steun en de plezierige sfeer waarin wij samen werken.

En last but not least, mijn gezin.

Lieve Monique, jij bent de motor achter het geheel. Op de beslissende momenten gaf jij me het zetje in de goede richting. Zonder jou had ik het niet gered. Ik hou van je.

Lieve Max en Luuk, mijn jongens. De computer is weer vrij voor spelletjes, maar samen buiten skaten is misschien wel zeker zo leuk. Ik ben zo trots op jullie. 


Marco L.M.J. Goessens werd op 17 april 1964 geboren te Maastricht. In 1982 werd het diploma Gymnasium behaald aan het Bisschoppelijk College te Weert. In hetzelfde jaar startte hij met de studie geneeskunde aan de Rijksuniversiteit Limburg te Maastricht. $\mathrm{Na}$ afronden van de co-schappen volgde hij, in 1989, gedurende een half jaar een stage tropengeneeskunde in het Holy Family Hospital te Berekum, Ghana. In 1990 werd het artsenexamen behaald.

In het kader van een opleiding tot tropenarts werkte hij als arts-assistent achtereenvolgens in het Sint Jansgasthuis te Weert (wisselassistentschap, opleider J.A.L. Janssen), op de afdeling Gynaecologie van het Streekziekenhuis Midden Twente te Hengelo (opleider dr. H.P. Gnodde) en op de afdeling Chirurgie van het Diaconessenhuis te Eindhoven (opleider dr. W.J. Prakken). Uiteindelijk volgde in 1993 geen uitzending naar de tropen, doch werd een opleidingsplaats chirurgie verworven. Van 1994 tot 1997 werkte hij als AGIO chirurgie in het Academisch Ziekenhuis te Maastricht (opleider prof. dr. G. Kootstra). Hier werd in 1995 gestart met de studie die aanleiding gaf tot het verschijnen van dit proefschrift, onder leiding van prof. dr. J.W.J.L. Stapert. Van 1997 tot 1999 werd het perifere deel van de opleiding gevolgd in het Diaconessenhuis te Eindhoven (opleider dr. W.J. Prakken). Het laatste jaar van de opleiding chirurgie werd wederom gevolgd in het Academisch Ziekenhuis Maastricht, in het kader van een differentiatie in de traumatologie, onder leiding van prof. dr. J.W.J.L. Stapert. In juli 2000 werd de opleiding tot chirurg afgerond. Van juli 2000 tot juli 2001 werkte hij als fellow intensive care/traumatologie (o.l.v. prof dr. G. Ramsay) in het Academisch Ziekenhuis Maastricht met een detachering gedurende 4 maanden naar de afdelingen intensive care en chirurgie van het Atrium Medisch Centrum te Heerlen (dr. C.J. van der Linden en dr. P.R.G. Brink). Vanaf 1 juli 2001 is hij toegetreden tot de maatschap chirurgie van Gelre Ziekenhuizen, locatie het Spittaal te Zutphen.

Marco Goessens is sedert september 1993 gehuwd met Monique Asbreuk. Zij hebben twee zonen, Max en Luuk. 


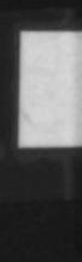

